\title{
A LABORATORY METHOD FOR ESTIMATION OF STORAGE CAPACITY OF ROCK SAMPLES UNDER EFFECTIVE STRESS
}

\author{
A Thesis \\ by \\ IVAN CAMILO ALDANA GALLEGO

\begin{abstract}
Submitted to the Office of Graduate and Professional Studies of Texas A\&M University

in partial fulfillment of the requirements for the degree of

MASTER OF SCIENCE
\end{abstract}

\begin{abstract}
Chair of Committee, I. Yucel Akkutlu
Committee Members, Marcelo Sanchez

David Schechter

Head of Department, Jeff Spath
\end{abstract}

August 2019

Major Subject: Petroleum Engineering

Copyright 2019 Ivan C Aldana 


\begin{abstract}
Fluid storage capacity measurement of core-plugs in the laboratory considers pore-volume as a function of effective stress. The latter is equal to (Applied Confining Pressure) - (Effective Stress Coefficient) x (Applied Pore Pressure). However, results are often reported as a function of difference in the applied pressures, because the effective stress coefficient is unknown and depends on the mechanical properties of the sample. This creates confusion during the interpretation of laboratory data and leads to added uncertainties in the analysis of storage.

In this study I present a new laboratory method that allows simultaneous prediction of the sample pore volume, coefficient of isothermal pore compressibility, and the effective stress coefficient. These quantities are necessary to predict the fluid storage as a function of effective stress. The method requires two stages of gas (helium) uptake by the sample under confining pressure and pore pressure and measures pressure-volume data. Confining pressure is always kept larger than the equilibrium pore-pressure but their values at each stage can be changed arbitrarily. The method considers gas leakage adjustments at high pore pressure. The analysis is simple and includes simultaneous solutions of two algebraic equations including the measured pressurevolume data.
\end{abstract}

The model is validated at zero stress. The reference volume predicted at zero stress matches with that measured independently using the standard helium porosimeter. For sandstone and shale, the pore compressibility is on average $1 \times 10^{-5} \mathrm{psi}^{-1}$ and the effective stress coefficient is slightly higher than unity.

The effective stress coefficient in isotropic elastic porous materials is known as the Biot's coefficient and the value we predict indicates the relationship between the bulk and grain volume 
moduli. Interestingly the effective stress coefficient predicted using shale samples rich in clays and organic matter is slightly higher than that for sandstone. This indicates other features of the sample such as fine-scale texture (laminations, and anisotropy, etc.) could come into play during the fluid storage measurements. 


\section{DEDICATION}

To Mita, PitoPa, Cachany and Cucu who are my lighthouse when the tides are high, and to whom I am indebted for life. Their love, support and voice in the middle of chaos, helped me through my days.

To Daisy and Julio who made my life in College Station easier, in ways they can't imagine. Also, to my sons, Matthi and Juli.

In memory of Omaira \& Caliche, who are deeply missed.

To Alex, Gonzalo, Bruno and Diana, who were there for me when most needed, I will always remember their support, time and dedication.

To Dr. Akkutlu and Dr. Brice, without whom this project would not have been possible. Their time, guidance, patience and dedication are invaluable to me.

To Riccardo, Seunghwan, Laura, Jeremy, El, Joel for the time shared together.

To Dr. King, Dr. Blasingame, Dr. Barrufet, Dr. Schechter, Dr. Kennedy, Dr. Sanchez, Dr. Gildin, Dr. Sun for their lessons.

To Marcela, the most beautiful thing that happened to me during my time at TAMU. 


\section{ACKNOWLEDGEMENTS}

Dr. I. Yucel Akkutlu supervised this work. I thank him and my thesis committee members Dr. David Schechter of the Department of Petroleum Engineering and Dr. Marcelo Sanchez of the Department of Civil Engineering. I also thank Brice Kim, for his invaluable help in the laboratory. 


\section{CONTRIBUTORS AND FUNDING SOURCES}

\section{Contributors}

This work was supported by a thesis committee consisting of professors I. Yucel Akkutlu and David Schechter of the Department of Petroleum Engineering and Professor Marcelo Sanchez of the Department of Civil Engineering.

\section{Funding Sources}

My graduate studies were supported using a student loan from Colfuturo FoundationColombia and a Graduate Teaching Assistantship granted by the Petroleum Engineering Department. 


\section{TABLE OF CONTENTS}

\section{Page}

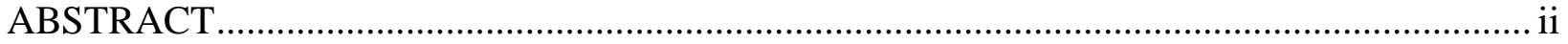

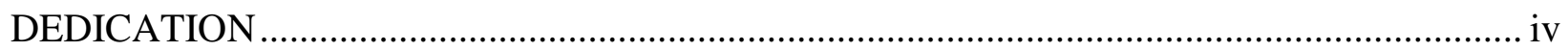

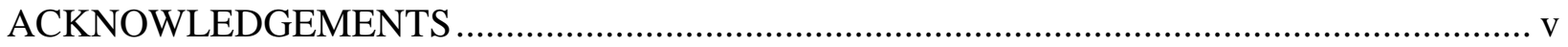

CONTRIBUTORS AND FUNDING SOURCES ….................................................... vi

TABLE OF CONTENTS .......................................................................................... vii

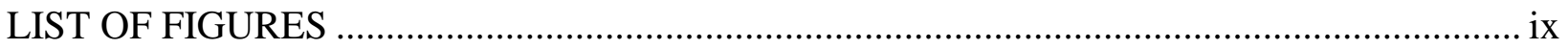

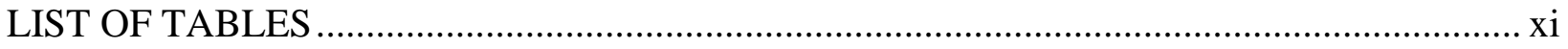

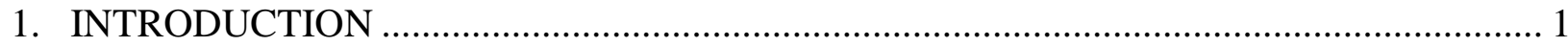

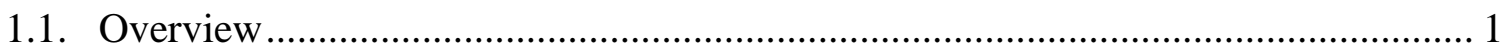

1.2. Previous research on the stress coefficient and pore compressibility ...................... 3

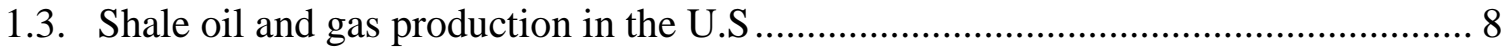

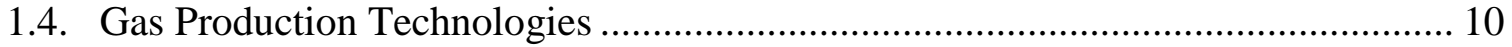

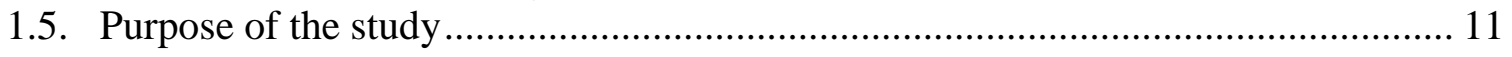

2. ORGANIC RICH SHALE FUNDAMENTALS ................................................... 12

2.1 Literature Review on Organic-rich Gas Shale ............................................ 12

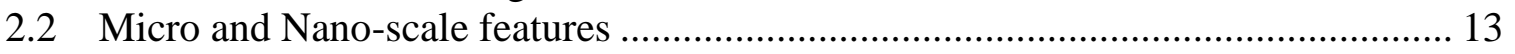

3. THEORY AND MODEL DEVELOPMENT ........................................................... 16

3.1 Brief Discussion on the Coefficient of Isothermal Compressibility ....................... 16

3.2 Brief Discussion on Effective Stress Coefficient.............................................. 17

3.3 Mass Balance for Helium Gas Expansion Method ............................................... 20

4. LABORATORY SETUP AND EXPERIMENTAL PROCEDURE ................................. 26

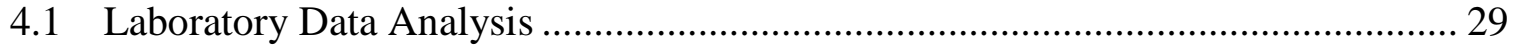

4.2 Specification of Samples used for the study ............................................... 32 


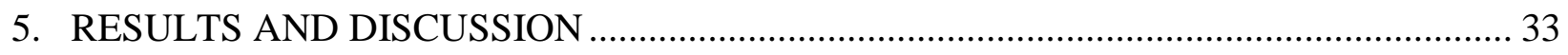

5.1 Petrophysical Parameters Determination ............................................................ 33

5.2 Acquisition of experimental data in the laboratory............................................ 33

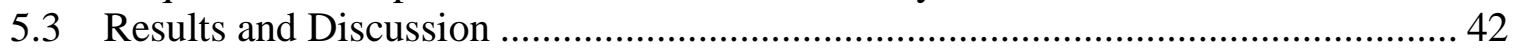

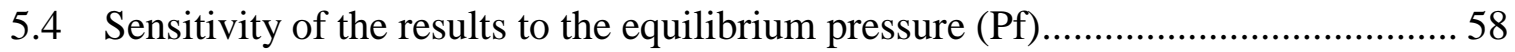

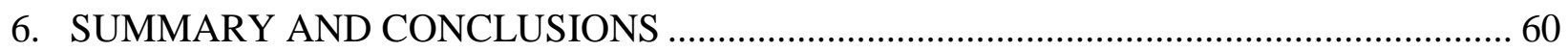

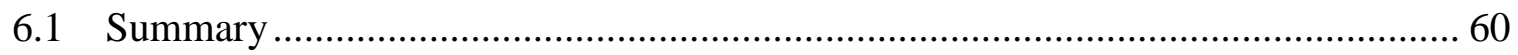

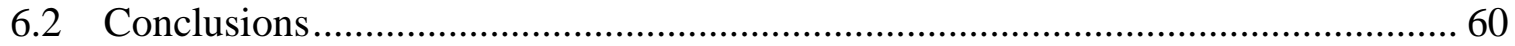

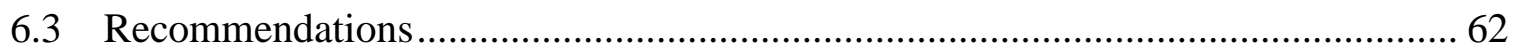

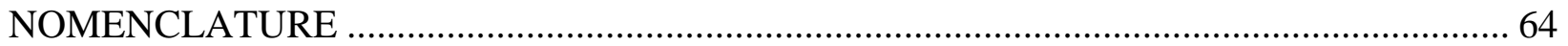

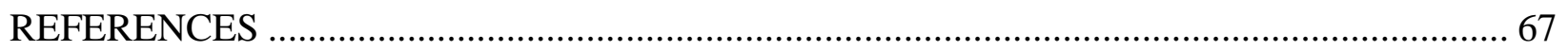

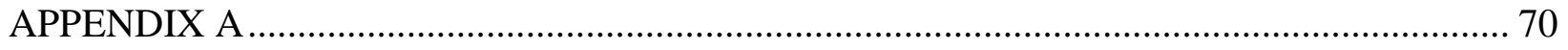

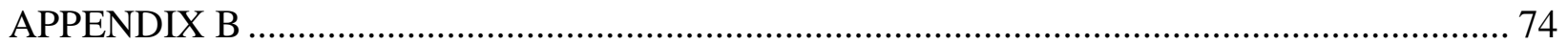




\section{LIST OF FIGURES}

Figure 1 Shale gas and tight oil production in the U.S from 1999 to 2050. 9

Figure 2 Shale gas plays in the U.S 10

Figure 3 2D Focused-Ion-Beam (FIB)/Scanning-Electron-Microscope (SEM) Images of an Organic-Rich Shale Sample Showing Finely Disperse Kerogen Pocket in an Organic Matrix.

Figure 4 Simplified diagram of laboratory apparatus used in the mass balance

Figure 5 Pore pressure and confinement pressure applied for each stage during the experiments using the shale sample \#1

Figure 6 Pore pressure and confinement pressure applied for each stage during experiment for a shale plug (additional data).

Figure 7 Pore pressure and confinement pressure applied for each stage during experiment for a sandstone plug.

Figure 8 Pore pressure and confinement pressure applied for each stage during experiment for a carbonate plug.

Figure 9 Estimated pore volume for sandstone samples as a function of differential pressure (LEFT) and effective stress (RIGHT).

Figure 10 Estimated pore volume for shale sample ( $1^{\text {st }}$ data set), as a function of differential pressure (LEFT) and effective stress (RIGHT).

Figure 11 Estimated pore volume for shale sample $\left(2^{\text {nd }}\right.$ data set) as a function of differential pressure (LEFT) and effective stress (RIGHT).

Figure 12 Estimated pore volume for carbonate sample as a function of differential pressure (LEFT) and effective stress (RIGHT).

Figure 13 Estimated effective stress coefficient for sandstone sample as a function of differential pressure (LEFT) and as a function of effective stress (RIGHT)

Figure 14 Estimated effective stress coefficient for shale sample ( $1^{\text {st }}$ data set), as a function of differential pressure (LEFT) and as a function of effective stress (RIGHT).

Figure 15 Estimated effective stress coefficient for shale ( $2^{\text {nd }}$ data set) samples as a function of differential pressure (LEFT) and as a function of effective stress (RIGHT)

Figure 16 Estimated effective stress coefficient for a carbonate sample as a function of differential pressure (LEFT) and as a function of effective stress (RIGHT).

Figure 17 Estimated pore compressibility for the sandstone sample as a function of differential pressure (LEFT) and effective stress (RIGHT).

Figure 18 Estimated pore compressibility for the shale sample ( $1^{\text {st }}$ data set) as a function of differential pressure (LEFT) and effective stress (RIGHT). 
Figure 19 Estimated pore compressibility for the shale sample ( $2^{\text {nd }}$ data set) as a function of differential pressure (LEFT) and effective stress (RIGHT). ................................................................... 54

Figure 20 Estimated pore compressibility for the carbonate sample as a function of differential pressure (LEFT) and effective stress (RIGHT).

Figure 21 Comparison of shale pore compressibility measured in this study (red triangle) vs. published data in literature (Modified from Davudov et al. 2018)

Figure 22 Comparison of effective stress coefficient $\mathrm{n}$ for shale measured in this study (red triangle) vs. published data in literature (Modified from Tinni et al. 2011)

Figure 23 Equilibrium pressure impact on the effective stress coefficient (n)............................................58

Figure 24 Equilibrium pressure impact on the Isothermal coefficient of pore compressibility $\left(\mathrm{C}_{\mathrm{p}}\right)$.

Figure 25 Equilibrium pressure impact on Pore volume (Vp)

Figure 26 Pressure measurement for dead volumes determination using gas expansion. 71

Figure 27 Example of graphical method for gas leakage correction....................................................... 74

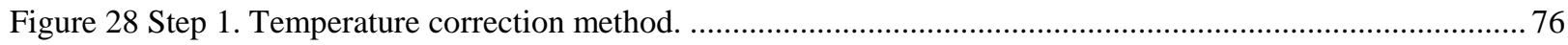

Figure 29 Step 2. Leakage correction applied after temperature correction. .................................................. 76 


\section{LIST OF TABLES}

\section{Page}

Table 1 Input data measured experimentally on a shale core plug …................................................................ 31

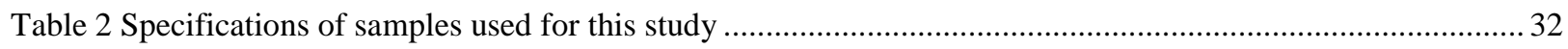

Table 3 Estimated Ranges of $\mathrm{C}_{\mathrm{p}}, \mathrm{V}_{\mathrm{p} 0}$ and $\mathrm{n}$ values for the core samples employed............................................. 33

Table 4 Confinement and pore equilibrium pressures obtained from 27 gas uptake measurements on shale

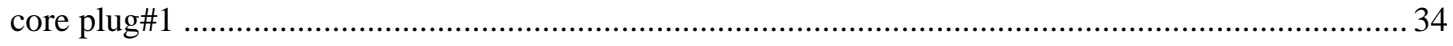

Table 5 Confinement and pore equilibrium pressures obtained from 16 additional gas uptake measurements

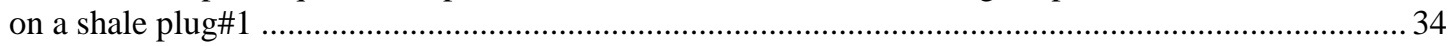

Table 6 Confinement and pore equilibrium pressures obtained from 44 gas uptake measurements on a

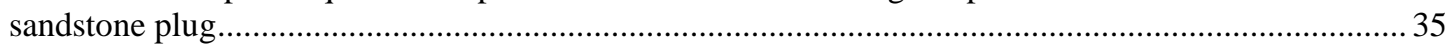

Table 7 Confinement and pore equilibrium pressures obtained from 28 gas uptake measurements on a

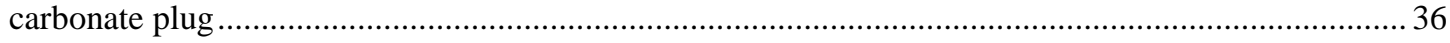

Table 8 Gas storage measurement results for the sandstone sample. …............................................................. 43

Table 9 Gas storage measurement results for the first set of shale sample data. ................................................... 44

Table 10 Gas storage measurement results for the second set of shale sample data............................................... 44

Table 11 Gas storage measurement results for the carbonate sample ................................................................... 45

Table 12 Dead volumes measurement using water..................................................................................... 72

Table 13 Dead volumes measurement using different fluids ............................................................................... 73 


\section{INTRODUCTION}

\subsection{Overview}

Routine laboratory measurement of fluid storage capacity of rocks is important for the assessment of underground water and petroleum resources. Helium gas expansion method based on Boyle's law is often used due to its accuracy and rapidity. The method measures the grain volume, and then the pore volume and porosity are estimated using the sample's bulk volume. The routine laboratory tests are applied in the absence of stresses; however, the external stresses and the pore pressure applied could affect the fluid storage. Considering these effects in the laboratory is important because they allow us to mimic the in-situ conditions of overburden stress and the reservoir fluid pressure. One solution would be to perform the helium porosity measurement at reservoir pressure and using core plug in Hassler-type core holder systems, which can be used to apply axial and radial stresses, i.e., the confining pressure (Santos \& Akkutlu, 2013). In that case, the analysis of such laboratory data should be done properly, and the storage capacity should be reported as a function of the applied stresses. The purpose of this study is to develop a new methodology for accurate measurement of the fluid storage capacity of common rocks under stress. The difference in methodology is mainly on the analysis of the measured data and reporting of the results.

An important fundamental quantity that relates the stresses applied in the laboratory to the subsurface conditions is the effective stress. A storage related quantity such as pore volume and pore compressibility can be described as a function of the effective stress. The latter is defined as the external stress that, if applied in isolation, would produce the same effect as the combination of the applied confining pressure, $\mathrm{p}_{\mathrm{c}}$, and pore pressure $\mathrm{p}$ (Hampton \& Boitnott, 2018). The 
effective stress, $\sigma$, for a storage-related quantity can be described as $\sigma=p_{c}$-np, where $n$ is the effective stress coefficient for the pore volume. This coefficient is commonly referred to as the Biot (or Biot-Willis, $\alpha$ ) coefficient when the rock under investigation is isotropic elastic. In the literature, during the reporting of the storage parameters, this coefficient is often taken as 1.0 and the storage is reported in terms of the applied pressures difference, $\mathrm{p}_{\mathrm{c}}-\mathrm{p}$; However, independent geomechanical tests showed that its value is controlled by the intrinsic mechanical properties of the rock and is different than unity.

In the literature, the pressure difference is used because the effective stress coefficient is unknown. Determination of the coefficient experimentally can be done separately using tri-axial compaction test, but the test is destructive, time-consuming and expensive. A more elegant approach would be to determine the coefficient simultaneously during the fluid storage capacity measurements, which are non-destructive, fast and inexpensive. The objective of this study is to develop a new theoretical model of fluid storage as a function of effective stress and show how this model can be used in the laboratory as data analysis tool. I show how the analysis can be used with the helium porosity data to determine the effective stress coefficient and to predict the pore volume of the rock change as a function of the effective stress.

This study is organized as follows. I first introduce the laboratory setup used and the experimental procedure applied. The setup is the same as the gas expansion method of porosity measurement but in our case Hassler core holder is used as the measurement cell and the gas expansion is applied multiple stages of fluid pressure and under varying confining pressure. We propose a new mathematical model, which is detailed mass balance describing gas storage in a core plug under stress. Measurements are done under the equilibrium conditions, hence the transient behavior of the gas during the expansion from the reference cell to core holder is ignored 
in the analysis. We perform the storage measurements under stress using a sandstone, shale and carbonate samples.

1.2. Previous research on the stress coefficient and pore compressibility

Organic rich shale is a paramount resource to the production of oil and gas nowadays. Shale has low intrinsic permeability and low porosity, so production of gas and oil to the wellbore must be aided by "creating a reservoir" composed of induced and natural fractures, which are of vital importance to production. Among the several factors to properly design and understand the shale gas and oil "reservoirs" are geomechanical properties of the rock.

Poroelasticity is important to understand rock mechanics applied to petroleum engineering, particularly in reservoir engineering, hydraulic fracturing operations and production maintenance. The development of shale gas unconventional resources has advanced fast, because multi-stage hydraulic fracturing techniques are being applied in horizontal wells. Effective stress coefficient $n$ or, in the case of poroelastic and isotropic materials termed Biot's coefficient $\alpha$, is one of the key mechanical parameters to interpret the applied effective stress, a key input in order to understand the formation of artificial fractures in shale formations.

Several efforts are reported in the literature by different authors to derive Biot's coefficient $\alpha$ conceptually. For a start, Terzaghi expressed the equation for differential pressure to describe soil samples subjected to oppose pressures, termed here as "confining pressure" and "pore pressure". Differential pressure is traditionally taken as the difference between these confining pressure $\left(\mathrm{P}_{\mathrm{c}}\right)$ and pore pressure $\left(\mathrm{P}_{\mathrm{p}}\right)($ Equation 1$)$.

$\mathrm{p}_{\mathrm{e}}=\mathrm{p}_{\mathrm{c}}-\mathrm{p}_{\mathrm{p}}$

Here, $\mathrm{P}_{\mathrm{p}}$ has a cancelling or counter-balancing effect on $\mathrm{P}_{\mathrm{c}}$; moreover, it works well in deformation of uniformly saturated (filled with incompressible fluids, such as water), 
unconsolidated sediments such as soils. However, this assumption is not strictly applicable for the deformation of most of the rocks. Differently from soils, the skeleton of consolidated rocks is stiffer and continuous. Contact and bond between the grains reduces the effective area where the pore fluids surround the grains, and the effect of pore pressure diminishes as rock skeleton becomes stiffer. Later Biot (Biot M. A., 1940) described a complete theory on the coefficient $\alpha$ to expand the application for rock samples and other stiff materials. This concept suggests that pore pressure counteracts the stress carried by the grains due to confinement pressure being applied, where $\alpha$ is a weighing factor.

Nur and Byerlee explicitly wrote the effective stress law (Nur \& Byerlee, 1971), which can be generalized following from Terzaghi's equation,

$\sigma_{e}=p_{c}-\alpha p_{p}$

Where $\sigma_{\mathrm{e}}$ is effective stress and $\alpha$ is Biot's coefficient (or Biot-Willis coefficient) (Biot \& Willis, 1957), which scales the contribution of pore pressure to effective stress. This equation was supported by rock volumetric deformation experiments performed by Nur and Byrlee. Additionally, Geertsma (Geertsma, 1956) and Skempton (Skempton, 1960) who first derived the Biot's coefficient for volumetric deformation, introduced an expression to determine the coefficient $\alpha$ experimentally, by introducing the bulk modulus $(\mathrm{K})$ and the grain modulus $\left(\mathrm{K}_{\mathrm{s}}\right)$ : $\alpha=1-\frac{\mathrm{K}}{\mathrm{K}_{\mathrm{s}}}$.

where $\mathrm{K}$ and $\mathrm{K}_{\mathrm{s}}$ are the bulk moduli of the aggregate and constituent minerals, respectively.

Furthermore, different authors produced values of the Biot's coefficient experimentally for several materials, such as oil- and gas-bearing sedimentary rocks, using Equation 3 as theoretical basis and by design of different approaches and techniques in the laboratory. Several authors have used conventional experimental techniques to measure both moduli, under jacketed and unjacketed 
samples to obtain the coefficient $\alpha$. (Nur \& Byerlee, 1971); (Warpinski \& Teufel, June 1992); (M., Khan, Abdulraheem, Rahim, \& Al-Qahtani, 2002). In the jacketed condition, pore pressure is set to zero, to obtain $\mathrm{K}$. In the unjacketed condition, pore pressure and confining pressure are set equals, to obtain $\mathrm{K}_{\mathrm{s}}$. It was shown that, if rock stiffness $\left(\mathrm{K}_{\mathrm{s}}\right)$ is near the matrix bulk modulus $(\mathrm{K})$, the Biot's coefficient approaches zero. This is when the pore pressure has no impact on the effective stress. Franquet and Abbas (Abass, 1999) proposed a technique to measure Biot's coefficient from change in pore volume with respect to change in total bulk volume of the sample.

Because the method measures amount of fluid drained from the rock, accurate pore volume determination is needed. Testing in rock samples as tight as mudrocks, would require using gas instead of liquid. He also proposed the failure envelope method, but it would require many samples to be tested. Despite such drawback, the method is advised for the experimentalist interested in acquiring additional geomechanics information.

For heterogeneous rocks with anisotropic properties (e.g., shale), it is challenging to measure $\mathrm{K}_{\mathrm{s}}$, because of the contribution of each mineral and complexity of the mixing rules. Also, $\mathrm{K}_{\mathrm{s}}$ possibly changes with variable confining pressure (especially for clay minerals or organic matter). Therefore, $\alpha$ is difficult to measure in terms of its poroelastic parameters. Similarly, using $\alpha$ is restricting for the elastic behavior of these rock types. Instead, we propose to follow the discussion in terms of effective stress coefficient, n. and conveniently write equation 2 as,

$\sigma_{\mathrm{e}}=\mathrm{p}_{\mathrm{c}}-\mathrm{np}$

Todd and Simmons proposed the following equation to determine n (Simmons, 1972)

$\mathrm{n}=1-\left(\frac{\partial \mathrm{Q}}{\partial \mathrm{P}_{\mathrm{p}}}\right)_{\sigma} /\left(\frac{\partial \mathrm{Q}}{\partial \sigma_{\mathrm{e}}}\right)_{\mathrm{P}_{\mathrm{p}}}$

where $\mathrm{Q}$ is any measured physical quantity. The authors used this equation to study stress with respect to wave propagation velocities. Other authors have used stiffness and permeability 
(Christensen \& Wang, 1985); (Hornby, 1996); (Sarker \& Batzle, June 2008). Some more recent authors have used the volumetric strain (Zoback, 2017). Note that by usage of volumetric strain in equation 5, we can recover equation 3, using the imposed conditions written on the equation and reproduced on the experiment.

Several authors tried other more recent experimental innovative approaches with basis on the equations already presented, Tinni et al. (Tinni, Sondergeld, Rai, \& Simo, 2011) used acoustic velocities and the electric measurements performed on several shale rock samples. An adaptation to Todd and Simmons equation (Simmons, 1972), would produce values of effective stress coefficient, as a function of pore pressure and confining pressure, using the seismic velocities under dynamic effective stress conditions. They also reported typical values for the effective stress coefficient reported in literature in several formations and lithology with quite variable porosity ranges, that the reader is encouraged to re-visit.

Qiao determined the effective stress coefficient during the permeability measurements using rock samples under the assumption that permeability follows the effective stress law (Qiao, Wong, Aguilera, \& Kantzas, 2012). Nonetheless it is difficult to identify permeability variations in tight rocks such as mudstones. More recently, Hasanov and Prasad worked with permeability measurements, and obtained several values for the effective stress coefficient. In their work, at the lowest effective stress, some values close to 1.3 were reported for permeability measurements on a mudstone, while the value was decreasing about $30 \%$ at higher effective stress. Moreover, as effective stress is increased further, the coefficient is reduced to values less than unity. (Hasanov \& Prasad, 2018)

Finally, several authors have made stress-strain measurements on shale rocks to determine Biot's coefficient (Jun He, 2014), (Xuejun Zhou, 2015), (Zhou, 2017), (Yuzheng Lan, 2017) by 
using tri-axial compression test. Biot's coefficient values for Bakken shale formation under stress showed quite variability, depending on the sample used. Xiadong Ma (Zoback, 2017) also experimented on shale plugs from the Bakken formation integrating SEM images, revealing that variations in bulk modulus and Biot's coefficient can be attributed to the texture of the rock and the abundance of the major constituents of the sample porosity (pores, micro-cracks, clays, organic matter) and their distribution in the rock matrix.

Among the governing equations of linearized poroelasticity, some authors expressed the coefficient of isothermal pore compressibility in the following comprehensive manner (Zimmerman, Somerton, \& King, 1986)

$$
\begin{gathered}
\mathrm{C}_{\mathrm{p}, \mathrm{c}}=-\frac{1}{\mathrm{~V}_{\mathrm{p}}}\left(\frac{\partial \mathrm{V}_{\mathrm{p}}}{\partial \mathrm{p}_{\mathrm{c}}}\right)_{\mathrm{T}, \mathrm{P}_{\mathrm{p}}} ; \\
\mathrm{C}_{\mathrm{p}, \mathrm{p}}=\frac{1}{\mathrm{~V}_{\mathrm{p}}}\left(\frac{\partial \mathrm{V}_{\mathrm{p}}}{\partial \mathrm{p}_{\mathrm{p}}}\right)_{\mathrm{T}, \mathrm{P}_{\mathrm{c}}} ; \ldots
\end{gathered}
$$

where the compressibility represents changes in the pore volume of a body when subjected to confining pressure (Equation 6), or the pore pressure (Equation 7). For a non-porous material, or a material with negligible fluid storage, the compressibility is governed by the former equations given above. For a porous rock, however, the compressibility is complex because it changes unpredictably due to changes in external (confining pressure) and internal (pore pressure) stresses. It is therefore necessary to account for pore volume and bulk volume changes due to pressure changes. Pore compressibility can change due to four factors: bulk volume, pore volume, pore pressure and confining pressure, as introduced in the equations above. Zimmerman et al., analyzed sandstone pore compressibility by two processes, changing confining pressure and fixing pore pressure constant, then varying pore pressure and fixing confining pressure constant. His results 
show how the pore compressibility is influenced by pore pressure changes. For shale samples, tough, changes in bulk volume are negligible and not taken into consideration.

The present work is an experimental approach designed to determine effective stress coefficient parameter easily, with the aid of a few data that turns the analysis practical and simple. Using pressure and volume data, we can derive not only this coefficient but obtain the coefficient of isothermal pore compressibility to perform calculations on storage capacity under stress. The method considers dynamic changes of both pore pressure and confining pressure affecting the properties. Also, the method considers gas leakage adjustments at high pressure. Because the samples used are from shale formations, we need to address their petro-physical characteristics and develop a better understanding of the laboratory results.

At micron-scale, organic rich shales have been visually investigated by several researchers including Loucks (Robert G. Loucks R. M., 2009); Wang and Reed (Reed, 2009) ; Sondergeld et al. (Sondergeld, Newsham, Cominsky, Rice, \& Rai, 2010); Kang et al. (Kang, 2011). They showed that shale organics are naturally occurring nano-porous materials. While they do not hold large quantities as free fluids, they also have large internal surface area that can trap large amounts of hydrocarbons in adsorbed state. The presence of small organic pores challenges the traditional quantification of gas storage. Storage capacity measurements have been recently modified to include the dynamic and stress-dependency effect on porosity by these research groups. Implementation of this present new methodology will lead to determination of total pore volume at zero stress, total shale porosity and pore compressibility as function of effective stress.

1.3. Shale oil and gas production in the U.S

According to the U.S. Energy Information Administration's International Energy Outlook 2016 report, natural gas production worldwide is expected to increase from 342 Billion cubic feet 
per day (Bcf/D) in 2015 to $554(\mathrm{Bcf} / \mathrm{D})$ by 2040. The largest component of this increase is natural gas production from shale gas resources, which will grow from $42 \mathrm{Bcf} / \mathrm{D}$ in 2015 to $168 \mathrm{Bcf} / \mathrm{D}$ by 2040. Shale gas will account for 30\% of the world's natural gas production by the end of 2040 . Only in the U.S., shale gas production accounted for more than half the natural gas production in 2015 and is expected to be more than double from 2015 to 2040. Production, numbers are expected to increase from almost $15 \mathrm{Tcf}$ to $33 \mathrm{Tcf}$ from now to 2050 (Statista, 2018). Figure 1.

Shale gas development will continue in response to the increasing demand for natural gas consumption, as new resources are added from the largest discoveries, such as Barnett, Fayetteville, Woodford and resources in the Permian Basin, including shale oil and gas.

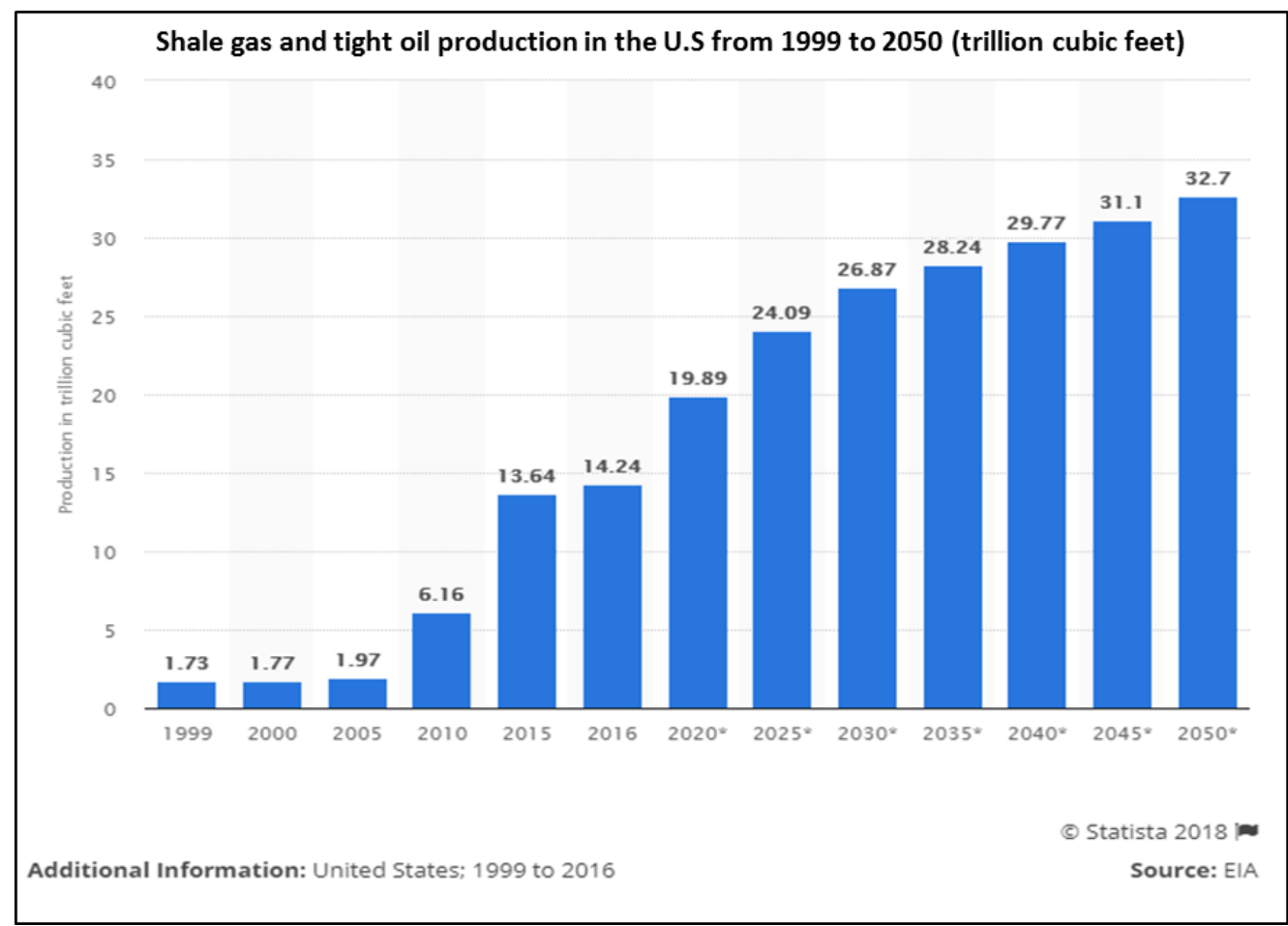

Figure 1 Shale gas and tight oil production in the U.S from 1999 to 2050 (forecasted) (trillion cubic feet). (Reprinted from Energy Information Administration, 2016). 
Top shale gas plays producers on a monthly basis up to date are Marcellus Shale with around $55 \mathrm{Bcf} / \mathrm{D}$, Utica producing $35 \mathrm{Bcf} / \mathrm{D}$ and Permian Basin in the order of $30 \mathrm{Bcf} / \mathrm{D}$. The total number of gas wells producing in the U.S. in 2016 are 553,495 wells. In 2016, the total natural gas proved reserves in the United States were around 341.1 Tcf. Some of the main plays can be observed in Figure 2. (EIA, 2011).

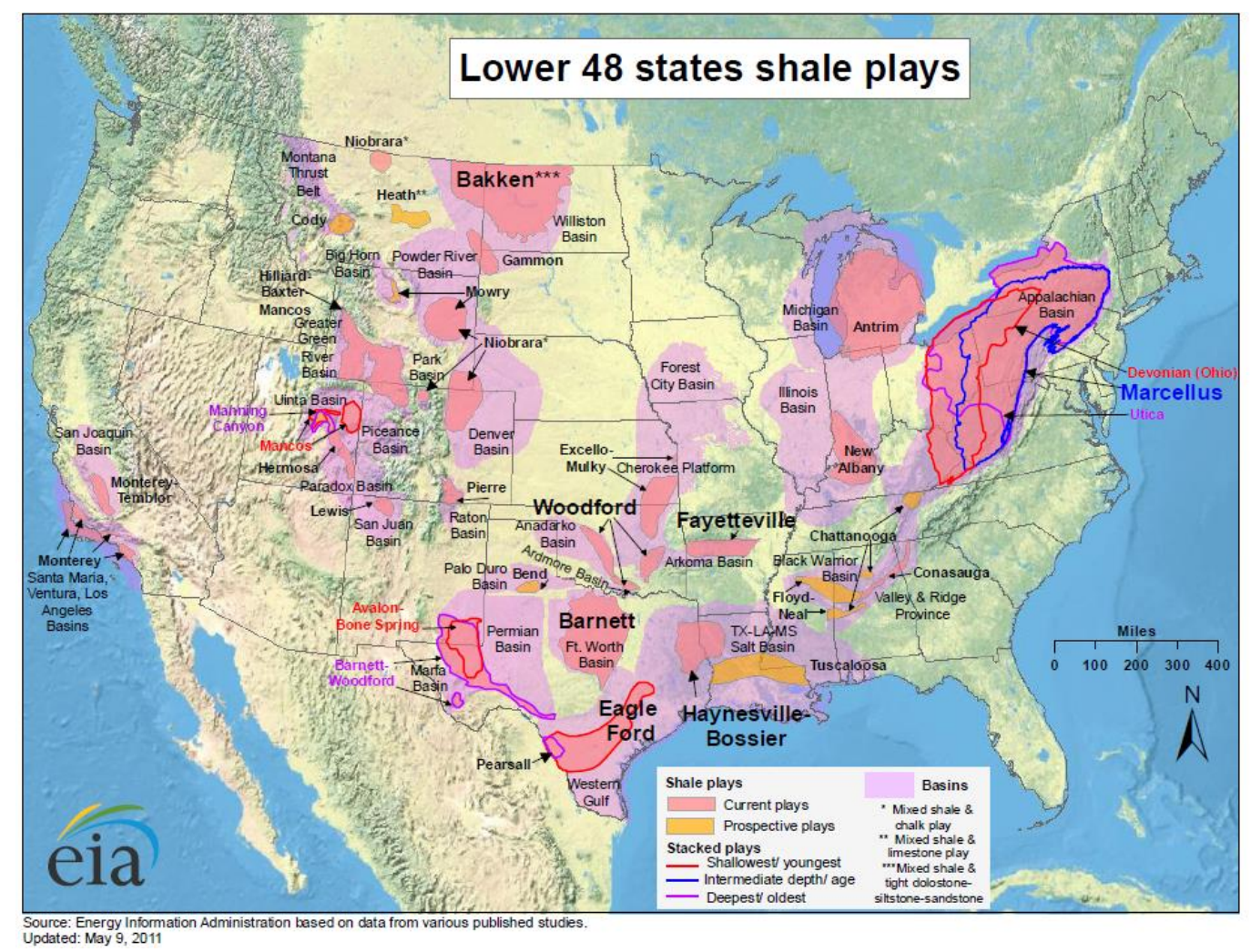

Figure 2 Shale gas plays in the U.S (Reprinted from EIA, 2011)

\subsection{Gas Production Technologies}

Some important factors have come into play for the development of shale gas production, turning it economically viable: Technological advances in horizontal drilling including multi-stage hydraulic fracturing, gas prices increase, are within a short margin where main economic portfolios 
development is feasible. Hydraulic fracturing increases production potential of gas wells, improving production rates. Without these technology advances, unconventional natural gas reservoirs would not be economical, nor possible to be produced. As of summer, 2018, Oil rigs in the United States were approximately 860 where 710 were drilling in unconventional resources including Permian, Woodford, Eagle Ford and Williston Basins; 480 of them drilling in the Permian Basin, most of them can apply horizontal drilling and hydraulic fracturing technology.

Because shale is a tight rock, usually it limits the production from this resource, due to its ultra-low matrix permeability, allowing only small amounts of fluid to be produced naturally. Such limitation must be overcome for the shale gas production to be economically viable. By drilling horizontal wells and creating multiple fracture completions, previously overlooked new resources have been included as reserves.

\subsection{Purpose of the study}

The purpose of this investigation is to develop a new methodology for accurate measurement of the fluid storage capacity of common rocks under stress including resource shale samples. The difference in methodology is mainly on the analysis of the measured data and reporting of the results. In this study measurements have been performed in Mississippian Lime formation shale core plugs, besides prototypical samples (Berea sandstone-outcrop dolomite) using a modified Hassler type core holder and applying a new data analysis tool, to determine the parameters effective stress coefficient, isothermal coefficient of pore compressibility and original pore volume at zero stress, that can be later integrated to enhance quantification of gas storage capacity in shale core samples. The fundamentals of the experimental methodology are found in Chapter 3, and results are included in Chapter 4. 


\section{ORGANIC RICH SHALE FUNDAMENTALS}

\subsection{Literature Review on Organic-rich Gas Shale}

An unconventional reservoir is one that cannot be produced at economic flow rates without assistance from massive stimulation treatments or special recovery processes and technologies". To understand more deeply about these reservoirs, their petrophysical properties must be investigated. Within the realm of unconventional reservoirs, shale gas and oil reservoirs are the one that catches our attention more deeply in terms of their characterization.

Shale is the most common of all sedimentary rocks. It typically constitutes $65 \%$ of all sedimentary rocks, and along sandstones and carbonates, constitutes $95 \%$ of all the variety of sedimentary rocks. Shales are laminated mudrocks. They are made up of clay-sized weathering debris. They exhibit a very fine grain size distribution, typically less than $0.0625 \mathrm{~mm}$. They differ from mudstone (fine grained mudrock, but of blocky aspect) because shale presents itself as a laminated and fissile rock, and bioturbation is rarely seen.

Shales can be present in a clastic (fine grained sand/silt) or carbonate system, depending upon the depositional environment. Also, they can be encountered interlayered in channel sands, forming discontinuous sweet spots. Shale is deposited in quiet water settings, common in basins, deltas, meandering rivers, flood plains, etc. They belong mostly to marine depositional environment (Arthur \& Sageman, 1994)

Shale is a self-sourcing reservoir that typically has more than $1 \%$ adsorbed gas plus free gas storage, with less than $10 \%(\mathrm{w} / \mathrm{w})$ organic matter in contrast to coal bed methane, which typically has more than $50 \%$. The organic matter content is regularly kerogen that is primarily classified as type II or III according to the Van Krevelen Diagram. 
As shale becomes richer in organic matter content, its characteristics change, turning ordinary shale rocks into organic-rich shale, an important resource from the petroleum recovery standpoint. Among these petrophysical properties we find, extremely low matrix permeability (less than $0.0001 \mathrm{mD}$, or 0.1 micro-Darcy), low porosity (Typically less than $10 \%$ ), a variable TOC (Total organic Carbon), which affects sorption and mechanical properties. Organic-rich shale can hold gas in both free (compressed) and sorbed states, and the matrix has variable mineralogy, often including high clay content.

Natural fractures occur in organic-rich shale formations, and they may contribute to the productivity. Natural fractures are observed in the wellbore image logs and should be differentiated from the thermally induced micro-fractures. Because presence of natural fractures is one key factor for having high production rates upon the induction of artificially created fractures in the formation. Brittleness of shale makes it easier to fracture, creating a fracture complexity with an often-unpredictable intensity. Other aspects of organic rich shale are the presence of sweet spots present in multi-layered "stack" formations, typically highly heterogeneous and laminated, making the petrophysical characterization of the formation overly complex.

\subsection{Micro and Nano-scale features}

Figure 3 shows a two-dimensional focused ion beam electron microscope (FIB/SEM) image of gas shale at micron scale. In the image the organic matter can be observed in dark gray as a finely dispersed material, imbedded in light gray inorganic clays. The pores are observed in black, and they are contained inside organic areas, namely kerogen pockets, displaying a characteristic size between 200-500 nanometers $(\mathrm{nm})$. The average size of organic pores is smaller than the ones observed in the inorganic matrix. Organic matter consists of micropores (pore length less than 2 
$\mathrm{nm}$ ) and mesopores (pore lengths between 2-50 nm) with an average size below 4-5 $\mathrm{nm}$. (Kang, 2011). The scale of nanopores is close to the size of the macro-molecular openings, and no technology including SEM can define such pore spaces for direct observation. However, lowpressure nitrogen adsorption porosimeter (or BET) can be used to measure the truly nanopores in shale. If one were allowed to observe at the details of the organic nanopore structure in Figure 3 , uniformly distributed organic nanopores would be observed, surrounding the visible ones, rendering a sponge-like appearance to the kerogen pockets.

Ambrose et al. (Ambrose, Hartman, M., \& Akkutlu, 2012) reported an analysis of hundreds of 2-D SEM images and recombined 3-D digital shale segments of Barnett shale samples pertaining to different depths and locations. The images revealed both kerogen network and kerogen pore-network. A typical kerogen network is made up of interconnected kerogen pockets as the one shown in Figure 3 (Bui \& Akkutlu, 2017). From their observations, it was concluded that organic-rich shale matrices consist of organic and inorganic materials that could be dispersed with one another, bi-continuous and intertwined. The major fraction of the total porosity is associated with the kerogen network and the storage capacity of such network is related to the organic fraction of the rock matrix.

The inorganic part of the shale matrix depicted in Figure 3 consists of clays, quartz, carbonates, feldspars and pyrite. The pores can be inter-granular or slit shaped pores. The latter can be considered as micro-cracks and fractures. Depending on the level of maturity of kerogen, the organic pores appear as rounded, of several sizes and connectivity. Passey et al. (Passey, Bohacs, Esch, Klimentidis, \& Shina, 2010) showed that the organic nanopores contained in the "kerogen pockets" may contribute to more than $50 \%$ of the total pore volume, where natural gas 
is contained as adsorbed gas on the internal surfaces of the nanopore network, or as free compressed gas residing in larger pores.

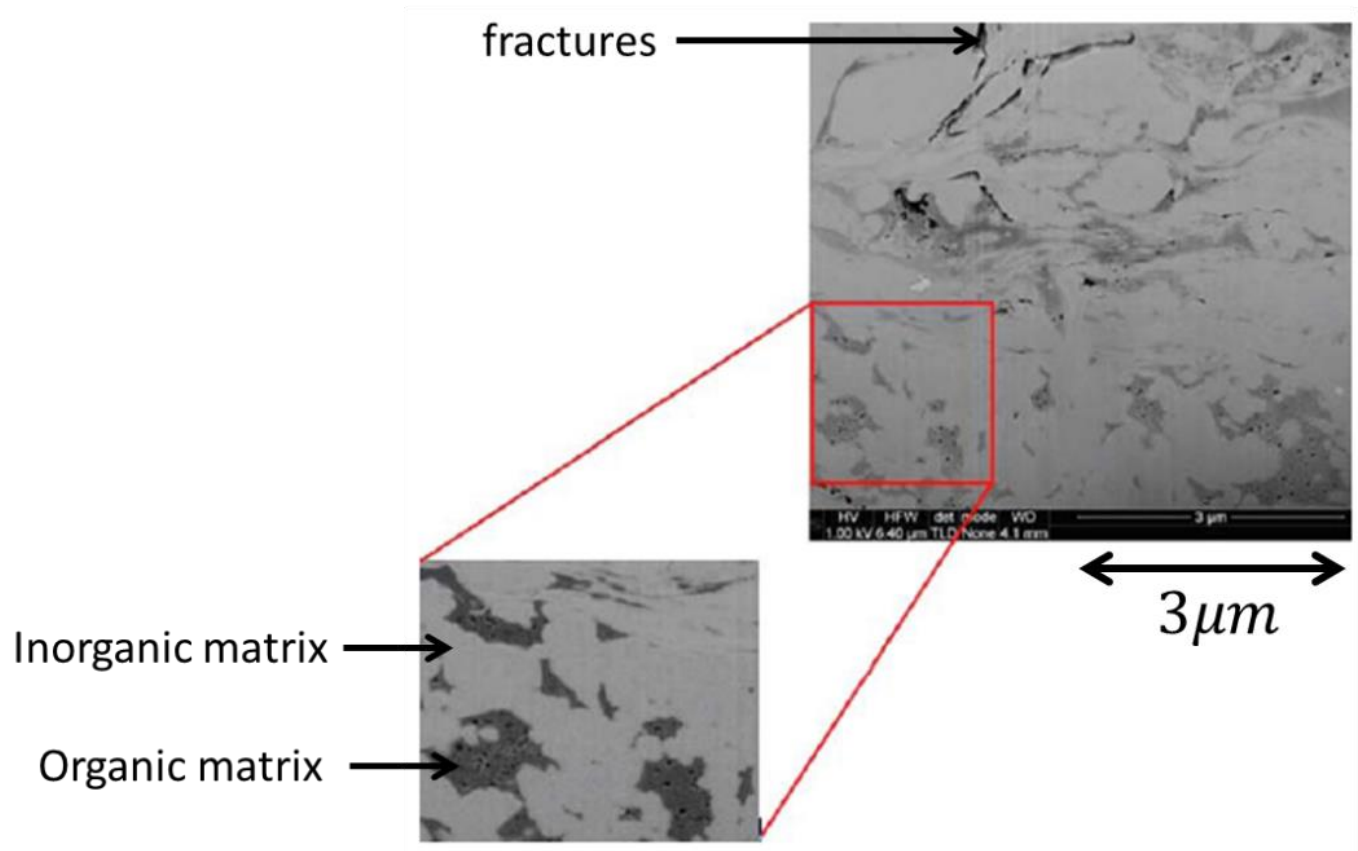

Figure 3 2D Focused-Ion-Beam (FIB)/Scanning-Electron-Microscope (SEM) Images of an Organic-Rich Shale Sample Showing Finely Disperse Kerogen Pocket in an Organic Matrix. (Reprinted from Khoa Bui et al., 2017) ${ }^{1}$

*Reprinted with permission from "Hydrocarbon Recovery from model-kerogen Nanopores" by Khoa Bui and I. Yucel Akkutlu, 2017. SPE Journal, Volume 22, 854-855, Copyright 2017 by SPE. 


\section{THEORY AND MODEL DEVELOPMENT}

The experimental studies of pore volume compressibility and effective stress coefficient are the target of this investigation on the storage capacity of shale and other sedimentary rocks. An adapted Hassler type core-holder was used for the helium gas expansion conducted.

\subsection{Brief Discussion on the Coefficient of Isothermal Compressibility}

For my study, the two equations introduced in the previous chapter 1, section 1.2 are of our interest (Zimmerman, Somerton, \& King, 1986), the pore volume compressibility which is termed in literature as $\mathrm{C}_{\mathrm{pc}}$ and $\mathrm{C}_{\mathrm{pp}}$ terms. As I will be combining these two equations, it will be simply treated as $\mathrm{C}_{\mathrm{p}}$ or pore compressibility; it defines relative changes in pore volume of core sample due to unit change in pore pressure. It is measured relative to a reference volume, that we will call $\mathrm{V}_{\mathrm{po}}$, or original pore volume at zero stress. We revisited the concept of pore compressibility, and redefined it in terms of effective stress, henceforth the equation is:

$\mathrm{C}_{\mathrm{p}}=-\frac{1}{\mathrm{~V}_{\mathrm{po}}}\left(\frac{\partial \mathrm{V}_{\mathrm{p}}}{\partial \sigma_{\mathrm{e}}}\right)_{\mathrm{T}}$.

Essentially, pore compressibility is inversely proportional to change in effective stress as we can see in the first formula. It is also the reciprocal of bulk modulus parameter. Note the temperature is taken as a constant, which is reasonable as temperature does not change greatly in the reservoir and its effect is negligible, also temperature can be controlled in the laboratory, therefore we drop $\mathrm{T}$ in equation (8), and exchange the partial derivative as single derivative, because the pore volume will be a function of effective stress only. The negative sign in the above equation is to make the compressibility value positive since an increase in confining pressure (therefore in effective stress) will result in a pore volume reduction.

$C_{p}=-\frac{1}{V_{p o}} \frac{d V_{p}}{d \sigma_{e}}$. 
As we are interested in the combined effect that external stress has on the core samples, we invoke confinement pressure $\left(\mathrm{P}_{\mathrm{c}}\right)$ and pore pressure $\left(\mathrm{P}_{\mathrm{p}}\right)$ from the former definitions of pore compressibility, using chain rule on Equation (9) and get,

$C_{p}=-\frac{1}{V_{p o}}\left(\frac{d V_{p}}{d p_{c}} \frac{d p_{c}}{d \sigma_{e}}+\frac{d V_{p}}{d p_{p}} \frac{d p_{p}}{d \sigma_{e}}\right)$

Next, we must invoke the concept of effective stress coefficient, which is an intrinsic property of the rock, as seen in chapter 1 .

\subsection{Brief Discussion on Effective Stress Coefficient}

I propose to derive my own theoretical approach to determine both pore compressibility, $\mathrm{C}_{\mathrm{p}}$, and the coefficient $\mathrm{n}$ to be used in equation (10). I will approach the problem mathematically using the volumes and pressures and the Boyle's law as previously shown by Kang et al. (Kang, 2011). Following on with the derivation of effective stress coefficient, and pore compressibility we have the following:

If I take derivative of the pressures with respect to effective stress using equation (5),

$\frac{\mathrm{dp}_{\mathrm{c}}}{\mathrm{d} \sigma_{\mathrm{e}}}=1$

$\frac{d p_{p}}{d \sigma_{e}}=-\frac{1}{n}$

Introducing these terms in equation (10),

$C_{p}=-\frac{1}{V_{p o}}\left[\frac{\mathrm{dV}_{\mathrm{p}}}{\mathrm{dp}_{\mathrm{c}}}(1)+\frac{\mathrm{dV} \mathrm{p}}{\mathrm{dp}_{\mathrm{p}}}\left(-\frac{1}{\mathrm{n}}\right)\right]$

which can be written as follows:

$\mathrm{C}_{\mathrm{p}} \mathrm{V}_{\mathrm{po}}=-\left(\frac{\mathrm{dV}_{\mathrm{p}}}{\mathrm{dp}_{\mathrm{c}}}-\frac{1}{\mathrm{n}} \frac{\mathrm{dV}_{\mathrm{p}}}{\mathrm{dp}_{\mathrm{p}}}\right)$

In literature a reduced form of Equation (11) is often used. For example, one common form is to maintain the pore pressure constant during the measurement and change the stress as a 
function of confining pressure only:

$C_{p, c}=-\frac{1}{V_{p o}}\left(\frac{d V_{p}}{d p_{c}}\right)$

Or take $\mathrm{n}=1$ (i.e., use the applied pressure difference) maintain the confining pressure and change the effective stress as a function of the pore pressure only:

$C_{p, p}=-\frac{1}{V_{p o}}\left(\frac{d v_{p}}{d p_{p}}\right)$

Henceforth, I recover the original equations of pore compressibility introduced by Zimmerman (Zimmerman, Somerton, \& King, 1986).

In this work, because our interest is to investigate the storage as a function of the effective stress, rather than the applied pressures, we do not consider these limiting cases; instead, we proceed with the general form given in Equation (11). This is necessary, if one would like to work with effective stress, which includes the rock's intrinsic geo-mechanical behavior. Let us now write Equation (11) as follows:

$\mathrm{nC}_{\mathrm{p}} \mathrm{V}_{\mathrm{po}}=\frac{\mathrm{dV}_{\mathrm{p}}}{\mathrm{dp_{ \textrm {p } }}}-\mathrm{n} \frac{\mathrm{dV_{ \textrm {p } }}}{\mathrm{dp}_{\mathrm{c}}}$

Also, recall that the confining pressure and the pore pressure can be applied independent from each other in the laboratory as we will review later in the laboratory setup section. Thus, we maintain a relation in between the two quantities as follows:

$\mathrm{p}_{\mathrm{c}}=\mathrm{an} \mathrm{p}_{\mathrm{p}}$

where $\mathrm{a}$, is a constant and positive for the experimental conditions representing the subsurface environment. Substituting Equation (13) into Equation (11), the following is obtained:

$\mathrm{nC}_{\mathrm{p}} \mathrm{V}_{\mathrm{po}}=\frac{\mathrm{dV}_{\mathrm{p}}}{\mathrm{dp}_{\mathrm{p}}}-\frac{1}{\mathrm{a}} \frac{\mathrm{dV}_{\mathrm{p}}}{\mathrm{dp_{ \textrm {p } }}} ;$

Now, separating the variables, 
$\mathrm{nC}_{\mathrm{p}} \mathrm{V}_{\mathrm{po}} \mathrm{dp}_{\mathrm{p}}=\mathrm{dV} \mathrm{V}_{\mathrm{p}}-\frac{1}{\mathrm{a}} \mathrm{dV} \mathrm{V}_{\mathrm{p}}$

And integrating from $p_{p}=p_{0}$ to $p_{p}=p_{1}$, when the pore volume of the rock sample changes from $\mathrm{V}_{\mathrm{p}}=\mathrm{V}_{\mathrm{po}}$ to $\mathrm{V}_{\mathrm{p}}=\mathrm{V}_{\mathrm{p} 1}$, I have:

$\mathrm{nC}_{\mathrm{p}} \mathrm{V}_{\mathrm{po}} \int_{\mathrm{p}_{0}}^{\mathrm{p}_{1}} \mathrm{dp} \mathrm{p}_{\mathrm{p}}=\int_{\mathrm{V}_{\mathrm{po}}}^{\mathrm{V}_{\mathrm{p} 1}} \mathrm{dV} \mathrm{V}_{\mathrm{p}}-\int_{\mathrm{Vp}_{0}}^{\mathrm{V}_{\mathrm{p} 1}} \frac{1}{\mathrm{a}} \mathrm{dV} \mathrm{V}_{\mathrm{p}}$

Integration gives the following algebraic form:

$\mathrm{nC}_{\mathrm{p}} \mathrm{V}_{\mathrm{po}}\left(\mathrm{p}_{1}-\mathrm{p}_{0}\right)=\left(\mathrm{V}_{\mathrm{p} 1}-\mathrm{V}_{\mathrm{po}}\right)-\left(\mathrm{V}_{\mathrm{p} 1}-\mathrm{V}_{\mathrm{po}}\right)\left(\frac{\frac{1}{\mathrm{a}_{1}}-\frac{1}{\mathrm{a}_{0}}}{2}\right)$

where we have used the trapezoidal rule for integration of the third term in Equation (15). The coefficient a takes the values of $\mathrm{a}_{\mathrm{o}}$ at the reference pressure $\mathrm{p}_{\mathrm{po}}$ and $\mathrm{a}_{1}$ at $\mathrm{p}_{\mathrm{p} 1}$. Re-organizing equation (15), we obtain the following:

$\mathrm{V}_{\mathrm{p} 1}\left(1-\frac{1}{\mathrm{a}_{\mathrm{avg} 1}}\right)=\mathrm{V}_{\mathrm{po}}\left[\mathrm{nC}_{\mathrm{p}}\left(\mathrm{p}-\mathrm{p}_{0}\right)+\left(1-\frac{1}{\mathrm{a}_{\mathrm{avg} 1}}\right)\right]$

$\mathrm{V}_{\mathrm{p} 1}\left(\frac{\sigma_{\mathrm{avg} 1}}{\mathrm{P}_{\text {cavg1 }}}\right)=\mathrm{V}_{\mathrm{po}}\left[\mathrm{nC}_{\mathrm{p}}\left(\mathrm{p}-\mathrm{p}_{0}\right)+\left(\frac{\sigma_{\mathrm{avg} 1}}{\mathrm{P}_{\text {cavg1 }}}\right)\right]$

where conceptually $\mathrm{a}_{\mathrm{avg} 1}$ has been defined as the arithmetic average of 1/a values; similarly, for other properties:

$$
\begin{aligned}
& \frac{1}{\mathrm{a}_{\mathrm{avg} 1}}=\frac{\frac{1}{\mathrm{a}_{1}}+\frac{1}{\mathrm{a}_{0}}}{2} ; \\
& \mathrm{P}_{\mathrm{cavg} 1}=\frac{\mathrm{P}_{\mathrm{c} 1}+\mathrm{P}_{\mathrm{c} 0}}{2} ; \\
& \sigma_{\mathrm{avg} 1}=\frac{\sigma_{\mathrm{c} 1}+\sigma_{\mathrm{c} 0}}{2} ;
\end{aligned}
$$

Equation (16) is the fundamental equation that describes the pore volume change due to effective stress. This equation will be used in the mass balance we develop later for the gas storage in the laboratory. 


\subsection{Mass Balance for Helium Gas Expansion Method}

The petrophysical parameters of interest are determined using Helium gas expansion. The measurements in the laboratory yield the coefficient of isothermal pore volume compressibility and the true pore volume of the shale sample at zero-gauge pressure besides the already mentioned effective stress parameter. During the measurement's helium adsorption in the rock sample is negligible.

From mass balance equations for number of moles of helium gas, pore volume and pore compressibility can be estimated. The schematic of the apparatus used in the laboratory is shown in Figure 4. The initial number of moles, $\mathrm{n}_{\mathrm{i}}$, is the sum of the number of moles in the reference volume, $\mathrm{n}_{\mathrm{ri}}$, the dead volume, $\mathrm{n}_{\mathrm{di}}$, the sample volume, $\mathrm{n}_{\mathrm{si}}$. The initial number of moles, $\mathrm{n}_{\mathrm{i}}$, in the core-holder, reference volume and dead volume at initial pressure, $\mathrm{P}_{\mathrm{i}}$, is the same as the final number of moles, $\mathrm{n}_{\mathrm{f}}$, in the same total volume at a final pressure, $\mathrm{P}_{\mathrm{f} .}$ In other words, moles (and mass) are conserved.

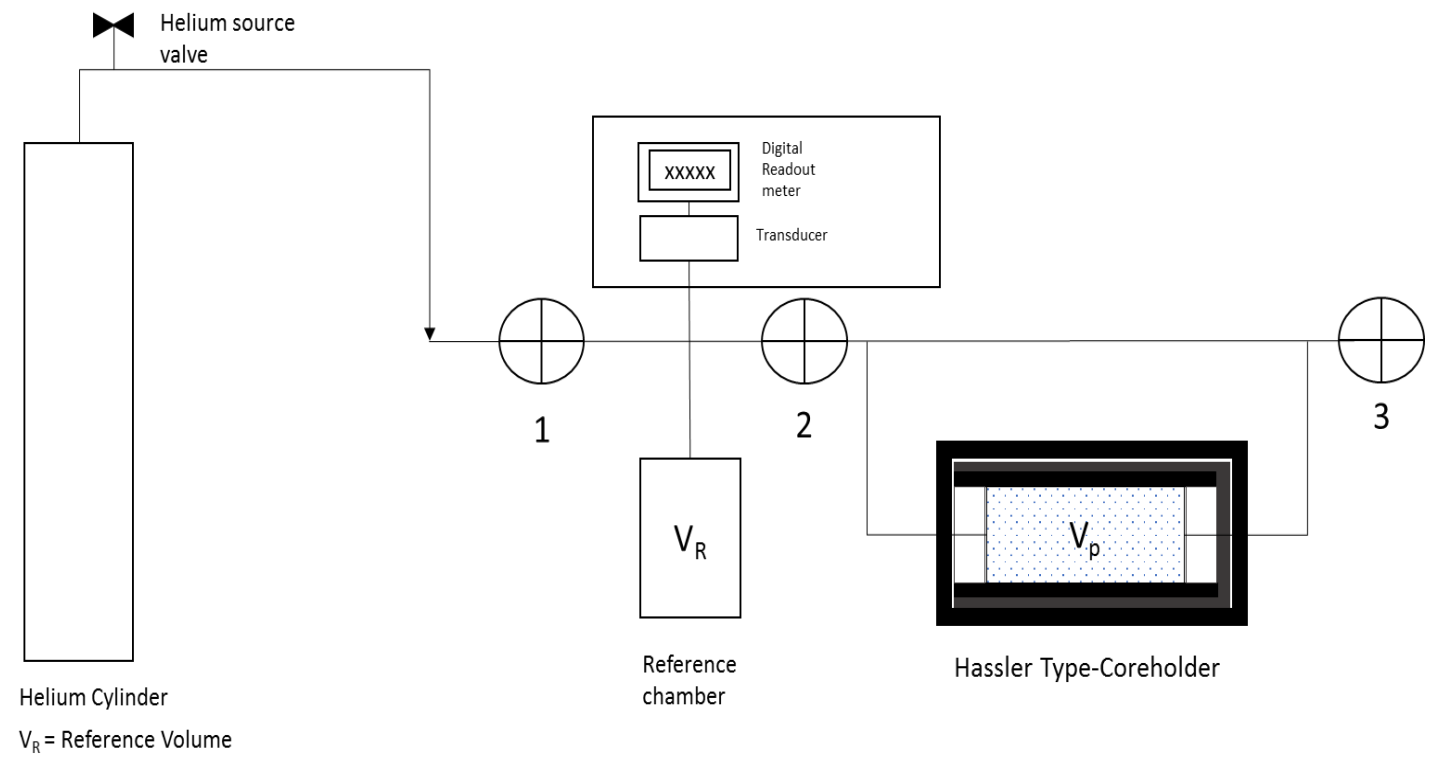

Figure 4 Simplified diagram of laboratory apparatus used in the mass balance (Adapted from API RP-40, February 1998). 
The volumes in our system are the reference volume, $\mathrm{V}_{\mathrm{r}}$, the sample pore volume, $\mathrm{V}_{\mathrm{s}}$, and the summation of the dead volumes in the system, $\mathrm{V}_{\mathrm{d}}$.

The initial number of moles of gas in the system, $\mathrm{n}_{\mathrm{i}}$, is equal to the sum of the number of moles in the reservoir volume, $\mathrm{n}_{\mathrm{ri}}$, the dead volume, $\mathrm{n}_{\mathrm{di}}$, and the sample volume, $\mathrm{n}_{\text {si. }}$. The final number of moles, $\mathrm{n}_{\mathrm{f}}$, is the sum of the number of moles in the reservoir volumes, $\mathrm{n}_{\mathrm{rf}}$, the dead volumes, $\mathrm{n}_{\mathrm{df}}$, and the sample volume, $\mathrm{n}_{\mathrm{sf}}$.

$\mathrm{n}_{\mathrm{i}}=\mathrm{n}_{\mathrm{f}}$

$\mathrm{n}_{\mathrm{i}}=\mathrm{n}_{\mathrm{ri}}+\mathrm{n}_{\mathrm{di}}+\mathrm{n}_{\mathrm{si}}$

$\mathrm{n}_{\mathrm{f}}=\mathrm{n}_{\mathrm{rf}}+\mathrm{n}_{\mathrm{df}}+\mathrm{n}_{\mathrm{sf}}$

Applying the mass balance and rearranging,

$\mathrm{n}_{\mathrm{ri}}+\mathrm{n}_{\mathrm{di}}+\mathrm{n}_{\mathrm{si}}=\mathrm{n}_{\mathrm{rf}}+\mathrm{n}_{\mathrm{df}}+\mathrm{n}_{\mathrm{sf}}$

$\mathrm{n}_{\mathrm{sf}}-\mathrm{n}_{\mathrm{si}}=\left[\mathrm{n}_{\mathrm{ri}}-\mathrm{n}_{\mathrm{rf}}\right]-\left[\mathrm{n}_{\mathrm{df}}-\mathrm{n}_{\mathrm{di}}\right]$

Next, we express the number of moles of gas in terms of pressure-volume using the compressibility equation of state:

$\mathrm{n}_{\mathrm{ri}}=\frac{\mathrm{P}_{\mathrm{ri}} \mathrm{V}_{\mathrm{r}}}{\mathrm{Z}_{\mathrm{ri}} \mathrm{RT}} ; \mathrm{n}_{\mathrm{rf}}=\frac{\mathrm{P}_{\mathrm{rf}} \mathrm{V}_{\mathrm{r}}}{\mathrm{Z}_{\mathrm{rf}} \mathrm{RT}}$

$\mathrm{n}_{\mathrm{di}}=\frac{\mathrm{P}_{\mathrm{di}} \mathrm{V}_{\mathrm{d}}}{\mathrm{Z}_{\mathrm{di}} \mathrm{RT}} ; \mathrm{n}_{\mathrm{df}}=\frac{\mathrm{P}_{\mathrm{df}} \mathrm{V}_{\mathrm{d}}}{\mathrm{Z}_{\mathrm{df}} \mathrm{RT}}$

$\mathrm{n}_{\mathrm{si}}=\frac{\mathrm{P}_{\mathrm{si}} \mathrm{V}_{\mathrm{si}}}{\mathrm{Z}_{\mathrm{si}} \mathrm{RT}} ; \mathrm{n}_{\mathrm{sf}}=\frac{\mathrm{P}_{\mathrm{sf}} \mathrm{V}_{\mathrm{sf}}}{\mathrm{Z}_{\mathrm{sf}} \mathrm{RT}}$

Here, $\mathrm{V}_{\mathrm{r}}, \mathrm{V}_{\mathrm{d}}, \mathrm{V}_{\mathrm{si}}$, and $\mathrm{V}_{\mathrm{sf}}$ are the reservoir volume, dead volume, and the sample volume at initial pressure and final pressure respectively. $\mathrm{R}$ is the universal gas constant, $\mathrm{T}$ is temperature and $\mathrm{z}_{\mathrm{ri}}, \mathrm{z}_{\mathrm{di}}, \mathrm{z}_{\mathrm{si}}, \mathrm{Z}_{\mathrm{rf}}, \mathrm{z}_{\mathrm{df}}$, and $\mathrm{z}_{\mathrm{sf}}$ are gas correction factors that account for deviation from ideal gas law. It depends on pressure, temperature and the type of gas. Numbers of tables and programs exist to provide accurate values of z-factors. In this study Abbou-Kassem-Dranchuck correlation was 
used, which is enough for pure gases (Abou-Kassem \& Dranchuk, 1975). Substituting the equations (21)-(23) into equation (20).

$\frac{P_{s f} V_{s f}}{Z_{s f} R T}-\frac{P_{s i} V_{s i}}{Z_{s i} R T}=\left[\frac{P_{r i} V_{r}}{Z_{r i} R T}-\frac{P_{r f} V_{r}}{Z_{r f} R T}\right]-\left[\frac{P_{d f} V_{d}}{Z_{d f} R T}-\frac{P_{d i} V_{d}}{Z_{d i} R T}\right]$

Cancelling RT product, which is constant, since the measurements are performed under isothermal conditions, I obtain

$\frac{P_{s f} V_{s f}}{Z_{s f}}-\frac{P_{s i} V_{s i}}{Z_{s i}}=\left[\frac{P_{r i} V_{r}}{Z_{r i}}-\frac{P_{r f} V_{r}}{Z_{r f}}\right]-\left[\frac{P_{d f} V_{d}}{Z_{d f}}-\frac{P_{d i} V_{d}}{Z_{d i}}\right]$

$\frac{P_{s f} V_{s f}}{Z_{s f}}-\frac{P_{s i} V_{s i}}{Z_{s i}}=V_{r}\left[\frac{P_{r i}}{Z_{r i}}-\frac{P_{r f}}{Z_{r f}}\right]-V_{d}\left[\frac{P_{d f}}{Z_{d f}}-\frac{P_{d i}}{Z_{d i}}\right]$

In equation (24), the sample volume changes from $\mathrm{V}_{\text {si }} \mathrm{O} \mathrm{V}_{\text {sf }}$, due to pore compressibility effects. Henceforth, recalling the previous equations derived for pore volume, equation (16):

$\mathrm{V}_{\mathrm{si}}\left(\frac{\sigma_{\text {avgi }}}{\mathrm{P}_{\text {cavgi }}}\right)=\mathrm{V}_{\mathrm{po}}\left[\mathrm{nC}_{\mathrm{p}}\left(\mathrm{p}_{\mathrm{si}}-\mathrm{p}_{0}\right)+\left(\frac{\sigma_{\text {avgi }}}{\mathrm{P}_{\text {cavgi }}}\right)\right]$

$\mathrm{V}_{\mathrm{sf}}\left(\frac{\sigma_{\text {avgf }}}{\mathrm{P}_{\text {cavgf }}}\right)=\mathrm{V}_{\mathrm{po}}\left[\mathrm{nC}_{\mathrm{p}}\left(\mathrm{p}_{\mathrm{sf}}-\mathrm{p}_{0}\right)+\left(\frac{\sigma_{\text {avgf }}}{\mathrm{P}_{\text {cavgf }}}\right)\right]$

Here, $\mathrm{V}_{\mathrm{si}}$ and $\mathrm{V}_{\mathrm{sf}}$ are the sample pore volumes at initial pressure and final pressure, respectively. The pore compressibility, $\mathrm{C}_{\mathrm{p}}$, is introduced as constant, and $\mathrm{V}_{\mathrm{po}}$, is introduced as the pore volume of the sample at zero effective stress (although in the laboratory there will always be a minimum pressure. i.e., for gas expansion porosimeters it's around $100 \mathrm{psig}$, as this is the device used for validation of $\mathrm{V}_{\mathrm{po}}$ ).

Note here that equations (25) and (26) are reduced to the commonly used linear approximation, when the applied confining pressure is much larger than the pore pressure.

$\mathrm{V}_{\mathrm{si}}=\mathrm{V}_{\mathrm{po}}\left[1+\mathrm{nC}_{\mathrm{p}}\left(\mathrm{p}_{\mathrm{si}}-\mathrm{p}_{0}\right)\right]$
$\mathrm{V}_{\mathrm{sf}}=\mathrm{V}_{\mathrm{po}}\left[1+\mathrm{nC}_{\mathrm{p}}\left(\mathrm{p}_{\mathrm{sf}}-\mathrm{p}_{0}\right)\right]$

Kang et al (Kang, 2011) used Equations (27) and (28) when the effective stress coefficient 
is taken $n=1$, which indeed is a limiting case for our model which includes the general expression for the effective stress.

Now, let us re-organize equations (25) and (26) so that the sample pore volume at the initial state and the volume at the final state are left alone:

$$
\begin{aligned}
& \mathrm{V}_{\mathrm{si}}=\frac{\mathrm{V}_{\mathrm{po}}\left[\mathrm{nC}_{\mathrm{p}}\left(\mathrm{p}_{\mathrm{si}}-\mathrm{p}_{0}\right)+\left(\frac{\sigma_{\text {avgi }}}{\mathrm{P}_{\text {cavgi }}}\right)\right]}{\left(\frac{\sigma_{\text {avgi }}}{\mathrm{P}_{\text {cavgi }}}\right)} \ldots \\
& \mathrm{V}_{\mathrm{sf}}=\frac{\mathrm{V}_{\mathrm{po}}\left[\mathrm{nC}_{\mathrm{p}}\left(\mathrm{p}_{\mathrm{sf}}-\mathrm{p}_{0}\right)+\left(\frac{\sigma_{\text {avgf }}}{\mathrm{P}_{\text {cavgf }}}\right)\right]}{\left(\frac{\sigma_{\text {avgf }}}{\mathrm{P}_{\text {cavgf }}}\right)} \ldots . .
\end{aligned}
$$

Next, we substitute equations (29) and (30) into the mass balance Equation (24):

$$
\frac{\mathrm{P}_{\mathrm{sf}}}{\mathrm{Z}_{\mathrm{sf}}}\left[\frac{\mathrm{V}_{\mathrm{po}}\left\{\mathrm{nC}_{\mathrm{p}}\left(\mathrm{p}_{\mathrm{sf}}-\mathrm{p}_{0}\right)+\left(\frac{\sigma_{\text {avgf }}}{\mathrm{P}_{\text {cavgf }}}\right)\right\}}{\left(\frac{\sigma_{\text {avgf }}}{\mathrm{P}_{\text {cavgf }}}\right)}\right]-\frac{\mathrm{P}_{\mathrm{si}}}{\mathrm{Z}_{\mathrm{si}}}\left[\frac{\mathrm{v}_{\mathrm{po}}\left\{\mathrm{nC}_{\mathrm{p}}\left(\mathrm{p}_{\mathrm{si}}-\mathrm{p}_{0}\right)+\left(\frac{\sigma_{\mathrm{avgi}}}{\mathrm{P}_{\text {cavgi }}}\right)\right\}}{\left(\frac{\sigma_{\text {avgi }}}{\mathrm{P}_{\text {cavgi }}}\right)}\right]=\mathrm{V}_{\mathrm{r}}\left[\frac{\mathrm{P}_{\mathrm{ri}}}{\mathrm{Z}_{\mathrm{ri}}}-\frac{\mathrm{P}_{\mathrm{rf}}}{\mathrm{Z}_{\mathrm{rf}}}\right]-\mathrm{V}_{\mathrm{d}}\left[\frac{\mathrm{P}_{\mathrm{df}}}{\mathrm{Z}_{\mathrm{df}}}-\frac{\mathrm{P}_{\mathrm{di}}}{\mathrm{Z}_{\mathrm{di}}}\right]
$$

There are three unknowns in the above equation: $C_{p}, V_{\text {po }}$ and $n$. Therefore, gas uptake measurements at three different pore pressures are needed to solve the equations with known volumes and pressures at isothermal conditions. If a standard porosimeter is available, $\mathrm{V}_{\text {po }}$ can be measured/approximated, therefore we can assume is a known quantity, leaving us with only two unknowns, therefore two gas uptake measurements are needed. To manipulate the latter equation, we keep the right-hand side and isolate $\mathrm{C}_{\mathrm{p}}$, using factorization.

$$
\begin{aligned}
& \frac{\mathrm{P}_{\mathrm{sf}}}{\mathrm{Z}_{\mathrm{sf}}}\left[\mathrm{V}_{\mathrm{po}}\left\{\frac{\mathrm{nC}_{\mathrm{p}}\left(\mathrm{P}_{\mathrm{sf}}-\mathrm{P}_{0}\right)}{\left(\frac{\sigma_{\text {avgf }}}{\mathrm{P}_{\text {cavgf }}}\right)}+\frac{\left(\frac{\sigma_{\text {avgf }}}{\mathrm{P}_{\text {cavgf }}}\right)}{\left(\frac{\sigma_{\text {avgf }}}{\mathrm{P}_{\text {cavgf }}}\right)}\right\}\right]-\frac{\mathrm{P}_{\mathrm{si}}}{\mathrm{Z}_{\mathrm{si}}}\left[\mathrm{V}_{\mathrm{po}}\left\{\frac{\mathrm{nC}_{\mathrm{p}}\left(\mathrm{P}_{\mathrm{si}}-\mathrm{P}_{0}\right)}{\left(\frac{\sigma_{\text {avgi }}}{\mathrm{P}_{\text {cavgi }}}\right)}+\frac{\left(\frac{\sigma_{\text {avgi }}}{\mathrm{P}_{\text {cavgi }}}\right)}{\left(\frac{\sigma_{\text {avgi }}}{\mathrm{P}_{\text {cavgi }}}\right)}\right\}\right]=\mathrm{V}_{\mathrm{r}}\left[\frac{\mathrm{P}_{\mathrm{ri}}}{\mathrm{Z}_{\mathrm{ri}}}-\frac{\mathrm{P}_{\mathrm{rf}}}{\mathrm{Z}_{\mathrm{rf}}}\right]-\mathrm{V}_{\mathrm{d}}\left[\frac{\mathrm{P}_{\mathrm{df}}}{\mathrm{Z}_{\mathrm{df}}}-\frac{\mathrm{P}_{\mathrm{di}}}{\mathrm{Z}_{\mathrm{di}}}\right] ; \\
& \frac{\mathrm{P}_{\mathrm{sf}}}{\mathrm{Z}_{\mathrm{sf}}}\left[\mathrm{V}_{\mathrm{po}}\left\{\frac{\mathrm{nC}_{\mathrm{p}}\left(\mathrm{P}_{\mathrm{sf}}-\mathrm{P}_{0}\right)}{\left(\frac{\sigma_{\text {avgf }}}{\mathrm{P}_{\text {cavg }}}\right)}+1\right\}\right]-\frac{\mathrm{P}_{\mathrm{si}}}{\mathrm{Z}_{\mathrm{si}}}\left[\mathrm{V}_{\mathrm{po}}\left\{\frac{\mathrm{nC}_{\mathrm{p}}\left(\mathrm{P}_{\mathrm{si}}-\mathrm{P}_{0}\right)}{\left(\frac{\sigma_{\text {avgi }}}{\mathrm{P}_{\text {cavgi }}}\right)}+1\right\}\right]=\mathrm{V}_{\mathrm{r}}\left[\frac{\mathrm{P}_{\mathrm{ri}}}{\mathrm{Z}_{\mathrm{ri}}}-\frac{\mathrm{P}_{\mathrm{rf}}}{\mathrm{Z}_{\mathrm{rf}}}\right]-\mathrm{V}_{\mathrm{d}}\left[\frac{\mathrm{P}_{\mathrm{df}}}{\mathrm{Z}_{\mathrm{df}}}-\frac{\mathrm{P}_{\mathrm{di}}}{\mathrm{Z}_{\mathrm{di}}}\right] \text {; } \\
& \frac{\mathrm{P}_{\mathrm{sf}}}{\mathrm{Z}_{\mathrm{sf}}} \mathrm{V}_{\mathrm{po}} \frac{\mathrm{nC}_{\mathrm{p}}\left(\mathrm{P}_{\mathrm{sf}}-\mathrm{P}_{0}\right)}{\left(\frac{\sigma_{\text {avgf }}}{\mathrm{P}_{\text {cavgf }}}\right)}+\frac{\mathrm{P}_{\mathrm{sf}}}{\mathrm{Z}_{\mathrm{sf}}} \mathrm{V}_{\mathrm{po}}-\frac{\mathrm{P}_{\mathrm{si}}}{\mathrm{Z}_{\mathrm{si}}} \mathrm{V}_{\mathrm{po}} \frac{\mathrm{nC}_{\mathrm{p}}\left(\mathrm{P}_{\mathrm{si}}-\mathrm{P}_{0}\right)}{\left(\frac{\sigma_{\text {avgi }}}{\mathrm{P}_{\text {cavgi }}}\right)}-\frac{\mathrm{P}_{\mathrm{si}}}{\mathrm{Z}_{\mathrm{si}}} \mathrm{V}_{\mathrm{po}}=\mathrm{V}_{\mathrm{r}}\left[\frac{\mathrm{P}_{\mathrm{ri}}}{\mathrm{Z}_{\mathrm{ri}}}-\frac{\mathrm{P}_{\mathrm{rf}}}{\mathrm{Z}_{\mathrm{rf}}}\right]-\mathrm{V}_{\mathrm{d}}\left[\frac{\mathrm{P}_{\mathrm{df}}}{\mathrm{Z}_{\mathrm{df}}}-\frac{\mathrm{P}_{\mathrm{di}}}{\mathrm{Z}_{\mathrm{di}}}\right]
\end{aligned}
$$


$\mathrm{V}_{\mathrm{po}} \mathrm{nC}_{\mathrm{p}}\left[\frac{\mathrm{P}_{\mathrm{sf}}}{\mathrm{Z}_{\mathrm{sf}}} \frac{\left(\mathrm{P}_{\mathrm{sf}}-\mathrm{P}_{0}\right)}{\left(\frac{\sigma_{\text {avgf }}}{\mathrm{P}_{\text {cavgf }}}\right)}-\frac{\mathrm{P}_{\mathrm{si}}}{\mathrm{Z}_{\mathrm{si}}} \frac{\left(\mathrm{P}_{\mathrm{si}}-\mathrm{P}_{0}\right)}{\left(\frac{\sigma_{\text {avgi }}}{\mathrm{P}_{\text {cavg }}}\right)}\right]=\mathrm{V}_{\mathrm{r}}\left[\frac{\mathrm{P}_{\mathrm{ri}}}{\mathrm{Z}_{\mathrm{ri}}}-\frac{\mathrm{P}_{\mathrm{rf}}}{\mathrm{Z}_{\mathrm{rf}}}\right]-\mathrm{V}_{\mathrm{d}}\left[\frac{\mathrm{P}_{\mathrm{df}}}{\mathrm{Z}_{\mathrm{df}}}-\frac{\mathrm{P}_{\mathrm{di}}}{\mathrm{Z}_{\mathrm{di}}}\right]-\mathrm{V}_{\mathrm{po}}\left[\frac{\mathrm{P}_{\mathrm{sf}}}{\mathrm{Z}_{\mathrm{sf}}}-\frac{\mathrm{P}_{\mathrm{si}}}{\mathrm{Z}_{\mathrm{si}}}\right] ;$

This equation can be written in an expanded form as follows:

$$
\begin{aligned}
& \mathrm{V}_{\mathrm{po}} \mathrm{nC}_{\mathrm{p}}\left[\frac{\mathrm{P}_{\mathrm{sf}}}{\mathrm{Z}_{\mathrm{sf}}}\left(\frac{\mathrm{P}_{\text {cavgf }}}{\sigma_{\text {avgf }}}\right)\left(\mathrm{p}_{\mathrm{sf}}-\mathrm{p}_{0}\right)-\frac{\mathrm{P}_{\mathrm{si}}}{\mathrm{Z}_{\mathrm{si}}}\left(\frac{\mathrm{P}_{\text {cavgi }}}{\sigma_{\text {avgi }}}\right)\left(\mathrm{p}_{\mathrm{si}}-\mathrm{p}_{0}\right)\right]=\mathrm{V}_{\mathrm{r}}\left[\frac{\mathrm{P}_{\mathrm{ri}}}{\mathrm{Z}_{\mathrm{ri}}}-\frac{\mathrm{P}_{\mathrm{rf}}}{\mathrm{Z}_{\mathrm{rf}}}\right]-\mathrm{V}_{\mathrm{d}}\left[\frac{\mathrm{P}_{\mathrm{df}}}{\mathrm{Z}_{\mathrm{df}}}-\frac{\mathrm{P}_{\mathrm{di}}}{\mathrm{Z}_{\mathrm{di}}}\right]-\mathrm{V}_{\mathrm{po}}\left[\frac{\mathrm{P}_{\mathrm{sf}}}{\mathrm{Z}_{\mathrm{sf}}}-\frac{\mathrm{P}_{\mathrm{si}}}{\mathrm{Z}_{\mathrm{si}}}\right] ;
\end{aligned}
$$

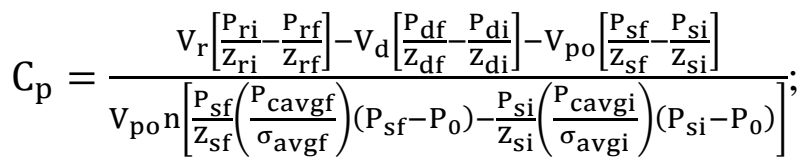

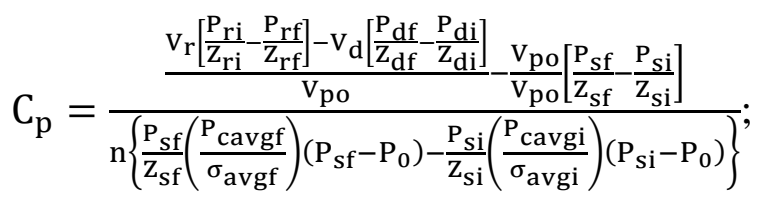

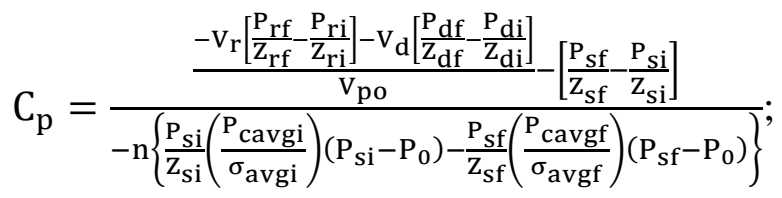

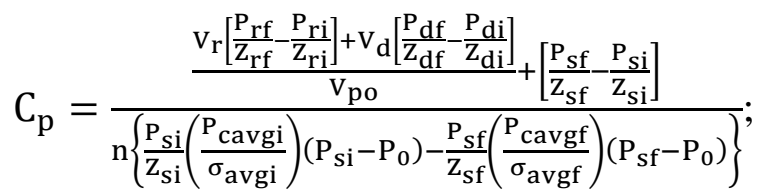

Now, we introduce coefficients A, B and C as follows:

$$
\begin{aligned}
& A=V_{r}\left(\frac{P_{r f}}{Z_{r f}}-\frac{P_{r i}}{Z_{r i}}\right)+V_{d}\left(\frac{P_{d f}}{Z_{d f}}-\frac{P_{d i}}{Z_{d i}}\right) \\
& \mathrm{B}=\frac{\mathrm{P}_{\mathrm{sf}}}{\mathrm{Z}_{\mathrm{sf}}}-\frac{\mathrm{P}_{\mathrm{si}}}{\mathrm{Z}_{\mathrm{si}}} \\
& \mathrm{C}=\frac{\mathrm{P}_{\mathrm{si}}}{\mathrm{Z}_{\mathrm{si}}}\left(\frac{\mathrm{P}_{\text {cavgi }}}{\sigma_{\text {avgi }}}\right)\left(\mathrm{p}_{\mathrm{si}}-\mathrm{p}_{0}\right)-\frac{\mathrm{P}_{\mathrm{sf}}}{\mathrm{Z}_{\mathrm{sf}}}\left(\frac{\mathrm{P}_{\text {cavgf }}}{\sigma_{\text {avgf }}}\right)\left(\mathrm{p}_{\mathrm{sf}}-\mathrm{p}_{0}\right) ;
\end{aligned}
$$

And,

$\left[\frac{1}{\mathrm{a}_{\mathrm{avg}}}\right]=\frac{\frac{1}{\mathrm{a}_{1}}+\frac{1}{\mathrm{a}_{0}}}{2} ;$

So, this gives us

$$
\left[1-\frac{1}{\mathrm{a}_{\text {avg }}}\right]=1-\frac{\mathrm{nP}_{\text {pavg }}}{\mathrm{P}_{\text {cavg }}}=\frac{\mathrm{P}_{\text {cavg }}-\mathrm{nP}_{\text {pavg }}}{\mathrm{P}_{\text {cavg }}}=\frac{\sigma_{\text {avg }}}{\mathrm{P}_{\text {cavg }}} ;
$$




$$
\begin{aligned}
& {\left[1-\frac{1}{a_{\mathrm{avgi}}}\right]=1-\frac{\frac{1}{\mathrm{a}_{\mathrm{i}}}+\frac{1}{\mathrm{a}_{0}}}{2}=1-\frac{n \mathrm{P}_{\mathrm{p} 0}}{2 \mathrm{P}_{\mathrm{c} 0}}-\frac{\mathrm{nP}_{\mathrm{pi}}}{2 \mathrm{P}_{\mathrm{ci}}}=\frac{2 \mathrm{P}_{\mathrm{co}} \mathrm{P}_{\mathrm{ci}}-\mathrm{nP}_{\mathrm{ci}} \mathrm{P}_{\mathrm{p} 0}-\mathrm{nP}_{\mathrm{co}} \mathrm{P}_{\mathrm{pi}}}{2 \mathrm{P}_{\mathrm{c} 0} \mathrm{P}_{\mathrm{ci}}}=\frac{\sigma_{\mathrm{avgi}}}{\mathrm{P}_{\mathrm{cavgi}}}} \\
& {\left[1-\frac{1}{\mathrm{a}_{\mathrm{avgf}}}\right]=1-\frac{\frac{1}{\mathrm{a}_{\mathrm{f}}}+\frac{1}{\mathrm{a}_{0}}}{2}=1-\frac{n \mathrm{P}_{\mathrm{p} 0}}{2 \mathrm{P}_{\mathrm{c} 0}}-\frac{\mathrm{nP}_{\mathrm{pf}}}{2 \mathrm{P}_{\mathrm{cf}}}=\frac{2 \mathrm{P}_{\mathrm{co}} \mathrm{P}_{\mathrm{cf}}-\mathrm{nP}_{\mathrm{cf}} \mathrm{P}_{\mathrm{p} 0}-\mathrm{nP}_{\mathrm{co}} \mathrm{P}_{\mathrm{pf}}}{2 \mathrm{P}_{\mathrm{c} 0} \mathrm{P}_{\mathrm{cf}}}=\frac{\sigma_{\mathrm{avgf}}}{\mathrm{P}_{\text {cavgf }}}}
\end{aligned}
$$

Substituting the coefficients, A, B, and C, in equations (31)-(33) into equation for $\mathrm{C}_{\mathrm{p}}$, we obtain,

$$
C_{p}=\frac{\frac{A}{v_{p o}}+B}{n C} ;
$$

As we need two consecutive gas uptake measurements, we can write:

For first pressure uptake:

$$
\mathrm{C}_{\mathrm{p}}=\frac{\frac{\mathrm{A}_{1}}{\mathrm{v}_{\mathrm{po}}}+\mathrm{B}_{1}}{\mathrm{n} \times \mathrm{C}_{1}}
$$

For second pressure uptake:

$$
C_{p}=\frac{\frac{A_{2}}{V_{p o}}+B_{2}}{n \times C_{2}}
$$




\section{LABORATORY SETUP AND EXPERIMENTAL PROCEDURE}

The equipment employed for the measurement is depicted in detail in Figure 4. This equipment was set up, based on a similar diagram that can be found in permeability experiment (Kim \& Akkutlu, 2018). It has a helium gas tank, with its regulator and valve; a reference volume $\left(\mathrm{V}_{\mathrm{r}}\right)$, connected to the gas tank by Valve 1. The tank holds the gas at low pressure. $\mathrm{V}_{\mathrm{r}}$ is used to adjust the gas pressure to any desired value. The volume is connected to a core-holder that fits 1inch diameter disk-shape core samples. The reference volume and sample are separated by Valve 2.

The core-holder has an internal rubber sleeve separating the sample from the steel walls of the holder. Water is injected into the gap in between the rubber and steel wall by means of a water hydraulic pump that permits confinement pressure to be applied on the sample. The core holder withstands pressures up to $10,000 \mathrm{psi}$ and confining pressure is applied up to 5000 psi. Two transducers are connected at the upstream and downstream ends to the core holder as show in the diagram below to measure the pressure. So, both the confinement pressure as well as the internal fluid pressures are recorded. The pressures can be recorded by the data acquisition program for a desired time interval.

The components of the pore pressure system such as valves, tubing and Swagelok fittings are rated to 5,000-10,000 psig. These components hold an additional but small volume for the gas storage. Estimation of this dead volume $\left(\mathrm{V}_{\mathrm{d}}\right)$ is important for the accuracy in our measurements especially for low porosity rocks and at high pore pressure.

Helium gas is used as the measurement fluid because it is an inert gas with a kinetic diameter of molecules relatively small to reach into smallest pores of the rock samples. Its high 
diffusivity is also an advantage. It is contained in the gas tank that supplies up to $1,800 \mathrm{psig}$. Hence a compressing system consisting of a syringe pump and an accumulator is added for the measurements at higher pressures.

The equipment has an additional valve to allow for permeability measurements using pressure pulse decay method. Some other valve (not shown) allows to purge gas from the system, to induce pulses across the sample and determine permeability of the rock samples. Because fluid transport is not the focus of this study, we do not detail those features.

The experiments are conducted at ambient temperature $25^{\circ} \mathrm{C}$. Two core samples are used: sandstone and shale. The sandstone sample is clean and in dry condition while the fluids in the shale sample has not been extracted. Because the sample was exposed to laboratory air long time, we assume the fluids were evaporated and left the pores. It is important that the edges of the samples are smooth for an accurate bulk volume measurement and to fit in the core-holder without gaps between the sample and the end caps-internal rubber sleeve that would cause overestimation of sample pore volume.

The experimental procedure follows the steps listed below:

1. Gather the information on the reference and dead volumes $\left(V_{r}\right.$ and $\left.V_{d}\right)$ in the apparatus shown in Figure 4. It is straightforward to either measure by injecting water into the equipment, keeping track of volumes injected by aid of a hydraulic pump, or using gas expansion and applying Boyle's law to calculate volumes from the pressures measured. Although the first approach is a direct method, the second approach yielded more accurate results in our case, despite being an indirect method of determination. For further details the reader is encouraged to visit the first section of the appendix.

2. Check core-holder inside, clean it if needed. 
3. Place core sample into the rubber, close end caps by tightening the screws, and adjust the position of the sample by pushing the piston of the core-holder, care no gaps are left between the sample and the borders.

4. Apply confining pressure using the water hydraulic pump.

5. Check pressures from gauges to match transducer reading. If not, perform the proper calibration.

6. Pressures inside core-holder should be zero-gauge pressure. If not, use Valve \#3 to purge the system and zero-in transducer.

7. Record the pressure data from the transducers using the data acquisition system. During our measurements, data was collected every second, and filtered/averaged for the analysis every 60 seconds.

8. Check all valves are initially closed, and the desired confining pressure is established. Then, open valve that is connected to the helium tank to let gas out. Slowly release helium to dead volume upstream of Valve \#1 using the regulator of tank to desired pressure.

9. Open Valve \#1 to charge reference volume to the desired pressure. Once the target pressure is reached, close Valve \#1 and let reference pressure reach equilibrium for about 5-10 minutes.

10. Open Valve \#2 to admit helium gas into the core-holder and reach the desired pore pressure. Keep a small differential pressure (20-30 psi) during the uptake. Let system reach equilibrium in about 6-12 hours, depending on the nature of the sample. For low pore pressure equilibrium, decay is exponential and can take days.

11. Close Valve \#2 to isolate the reference volume from the core holder.

12. Allow the system to reach equilibrium and read the final pressure values. Record the 
corresponding ratio $\mathrm{a}=\mathrm{p}_{\mathrm{c}} / \mathrm{p}_{\mathrm{f}}$.

13. Repeat step 8-11 until the desired number of pressure stages is reached. Perform at least two consecutive pressure stages in order to solve once for the parameters $n$ and $C_{p}$ simultaneously. At the end of the experiment purge system using Valve \#2.

We perform the initial measurement at low pore pressure (0-50 psi) and low confinement (below $100 \mathrm{psi}$ ) in order to determine the reference pore volume, $\mathrm{V}_{\text {po }}$ near zero stress using the analysis method that will be described in the next section. We compare the value using a separate standard helium porosimeter setup that we use for routine measurements.

Pressure values at equilibrium should be measured carefully at each stage. This is especially the case when the pore pressure is high. We inspect the pressure behavior for potential gas leakage. During the high pore pressure measurements, we observe the recorded pressure change in time linearly as an indication of the presence of leakage. The leakage exists if the pressure does not reach a true stability and continue declining at a low, constant rate. A gas-leakage correction must be performed then to approximate the equilibrium (or final) pressure, $\mathrm{P}_{\mathrm{f}}$, which the system should have reached in the absence of leakage.

\subsection{Laboratory Data Analysis}

From the previous sections, we obtained an algebraic equation (34) for the pore compressibility as a function of the effective stress. This equation includes three unknowns: the effective stress coefficient $\mathrm{n}$, the pore compressibility $\mathrm{C}_{\mathrm{p}}$, and finally the reference pore volume when the effective stress is zero, $\mathrm{V}_{\mathrm{p} 0}$. A separate measurement can be done for the $\mathrm{V}_{\mathrm{p} 0}$ using the routine helium porosimeter. The measurement is typically done in the absence of confining pressure and applying low values of pore pressure. This leaves us with 2 unknowns only. In order to determine the other two unknowns, two consecutive uptake pressure measurements are applied 
in the laboratory using the apparatus explained in Figure 4

For the first pressure uptake, this equation is written as follows:

$C_{p}=\frac{\frac{A_{1}}{v_{p o}}+B_{1}}{n \times C_{1}}$

Similarly, for the second uptake, we have:

$C_{p}=\frac{\frac{A_{2}}{V_{p o}}+B_{2}}{n \times C_{2}}$

The expressions for coefficients A, B, C, are given as Equations (31) - (33) at the end of the previous section. Notice that these coefficients all change with the pressure stages 1 and 2 . Coefficients $A_{1}, A_{2}$, are known but the other coefficients are functions of the effective stress coefficient, $\mathrm{n}$. The following is a brief description of the numerical method used in determining the parameters involved in the coupled equations.

MATLAB is used as the computational platform for the execution of the numerical procedure to solve the Equations 35-36 simultaneously for $\mathrm{n}$ and $\mathrm{C}_{\mathrm{p}}$. A built-in function such as vpasolve shall suffice for the purpose. Keep in mind these solutions are obtained for every two stages, but we perform several stages in order to have a complete set of effective stress coefficient and pore volume compressibility with changing stress, consequently several consecutive pressure stages should be performed in the lab.

Pressure values are designated as $\mathrm{P}_{\mathrm{ri}}, \mathrm{P}_{\mathrm{rf}}, \mathrm{P}_{\mathrm{di}}, \mathrm{P}_{\mathrm{df}}, \mathrm{P}_{\mathrm{si}}, \mathrm{P}_{\text {sf. }}$ and are all known to the user by aid of the transducers and data acquisition system. The dead volume and the reference volume are previously determined and considered known during the analysis. The Z-factor for helium is calculated using Abou-Kassem \& Dranchuk correlation (Abou-Kassem \& Dranchuk, 1975). This correlation is for single-phase fluid and intermediate pressures, as the ones used in the core holder, therefore it should be accurate for our calculation purposes. Because the factor is a function of 
pressure, it is designated as follows: $\mathrm{Z}_{\mathrm{r}}, \mathrm{Z}_{\mathrm{rf}}, \mathrm{Z}_{\mathrm{di}}, \mathrm{Z}_{\mathrm{df}}, \mathrm{Z}_{\mathrm{si}}$, and $\mathrm{Z}_{\mathrm{sf}}$. With all relevant parameters established, it is straightforward to upload the data in the MATLAB environment by using built in functions in a single script. The following is a description of the logic that goes into the MATLAB code, used for two consecutive pressure stages. Here we have used data for two stages experimentally acquired on a shale sample, as shown in Table 1.

Table 1 Input data measured experimentally on a shale core plug

\begin{tabular}{|r|l|l|l|l|l|l|l|l|l|}
\hline Stages & Pc, & $\begin{array}{l}\text { Pr } \\
(\text { psia) }\end{array}$ & $\begin{array}{l}\text { Pd } \\
(\text { psia })\end{array}$ & $\begin{array}{l}\text { Ps } \\
\text { (psia) }\end{array}$ & $\begin{array}{l}\text { Pf } \\
(\text { psia) }\end{array}$ & Zr & Zd & Zs & Zf \\
\hline $\mathbf{1}$ & 600 & 165.7 & 14.6 & 14.6 & 122.5 & 1.0075 & 1.0006 & 1.0006 & 1.0055 \\
\hline $\mathbf{2}$ & 900 & 197.5 & 14.6 & 14.6 & 146.3 & 1.0090 & 1.0006 & 1.0006 & 1.0066 \\
\hline
\end{tabular}

In Table 1, I introduce the following quantities:

$\mathrm{P}_{\mathrm{c}}$ - Confinement pressure for first stage, psia

$\mathrm{P}_{\mathrm{r}}$ - Pressure of the reference volume, psia

$P_{d}$ - Pressure in the dead volume, psia

$\mathrm{P}_{\mathrm{s}}$ - Pressure of the sample pore volume, psia

$Z_{\mathrm{s}}$ - Gas compressibility factor of the gas in sample pore volume

$Z_{r}$ - Gas compressibility factor of the gas in reference volume

$Z_{d}$ - Gas compressibility factor of the gas in dead volume

$\mathrm{V}_{\mathrm{d}}$ - Dead volume, cc

$\mathrm{V}_{\mathrm{r}}$ - Reference volume, $\mathrm{cc}$

$\mathrm{V}_{\mathrm{p} 0}$ - Original pore volume at zero stress, cc

For the first stage: 


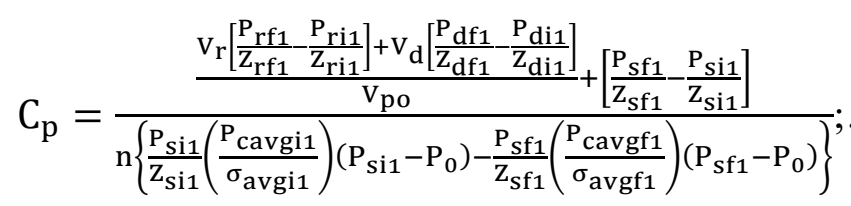

For the second stage:

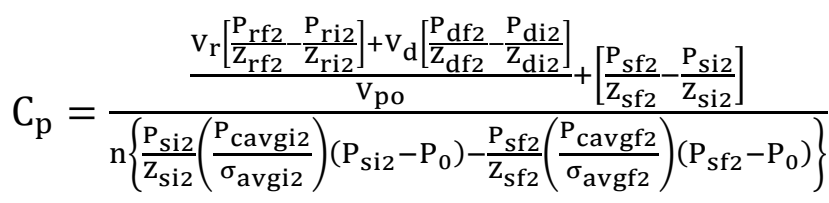

where subscripts $\mathrm{r}$ means reference volume, $\mathrm{d}$ stands for dead volume, s represents sample pore volume. Similarly, i subscript represents initial state of any gas uptake stage, and f subscript stands for final state. Subscript 1 is for first stage, while subscript 2 represents 2 nd stage, and so on.

4.2 Specification of Samples used for the study

Two Mississippian Lime formation shale samples were used for this study. Also, one outcrop carbonate sample and one outcrop sandstone sample. Table 2 shows the specification of the samples used.

Table 2 Specifications of samples used for this study

\begin{tabular}{|l|l|l|l|l|l|}
\hline Item & $\begin{array}{l}\text { Dry weight } \\
(\mathbf{g})\end{array}$ & Length $(\mathbf{m m})$ & $\begin{array}{l}\text { Diameter } \\
(\mathbf{m m})\end{array}$ & $\begin{array}{l}\text { Bulk Volume } \\
(\mathbf{c c})\end{array}$ & $\begin{array}{l}\text { Approximate } \\
\text { Porosity (\%) }\end{array}$ \\
\hline Shale Plug \#1 & 77.7 & 60.3 & 25.4 & 30.5 & 3.86 \\
\hline Shale Plug \#2 & 63.6 & 49.8 & 25.6 & 25.7 & 3.46 \\
\hline Sandstone Plug & 41.6 & 38.0 & 25.4 & 19.3 & 13.61 \\
\hline $\begin{array}{l}\text { Carbonate } \\
\text { Plug }\end{array}$ & 106.5 & 78.4 & 25.6 & 40.3 & 8.39 \\
\hline
\end{tabular}




\section{RESULTS AND DISCUSSION}

\subsection{Petrophysical Parameters Determination}

Gas uptake measurements were performed at several different and consecutive pore pressures as specified in the methodology section, therefore we were able to reproduce: True pore volume at zero stress, $\mathrm{V}_{\mathrm{po}}$, isothermal coefficient of pore compressibility, $\mathrm{C}_{\mathrm{p}}$, and effective stress coefficient $n$, from the equations described in chapter 3. A summary of properties range of $C_{p}, V_{p o}$ and $\mathrm{n}$ are given in the Table 3, obtained from the combination of equations written for every pressure stage measured.

\subsection{Acquisition of experimental data in the laboratory}

Using the methodology described in previous chapter (section 3.4), raw pressures were acquired, filtered and corrected for 27 stages in the case of shale plug\#1 (see Table 4) and 16 additional stages were also corrected (see Table 5). The equilibrium pressure was read directly from the graphs and is presented below in tabulated form.

Table 3 Estimated Ranges of $\mathrm{C}_{\mathrm{p}}, \mathrm{V}_{\mathrm{p} 0}$ and $\mathrm{n}$ values for the core samples employed.

\begin{tabular}{|l|l|l|l|l|}
\hline Item & $\mathbf{C}_{\mathbf{p}}\left(\mathbf{p s i}^{-\mathbf{1}}\right)$ & $\mathbf{V}_{\mathbf{p o}} \mathbf{( c c )}$ & $\mathbf{n}$ & Porosity $\mathbf{( \% )}$ \\
\hline Shale Plug \#1 & $1.7 \times 10^{-4}-1.6 \times 10^{-6}$ & 1.056 & $1.05-1.85$ & 3.86 \\
\hline Shale Plug \#2 & $5.9 \times 10^{-4}-1.7 \times 10^{-4}$ & 0.993 & $1.65-1.69$ & 3.46 \\
\hline Sandstone Plug & $1.7 \times 10^{-5}-1.2 \times 10^{-6}$ & 2.737 & $0.88-1.87$ & 13.61 \\
\hline Carbonate Plug & $4.7 \times 10^{-4}-1.6 \times 10^{-6}$ & 3.280 & $1.03-2.04$ & 8.39 \\
\hline
\end{tabular}

$* \mathrm{~V}_{\mathrm{p} 0}$ value is taken from the standard helium porosimeter measurement. 
Table 4 Confinement pressure and equilibrium pore pressure obtained from 27 gas uptake measurements on shale sample

\begin{tabular}{|l|l|l|l|l|l|}
\hline Stages & Confinement (psi) & Pr (psia) & Pd (psia) & Ps (psia) & Pf (psia) \\
\hline $\mathbf{1}$ & 600 & 165.7 & 14.6 & 14.6 & 122.5 \\
\hline $\mathbf{2}$ & 900 & 197.5 & 14.6 & 14.6 & 146.3 \\
\hline $\mathbf{3}$ & 1500 & 204.4 & 14.6 & 14.6 & 150.6 \\
\hline $\mathbf{4}$ & 1500 & 592.9 & 150.6 & 150.6 & 441.7 \\
\hline $\mathbf{5}$ & 1500 & 789.3 & 441.74 & 441.74 & 709.8 \\
\hline $\mathbf{6}$ & 1500 & 1029.5 & 709.8 & 709.8 & 929.3 \\
\hline $\mathbf{7}$ & 2200 & 773.8 & 550.3 & 550.3 & 707.7 \\
\hline $\mathbf{8}$ & 2200 & 1130.4 & 707.7 & 707.7 & 1004.6 \\
\hline $\mathbf{9}$ & 2200 & 1482.6 & 1004.6 & 1004.6 & 1332.5 \\
\hline $\mathbf{1 0}$ & 2700 & 1083.5 & 934.7 & 934.7 & 1043.5 \\
\hline $\mathbf{1 1}$ & 2700 & 1242.6 & 1043.5 & 1043.5 & 1174.1 \\
\hline $\mathbf{1 2}$ & 2700 & 1430.6 & 1174.1 & 1174.1 & 1355.1 \\
\hline $\mathbf{1 3}$ & 3200 & 1141.6 & 914.7 & 914.7 & 1067.1 \\
\hline $\mathbf{1 4}$ & 3200 & 1324.4 & 1075.5 & 1075.5 & 1256.6 \\
\hline $\mathbf{1 5}$ & 3200 & 1667.5 & 1256.6 & 1256.6 & 1538.0 \\
\hline $\mathbf{1 6}$ & 3700 & 938.1 & 761.1 & 761.1 & 883.0 \\
\hline $\mathbf{1 7}$ & 3700 & 1161.1 & 883.0 & 883.0 & 1081.7 \\
\hline $\mathbf{1 8}$ & 3700 & 1337.0 & 1081.7 & 1081.7 & 1265.3 \\
\hline $\mathbf{1 9}$ & 4200 & 1114.0 & 841.3 & 841.3 & 1024.5 \\
\hline $\mathbf{2 0}$ & 4200 & 1353.7 & 1024.5 & 1024.5 & 1269.1 \\
\hline $\mathbf{2 1}$ & 4200 & 1459.7 & 1269.1 & 1269.1 & 1405.4 \\
\hline $\mathbf{2 2}$ & 4750 & 1520.9 & 1390.7 & 1390.7 & 1479.7 \\
\hline $\mathbf{2 3}$ & 4990 & 435.2 & 128.1 & 128.1 & 348.9 \\
\hline $\mathbf{2 4}$ & 4990 & 725.3 & 348.9 & 348.9 & 618.4 \\
\hline $\mathbf{2 5}$ & 4990 & 1097.6 & 618.4 & 618.4 & 940.1 \\
\hline $\mathbf{2 6}$ & 4990 & 1424.6 & 940.1 & 940.1 & 1305.7 \\
\hline $\mathbf{2 7}$ & 4990 & 1630.0 & 1305.7 & 1305.7 & 1531.4 \\
\hline & & & & & \\
\hline
\end{tabular}

Table 5 Confinement pressure and equilibrium pore pressure obtained from 16 additional gas uptake measurements on a shale sample

\begin{tabular}{|l|l|l|l|l|l|}
\hline Stages & Confinement (psi) & Pr (psia) & Pd (psia) & Ps (psia) & Pf (psia) \\
\hline $\mathbf{1}$ & 600 & 179.6 & 14.6 & 14.6 & 122.6 \\
\hline $\mathbf{2}$ & 900 & 604.5 & 122.9 & 122.9 & 413.5 \\
\hline $\mathbf{3}$ & 1200 & 844.0 & 407.7 & 407.7 & 682.2 \\
\hline $\mathbf{4}$ & 1500 & 1124.4 & 674.2 & 674.2 & 955.9 \\
\hline $\mathbf{5}$ & 1800 & 1435.9 & 948.2 & 948.2 & 1257.4 \\
\hline $\mathbf{6}$ & 2100 & 1760.4 & 947.7 & 947.7 & 1468.3 \\
\hline $\mathbf{7}$ & 2400 & 1775.4 & 1456.7 & 1456.7 & 1655.3 \\
\hline $\mathbf{8}$ & 2700 & 1759.4 & 1648.7 & 1648.7 & 1715.3 \\
\hline
\end{tabular}


Table 5. Continued.

\begin{tabular}{|l|l|l|l|l|l|}
\hline Stages & Confinement (psi) & Pr (psia) & Pd (psia) & Ps (psia) & Pf (psia) \\
\hline $\mathbf{9}$ & 3000 & 1778.1 & 1708.7 & 1708.7 & 1745.2 \\
\hline $\mathbf{1 0}$ & 3300 & 1785.5 & 1743.7 & 1743.7 & 1768.0 \\
\hline $\mathbf{1 1}$ & 3600 & 1766.9 & 1755.7 & 1755.7 & 1755.9 \\
\hline $\mathbf{1 2}$ & 3900 & 1779.4 & 1748.7 & 1748.7 & 1755.1 \\
\hline $\mathbf{1 3}$ & 4200 & 1764.7 & 1749.7 & 1749.7 & 1757.5 \\
\hline $\mathbf{1 4}$ & 4500 & 1764.8 & 1741.7 & 1741.7 & 1744.2 \\
\hline $\mathbf{1 5}$ & 4800 & 1761.9 & 1744.7 & 1744.7 & 1748.9 \\
\hline $\mathbf{1 6}$ & 5000 & 1768.9 & 1748.7 & 1748.7 & 1754.2 \\
\hline
\end{tabular}

Likewise, 44 raw pressure stages were acquired for a sandstone plug (See Table 6), and 28 pressure stages for a carbonate plug. (See Table 7). These pressures were leakage and temperature corrected according to the procedures described in the second section of the appendix.

Table 6 Confinement pressure and equilibrium pore pressure obtained from 44 gas uptake measurements on a sandstone sample

\begin{tabular}{|l|l|l|l|l|l|}
\hline Stages & Confinement (psi) & Pr $(\mathbf{p s i a})$ & Pd (psia) & Ps (psia) & Pf (psia) \\
\hline $\mathbf{1}$ & 1000 & 102.9 & 14.7 & 14.7 & 67.2 \\
\hline $\mathbf{2}$ & 1000 & 152.4 & 68.06 & 68.06 & 118.2 \\
\hline $\mathbf{3}$ & 1000 & 216.3 & 118.9 & 118.9 & 177.8 \\
\hline $\mathbf{4}$ & 1000 & 282.0 & 177.7 & 177.7 & 239.6 \\
\hline $\mathbf{5}$ & 1000 & 344.5 & 239.66 & 239.66 & 302.0 \\
\hline $\mathbf{6}$ & 1000 & 405.4 & 301.5 & 301.5 & 364.3 \\
\hline $\mathbf{7}$ & 1000 & 453.2 & 349.8 & 349.8 & 409.4 \\
\hline $\mathbf{8}$ & 1000 & 516.2 & 423.3 & 423.3 & 477.9 \\
\hline $\mathbf{9}$ & 1500 & 516.2 & 423.3 & 423.3 & 477.9 \\
\hline $\mathbf{1 0}$ & 1500 & 566.0 & 477.5 & 477.5 & 529.9 \\
\hline $\mathbf{1 1}$ & 1500 & 615.2 & 530.2 & 530.2 & 565.1 \\
\hline $\mathbf{1 2}$ & 1500 & 666.2 & 582.1 & 582.1 & 630.3 \\
\hline $\mathbf{1 3}$ & 1500 & 714.3 & 632.2 & 632.2 & 679.5 \\
\hline $\mathbf{1 4}$ & 1500 & 766.4 & 681.7 & 681.7 & 730.1 \\
\hline $\mathbf{1 5}$ & 1500 & 816.4 & 731.8 & 731.8 & 781.5 \\
\hline $\mathbf{1 6}$ & 1500 & 866.4 & 783.5 & 783.5 & 831.3 \\
\hline $\mathbf{1 7}$ & 1500 & 913.9 & 834.6 & 834.6 & 880.2 \\
\hline $\mathbf{1 8}$ & 1500 & 969.1 & 881.9 & 881.9 & 932.4 \\
\hline $\mathbf{1 9}$ & 1500 & 1012.4 & 934.6 & 934.6 & 978.5 \\
\hline $\mathbf{2 0}$ & 2000 & 1012.4 & 934.6 & 934.6 & 977.9 \\
\hline
\end{tabular}


Table 6. Continued.

\begin{tabular}{|l|l|l|l|l|l|}
\hline Stages & Confinement (psi) & Pr (psia) & Pd (psia) & Ps (psia) & Pf (psia) \\
\hline $\mathbf{2 1}$ & 2000 & 1065.3 & 980.4 & 980.4 & 1029.7 \\
\hline $\mathbf{2 2}$ & 2000 & 1121.3 & 1031.2 & 1031.2 & 1083.2 \\
\hline $\mathbf{2 3}$ & 2000 & 1163.5 & 1084.0 & 1084.0 & 1131.1 \\
\hline $\mathbf{2 4}$ & 2000 & 1215.2 & 1133.1 & 1133.1 & 1179.9 \\
\hline $\mathbf{2 5}$ & 2000 & 1266.7 & 1181.7 & 1181.7 & 1230.9 \\
\hline $\mathbf{2 6}$ & 2000 & 1314.6 & 1234.0 & 1234.0 & 1279.9 \\
\hline $\mathbf{2 7}$ & 2000 & 1365.2 & 1282.3 & 1282.3 & 1329.5 \\
\hline $\mathbf{2 8}$ & 2000 & 1414.0 & 1332.3 & 1332.3 & 1379.0 \\
\hline $\mathbf{2 9}$ & 2000 & 1465.3 & 1381.6 & 1381.6 & 1430.0 \\
\hline $\mathbf{3 0}$ & 2000 & 1513.9 & 1431.8 & 1431.8 & 1478.8 \\
\hline $\mathbf{3 1}$ & 2500 & 1513.9 & 1431.8 & 1431.8 & 1478.8 \\
\hline $\mathbf{3 2}$ & 2500 & 1570.2 & 1481.5 & 1481.5 & 1532.5 \\
\hline $\mathbf{3 3}$ & 2500 & 1614.9 & 1533.3 & 1533.3 & 1581.5 \\
\hline $\mathbf{3 4}$ & 2500 & 1660.4 & 1581.6 & 1581.6 & 1627.3 \\
\hline $\mathbf{3 5}$ & 2500 & 1711.3 & 1628.3 & 1628.3 & 1676.4 \\
\hline $\mathbf{3 6}$ & 2500 & 1734.5 & 1676.2 & 1676.2 & 1709.6 \\
\hline $\mathbf{3 7}$ & 3000 & 1563.4 & 1518.0 & 1518.0 & 1543.2 \\
\hline $\mathbf{3 8}$ & 3000 & 1613.2 & 1546.1 & 1546.1 & 1584.0 \\
\hline $\mathbf{3 9}$ & 3000 & 1664.6 & 1585.9 & 1585.9 & 1631.0 \\
\hline $\mathbf{4 0}$ & 3000 & 1715.8 & 1634.0 & 1634.0 & 1680.7 \\
\hline $\mathbf{4 1}$ & 3500 & 1550.9 & 1498.0 & 1498.1 & 1527.4 \\
\hline $\mathbf{4 2}$ & 3500 & 1609.0 & 1532.2 & 1532.2 & 1575.5 \\
\hline $\mathbf{4 3}$ & 3500 & 1640.6 & 1579.4 & 1579.4 & 1616.7 \\
\hline & & & & & \\
\hline
\end{tabular}

Table 7 Confinement pressure and equilibrium pore pressure obtained from 28 gas uptake measurements on a carbonate sample

\begin{tabular}{|r|r|r|r|r|r|}
\hline Stages & Confinement (psi) & Pr (psia) & Pd (psia) & Ps (psia) & Pf (psia) \\
\hline $\mathbf{1}$ & 500 & 98.9 & 14.7 & 14.7 & 55.8 \\
\hline $\mathbf{2}$ & 500 & 198.2 & 55.8 & 55.8 & 108.0 \\
\hline $\mathbf{3}$ & 1000 & 318.5 & 108.0 & 108.0 & 136.6 \\
\hline $\mathbf{4}$ & 1000 & 516.0 & 136.6 & 136.6 & 265.0 \\
\hline $\mathbf{5}$ & 1000 & 717.4 & 265.0 & 265.0 & 427.3 \\
\hline $\mathbf{6}$ & 1000 & 704.5 & 427.3 & 427.3 & 508.9 \\
\hline $\mathbf{7}$ & 1500 & 563.4 & 14.7 & 14.7 & 238.1 \\
\hline $\mathbf{8}$ & 1500 & 766.3 & 238.1 & 238.1 & 425.9 \\
\hline $\mathbf{9}$ & 1500 & 917.7 & 425.9 & 425.9 & 606.3 \\
\hline $\mathbf{1 0}$ & 2000 & 419.8 & 14.7 & 14.7 & 177.8 \\
\hline $\mathbf{1 1}$ & 2000 & 922.3 & 177.8 & 177.8 & 457.9 \\
\hline $\mathbf{1 2}$ & 2000 & 1113.6 & 457.9 & 457.9 & 570.9 \\
\hline
\end{tabular}


Table 7. Continued.

\begin{tabular}{|r|r|r|r|r|r|}
\hline Stages & Confinement (psi) & Pr (psia) & Pd (psia) & Ps (psia) & Pf (psia) \\
\hline $\mathbf{1 3}$ & 2500 & 152.5 & 14.7 & 14.7 & 73.9 \\
\hline $\mathbf{1 4}$ & 2500 & 516.2 & 73.9 & 73.9 & 241.7 \\
\hline $\mathbf{1 5}$ & 2500 & 712.5 & 241.7 & 241.7 & 413.7 \\
\hline $\mathbf{1 6}$ & 2500 & 1114.7 & 413.7 & 413.7 & 646.2 \\
\hline $\mathbf{1 7}$ & 3000 & 404.1 & 14.7 & 14.7 & 161.9 \\
\hline $\mathbf{1 8}$ & 3000 & 827.8 & 161.9 & 161.9 & 400.0 \\
\hline $\mathbf{1 9}$ & 3000 & 1164.2 & 400.0 & 400.0 & 668.7 \\
\hline $\mathbf{2 0}$ & 3500 & 164.0 & 14.7 & 14.7 & 75.1 \\
\hline $\mathbf{2 1}$ & 3500 & 447.1 & 75.1 & 75.1 & 217.6 \\
\hline $\mathbf{2 2}$ & 3500 & 708.4 & 217.6 & 217.6 & 390.2 \\
\hline $\mathbf{2 3}$ & 4000 & 175.2 & 14.7 & 14.7 & 77.2 \\
\hline $\mathbf{2 4}$ & 4000 & 722.1 & 77.2 & 77.2 & 338.9 \\
\hline $\mathbf{2 5}$ & 4000 & 1067.8 & 338.9 & 338.9 & 590.3 \\
\hline $\mathbf{2 6}$ & 4500 & 164.2 & 14.7 & 14.7 & 77.2 \\
\hline $\mathbf{2 7}$ & 4500 & 612.3 & 77.2 & 77.2 & 279.2 \\
\hline $\mathbf{2 8}$ & 4500 & 972.4 & 279.2 & 279.2 & 530.8 \\
\hline
\end{tabular}

From this data it can be observed that minimum pore pressure reached was 122 psi in both sets acquired for shale plug\#1, while maximum pore pressure reached was 1768 psi, due to equipment limitations. In the case of sandstone plug minimum pore pressure achieved was 67 psi maximum while maximum pore pressure reached was 1710 psi. A minimum pressure of 55 psi and a maximum pressure of 669 were attained for the carbonate plug. The pore pressures and confinement used are detailed in the following bar charts (Figure 5, Figure 6, Figure 7 and Figure 8). 


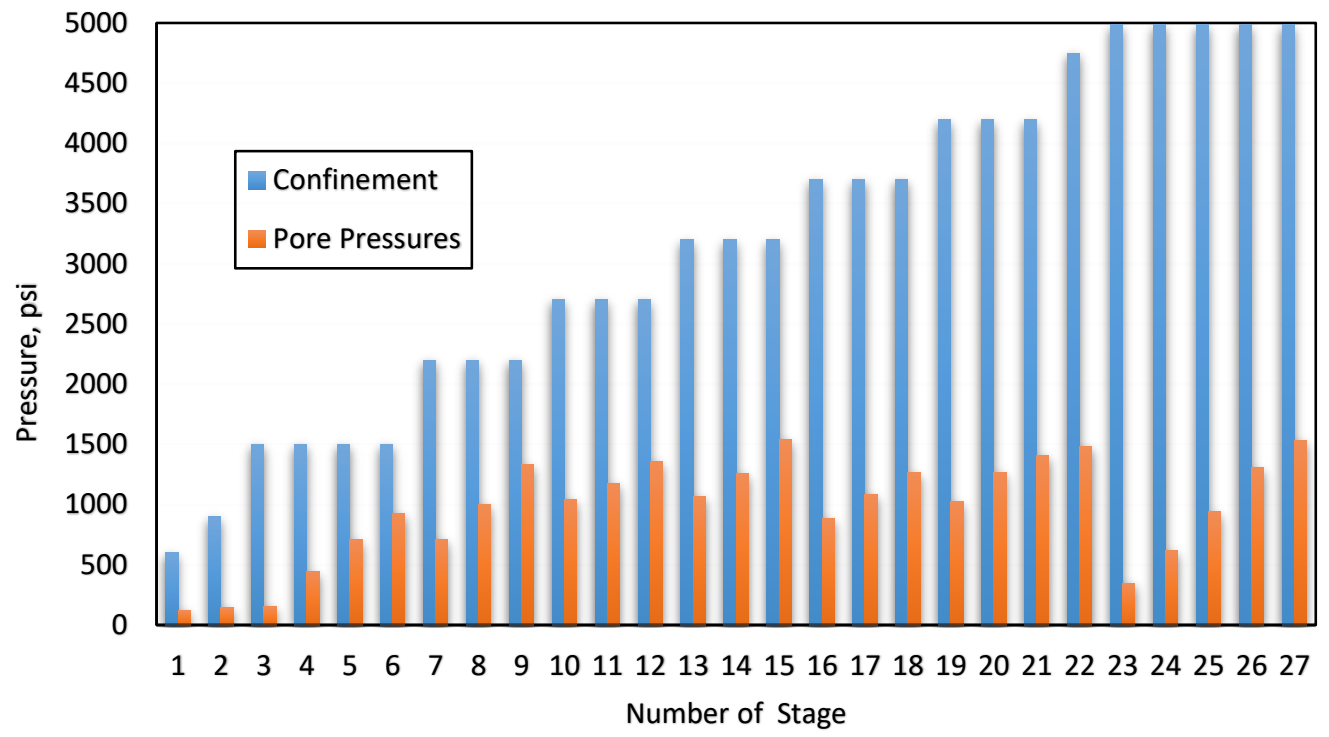

Figure 5 Pore pressure and confinement pressure applied for each stage during the experiments using a shale sample.

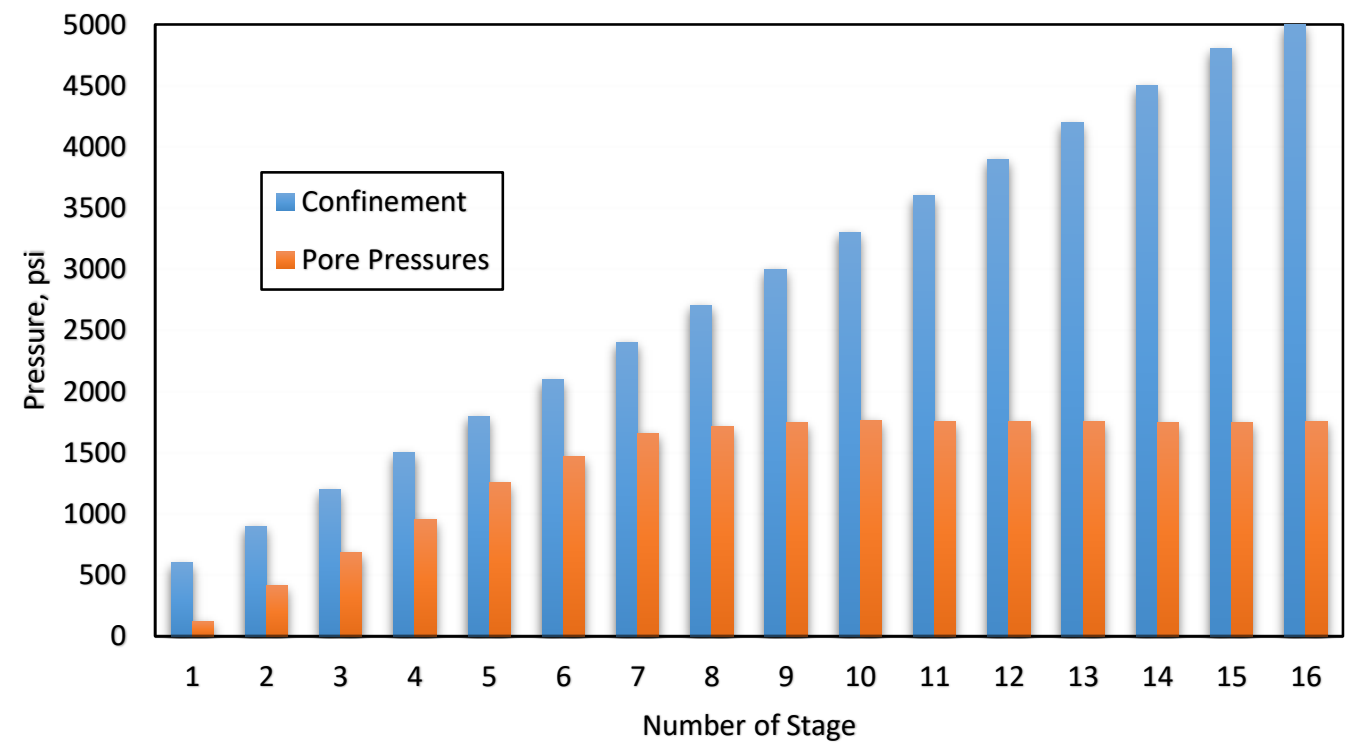

Figure 6 Pore pressure and confinement pressure applied for each stage during experiment for a shale sample (additional data). 


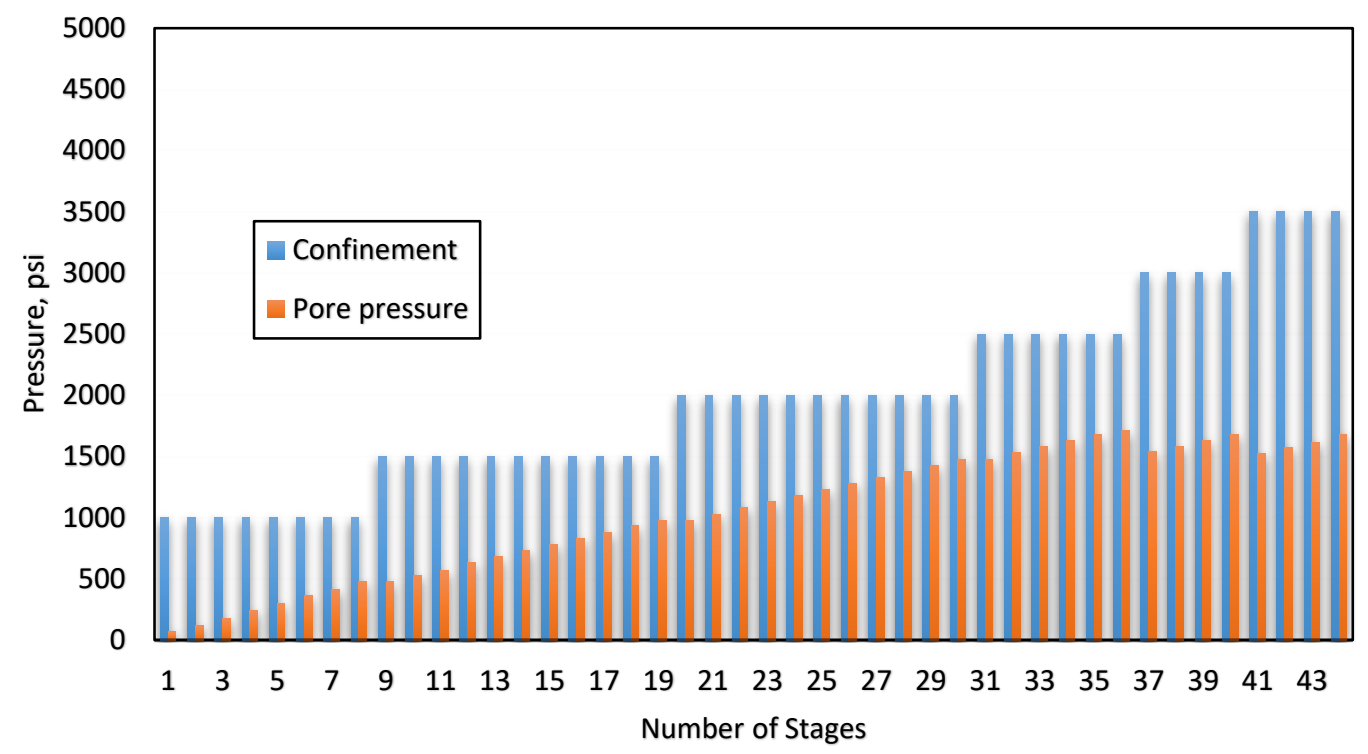

Figure 7 Pore pressure and confinement pressure applied for each stage during experiment for a sandstone sample.

The confinement and pore pressures for the carbonate plug are seen below in Figure 8

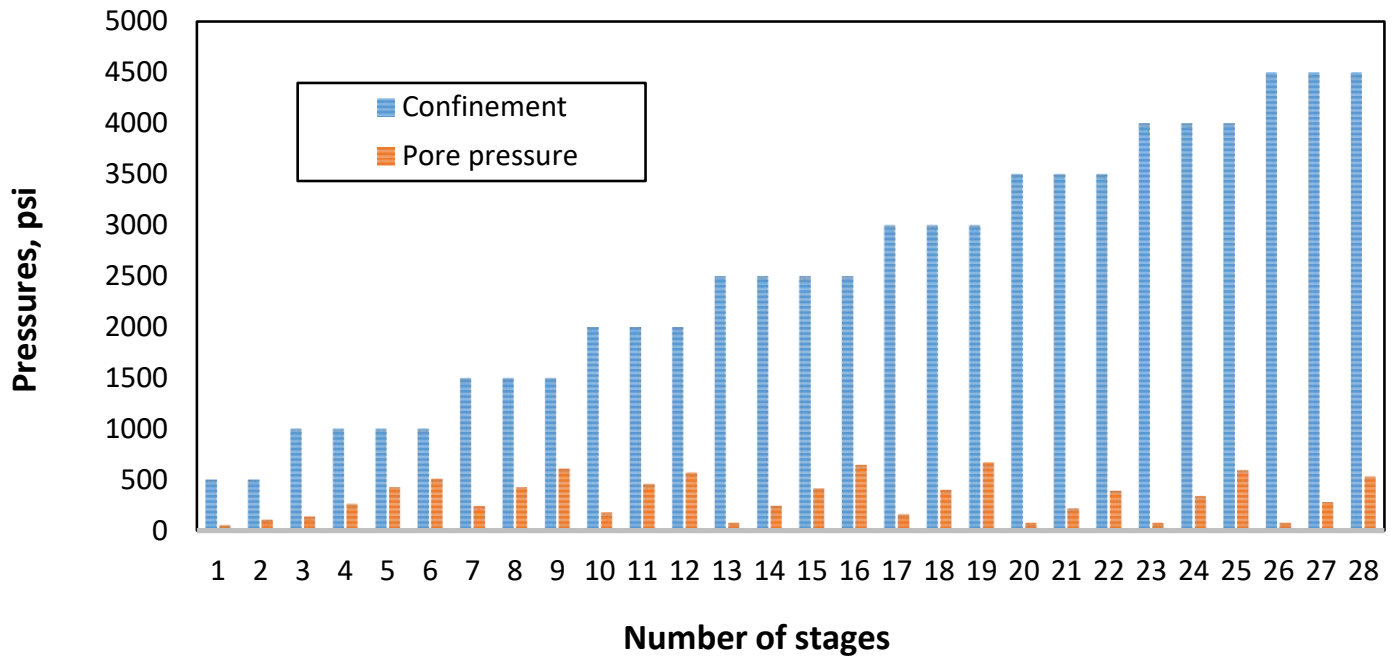

Figure 8 Pore pressure and confinement pressure applied for each stage during experiment for a carbonate sample. 
A wide range of differential pressure [Confinement Pressure] $\mathrm{x}$ [Pore Pressure] was generated throughout the gas uptake process, and such varying conditions aided to test the usefulness of the methodology described in previous section. A sample calculation is provided below, using first two data points of the first set of data acquired for the shale plug, to illustrate how the methodology is applied.

Departing from the data tabulated above, using first two stages of pressures for the shale plug as required, we have,

$$
\begin{aligned}
& C_{p}=\frac{\frac{A_{1}}{V_{p o}}+B_{1}}{n \times C_{1}} ; \\
& C_{p}=\frac{\frac{A_{2}}{V_{p o}}+B_{2}}{n \times C_{2}} ;
\end{aligned}
$$

where each constant is defined as,

$$
\begin{aligned}
& A_{1}=V_{r}\left[\frac{P_{\text {rf } 1}}{Z_{\mathrm{rf} 1}}-\frac{P_{\text {ri } 1}}{Z_{\mathrm{ri1}}}\right]+V_{d}\left[\frac{P_{\mathrm{df} 1}}{Z_{\mathrm{df} 1}}-\frac{P_{\mathrm{di1}}}{Z_{\mathrm{di} 1}}\right] \\
& A_{1}=19.211 \times\left[\frac{122.5}{1.0055}-\frac{165.7}{1.0075}\right]+6.6434 \times\left[\frac{122.5}{1.0055}-\frac{14.6}{1.0006}\right]=-103.30 ; \\
& A_{2}=V_{r}\left[\frac{P_{\mathrm{rf} 2}}{Z_{\mathrm{rf} 2}}-\frac{P_{\mathrm{ri} 2}}{Z_{\mathrm{ri} 2}}\right]+V_{d}\left[\frac{P_{\mathrm{df} 2}}{Z_{\mathrm{df} 2}}-\frac{P_{\mathrm{di} 2}}{Z_{\mathrm{di} 2}}\right] \\
& A_{2}=19.211 \times\left[\frac{146.3}{1.0066}-\frac{197.5}{1.0090}\right]+6.6434 \times\left[\frac{146.3}{1.0066}-\frac{14.6}{1.0006}\right]=-100.21 ; \\
& \mathrm{B}_{1}=\frac{\mathrm{P}_{\mathrm{sf} 1}}{\mathrm{Z}_{\mathrm{sf} 1}}-\frac{\mathrm{P}_{\mathrm{si1}}}{\mathrm{Z}_{\mathrm{si1}}}=\frac{122.5}{1.0055}-\frac{14.6}{1.0006}=107.14 \\
& \mathrm{~B}_{2}=\frac{\mathrm{P}_{\mathrm{sf} 2}}{\mathrm{Z}_{\mathrm{sf} 2}}-\frac{\mathrm{P}_{\mathrm{si} 2}}{\mathrm{Z}_{\mathrm{si} 2}}=\frac{146.3}{1.0066}-\frac{14.6}{1.0006}=130.65 \\
& \mathrm{C}_{1}=\frac{\mathrm{P}_{\mathrm{si} 1}}{\mathrm{Z}_{\mathrm{si} 1}}\left(\frac{\mathrm{P}_{\text {cavgi1 }}}{\sigma_{\text {avgi1 }}}\right)\left(\mathrm{P}_{\mathrm{si} 1}-\mathrm{P}_{0}\right)-\frac{\mathrm{P}_{\mathrm{sf} 1}}{\mathrm{Z}_{\mathrm{sf} 1}}\left(\frac{\mathrm{P}_{\text {cavgf } 1}}{\sigma_{\text {avgf } 1}}\right)\left(\mathrm{P}_{\mathrm{sf} 1}-\mathrm{P}_{0}\right) ;
\end{aligned}
$$

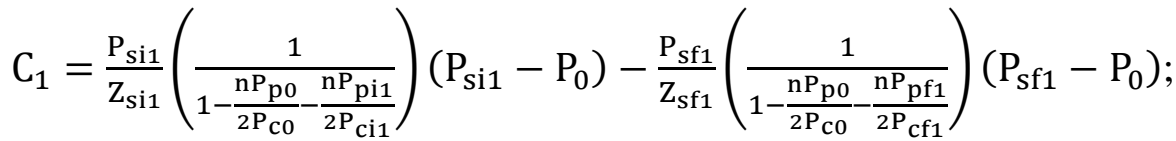




$$
\begin{aligned}
& \mathrm{C}_{1}=\frac{14.7}{1.0006}\left(\frac{1}{1-\frac{\mathrm{n} * 14.7}{2 * 14.7}-\frac{\mathrm{n} * 14.7}{2 * 600}}\right)(14.7-14.7)-\frac{122.5}{1.0055}\left(\frac{1}{1-\frac{\mathrm{n} * 14.7}{2 * 14.7}-\frac{\mathrm{n} * 122.5}{2 * 600}}\right)(122.5-14.7) \\
& \mathrm{C}_{1}=-\left(\frac{13133.27}{1-0.5 \mathrm{n}-0.1021 \mathrm{n}}\right)=\left(\frac{13133.27}{0.6021 \mathrm{n}-1}\right) \\
& \mathrm{C}_{2}=\frac{\mathrm{P}_{\mathrm{si}}}{\mathrm{Z}_{\mathrm{si}}}\left(\frac{\mathrm{P}_{\text {cavgi2 } 2}}{\sigma_{\text {avgi } 2}}\right)\left(\mathrm{P}_{\mathrm{si} 2}-\mathrm{P}_{0}\right)-\frac{\mathrm{P}_{\mathrm{sf} 2}}{\mathrm{Z}_{\mathrm{sf} 2}}\left(\frac{\mathrm{P}_{\text {cavgf } 2}}{\sigma_{\text {avgf } 2}}\right)\left(\mathrm{P}_{\mathrm{sf} 2}-\mathrm{P}_{0}\right) ; \\
& \mathrm{C}_{2}=\frac{\mathrm{P}_{\mathrm{si2}}}{\mathrm{Z}_{\mathrm{si} 2}}\left(\frac{1}{1-\frac{\mathrm{nP} \mathrm{p} 0}{2 \mathrm{P}_{\mathrm{c} 0}}-\frac{\mathrm{nP} \mathrm{pi} 2}{2 \mathrm{P}_{\mathrm{ci} 2}}}\right)\left(\mathrm{P}_{\mathrm{si2}}-\mathrm{P}_{0}\right)-\frac{\mathrm{P}_{\mathrm{sf} 2}}{\mathrm{Z}_{\mathrm{sf} 2}}\left(\frac{1}{1-\frac{\mathrm{nP} 0}{2 \mathrm{P}_{\mathrm{c} 0}}-\frac{\mathrm{nP}_{\mathrm{pf} 2}}{2 \mathrm{P}_{\mathrm{cf} 2}}}\right)\left(\mathrm{P}_{\mathrm{sf2}}-\mathrm{P}_{0}\right) \\
& \mathrm{C}_{2}=\frac{14.7}{1.0006}\left(\frac{1}{1-\frac{\mathrm{n} * 14.7}{2 * 14.7}-\frac{\mathrm{n} * 14.7}{2 * 900}}\right)(14.7-14.7)-\frac{146.3}{1.0066}\left(\frac{1}{1-\frac{\mathrm{n} * 14.7}{2 * 14.7}-\frac{\mathrm{n} * 146.3}{2 * 900}}\right)(146.3-14.7) \\
& C_{2}=-\left(\frac{19126.84}{1-0.5 n-0.08128 n}\right)=\left(\frac{19126.84}{0.5813 n-1}\right)
\end{aligned}
$$

Replacing in equation 35-36,

$$
\begin{aligned}
& C_{p}=\frac{\frac{-103.3}{1.056}+107.14}{n \times\left(\frac{13133.27}{0.6021 n-1}\right)}=\frac{9.3180 \times(0.6021 n-1)}{13133.27 n}=\frac{5.6104 n-9.3180}{13133.27 n} ; \\
& C_{p}=\frac{\frac{-100.21}{1.056}+130.65}{n \times\left(\frac{19126.84}{0.5813 n-1}\right)}=\frac{35.7541 \times(0.5813 n-1)}{19126.84 n}=\frac{20.7839 n-35.7541}{19126.84 n} ;
\end{aligned}
$$

We take $\mathrm{Cp}$ equal between 2 consecutive states, therefore:

$$
\begin{aligned}
& \mathrm{C}_{\mathrm{p} 1}=\mathrm{C}_{\mathrm{p} 2} ; \\
& \frac{5.6104 \mathrm{n}-9.3180}{13133.27 \mathrm{n}}=\frac{20.7839 \mathrm{n}-35.7541}{19126.84 \mathrm{n}} ; \\
& \frac{19126.84 \mathrm{n}}{13133.27 \mathrm{n}}(5.6104 \mathrm{n}-9.3180)=20.7839 \mathrm{n}-35.7541 ; \\
& 1.4564 \times(5.6104 \mathrm{n}-9.3180)=20.7839 \mathrm{n}-35.7541 ; \\
& 8.1708 \mathrm{n}-13.5707=20.7839 \mathrm{n}-35.7541 ; \\
& -20.7839 \mathrm{n}+8.1708 \mathrm{n}=-35.7541+13.5707 ; \\
& -12.6131 \mathrm{n}=-22.1834 ;
\end{aligned}
$$


$\mathrm{n}=1.7588$

Consequently, we can substitute back into either equation (35) or (36) to determine $C_{p}$. Here, I use equation (35) and solve for $\mathrm{C}_{\mathrm{p}}$ :

$\mathrm{C}_{\mathrm{p}}=\frac{\frac{\mathrm{A}_{1}}{\mathrm{~V}_{\mathrm{po}}+\mathrm{B}_{1}}}{\mathrm{n} \times \mathrm{C}_{1}}=\frac{\frac{-103.3}{1.056}+107.14}{\mathrm{n} \times\left(\frac{13133.27}{0.6021 \mathrm{n}-1}\right)}=\frac{5.6104(1.7588)-9.3180}{13133.27(1.7588)}=2.3792 \times 10^{-5} \mathrm{psi}^{-1} ;$

Finally, change in pore volume is obtained from equation (27) in previous chapter as follows,

$\mathrm{V}_{\mathrm{sf}}=\mathrm{V}_{\mathrm{po}} \times\left[1+\mathrm{nC}_{\mathrm{p}}\left(\mathrm{p}_{\mathrm{sf}}-\mathrm{p}_{0}\right)\right]=1.056 \times\left[1+1.7588 \times 2.3792 \times 10^{-5} \times(134.4-14.7)\right]$

$\mathrm{V}_{\mathrm{sf}}=1.06128 \mathrm{cc}$;

where the equilibrium pressure was taken as average between the first two equilibrium pressures pressure stages.

This process was utilized for other pressure combinations, for instance stages 1-2; 2-3; 3$4 ; 4-5 ; 5-6$ and so on. Combinations were done only between consecutive pressure stages. Solution for 11 out of the 27 stages were done for the shale sample. For the additional shale plug data, results for 9 out of the 16 stages are reported in next section. Similarly, for the sandstone sample, results for 13 stages out of 44 stages performed and results for 16 data points on the carbonate sample are found in next section as well. Not all results are reported here, because some of the data points are of bad quality, even after pressure/temperature corrections are made, while some other simply did not produce satisfactory results (either too low/high pore compressibility values, or even negative values).

\subsection{Results and Discussion}

The reference pore volume $V_{p 0}$ of the samples near zero effective stress were previously obtained using a Temco porosimeter. For the sandstone plug, a value of $2.74 \mathrm{cc}$ was obtained. Using the setup described in previous chapter\#3 at zero confining pressure gives $2.65 \mathrm{cc}$. The measurement error is $3.3 \%$, which is quite reasonable. As for the estimated reference pore volume of the shale 
sample near zero stress, it has a reference pore volume close to $1.06 \mathrm{cc}$ using the Temco porosimeter. The predicted volumes using gas expansion in the core holder are somehow constant and close to the pore volume measurement results using the routine helium porosity method. This is indicating that the laboratory analysis method yields meaningful results.

The measurements at higher pore pressure and changing confining pressures are tabulated in Table 8 for the sandstone sample, Table 9 to Table 10 for the shale sample and Table 11 for the carbonate sample. Additionally, pore compressibility and effective stress coefficient can be found on these tables as well. An average value of effective stress coefficient around 1.2 is observed for sandstone (min 0.9-max 1.5) while shale has an average value of 1.7 (min 1.1-max 1.8) and carbonate has an average $1.8(\min 1.0-\max 2.0)$. An average value for pore compressibility of $2.2 \times 10^{-5} \mathrm{psi}^{-1}\left(\min 1.2 \times 10^{-6}-\max 8.7 \times 10^{-5}\right)$ is observed for sandstone sample, while shale has an average value of $1.6 \times 10^{-4}\left(\min 1.6 \times 10^{-6}-\max 5.7 \times 10^{-4}\right)$ and carbonate $7.0 \times 10^{-5}\left(\min 1.6 \times 10^{-6}-\mathrm{max}\right.$ $\left.4.7 \times 10^{-4}\right)$.

Table 8 Gas storage measurement results for the sandstone sample.

\begin{tabular}{|l|l|l|l|l|l|l|}
\hline $\mathbf{P}_{\mathbf{c}}$ & $\mathbf{P s f}$ & $\begin{array}{l}\text { Differential } \\
\mathbf{P r e s s u r e} \\
\mathbf{P}_{\mathbf{c}}-\mathbf{P}_{\text {sf }}\end{array}$ & $\mathbf{n}$ & $\begin{array}{l}\text { Effective Stress, } \\
\mathbf{P}_{\mathbf{c}}-\mathbf{n}_{\mathbf{p}} \text { * } \mathbf{P}_{\mathbf{s f}}\end{array}$ & $\mathbf{\mathbf { V } _ { \mathbf { p } }}$ \\
\hline $\mathbf{p s i}$ & $\mathbf{p s i a}$ & $\mathbf{p s i a}$ & - & $\mathbf{p s i a}$ & $\mathbf{c c}$ & $\mathbf{1 / p s i}$ \\
\hline 1000.0 & 386.9 & 613.2 & 1.325 & 487.3 & 2.771 & $3.32 \mathrm{E}-05$ \\
\hline 1000.0 & 443.7 & 556.4 & 1.413 & 373.1 & 2.739 & $1.16 \mathrm{E}-06$ \\
\hline 1500.0 & 547.5 & 952.5 & 1.443 & 709.9 & 2.743 & $3.59 \mathrm{E}-06$ \\
\hline 1500.0 & 597.7 & 902.3 & 1.503 & 601.9 & 2.765 & $1.70 \mathrm{E}-05$ \\
\hline 1500.0 & 806.4 & 693.6 & 1.068 & 638.5 & 2.859 & $5.59 \mathrm{E}-05$ \\
\hline 1500.0 & 955.5 & 544.6 & 1.059 & 488.1 & 2.826 & $3.43 \mathrm{E}-05$ \\
\hline 2000.0 & 1003.8 & 996.2 & 0.968 & 1028.4 & 2.973 & $8.69 \mathrm{E}-05$ \\
\hline 2000.0 & 1155.5 & 844.5 & 1.191 & 623.8 & 2.756 & $5.99 \mathrm{E}-06$ \\
\hline 2000.0 & 1255.4 & 744.6 & 1.037 & 698.0 & 2.845 & $3.16 \mathrm{E}-05$ \\
\hline
\end{tabular}


Table 8. Continued

\begin{tabular}{|l|l|l|l|l|l|l|}
\hline $\mathbf{P}_{\mathbf{c}}$ & Psf & $\begin{array}{l}\text { Differential } \\
\text { Pressure, } \\
\mathbf{P}_{\mathbf{c}}-\mathbf{P}_{\mathbf{s f}}\end{array}$ & $\mathbf{n}$ & $\begin{array}{l}\text { Effective Stress, } \\
\mathbf{P}_{\mathbf{c}}-\mathbf{n}_{\mathbf{p}} \mathbf{P}_{\mathbf{s f}}\end{array}$ & $\mathbf{V}_{\mathbf{p}}$ \\
\hline $\mathbf{p s i}$ & $\mathbf{p s i a}$ & $\mathbf{p s i a}$ & - & $\mathbf{p s i a}$ & $\mathbf{c c}$ & $\mathbf{1} / \mathbf{p s i}$ \\
\hline 2250.0 & 1478.8 & 771.2 & 1.206 & 466.5 & 2.748 & $2.70 \mathrm{E}-06$ \\
\hline 2500.0 & 1604.4 & 895.6 & 1.111 & 717.1 & 2.768 & $7.04 \mathrm{E}-06$ \\
\hline 2750.0 & 1626.4 & 1123.6 & 1.257 & 705.5 & 2.756 & $4.19 \mathrm{E}-06$ \\
\hline 3250.0 & 1604.1 & 1646.0 & 1.342 & 1097.3 & 2.749 & $2.64 \mathrm{E}-06$ \\
\hline
\end{tabular}

Table 9 Gas storage measurement results for the first set of shale sample data.

\begin{tabular}{|l|l|l|l|l|l|l|}
\hline $\mathbf{P}_{\mathbf{c}}$ & Psf & $\begin{array}{l}\text { Differential } \\
\text { Pressure, } \\
\mathbf{P}_{\mathbf{c}}-\mathbf{P}_{\mathbf{s f}}\end{array}$ & $\mathbf{n}$ & $\begin{array}{l}\text { Effective Stress, } \\
\mathbf{P}_{\mathbf{c}}-\mathbf{n}_{\mathbf{p}} \mathbf{P}_{\mathbf{s f}}\end{array}$ & $\mathbf{V}_{\mathbf{p}}$ & $\mathbf{C}_{\mathbf{p}}$ \\
\hline $\mathbf{p s i}$ & $\mathbf{p s i a}$ & $\mathbf{p s i a}$ & - & $\mathbf{p s i a}$ & $\mathbf{c c}$ & $\mathbf{1 / p s i}$ \\
\hline 750 & 134.4 & 616 & 1.738 & 516 & 1.057 & $1.13 \mathrm{E}-05$ \\
\hline 2700 & 1264.6 & 1435 & 1.453 & 862 & 1.058 & $1.61 \mathrm{E}-06$ \\
\hline 2950 & 1211.1 & 1739 & 1.475 & 1164 & 1.06 & $2.87 \mathrm{E}-06$ \\
\hline 3200 & 1161.9 & 2038 & 1.715 & 1208 & 1.627 & $4.71 \mathrm{E}-04$ \\
\hline 3450 & 1210.5 & 2240 & 1.506 & 1626 & 1.072 & $1.25 \mathrm{E}-05$ \\
\hline 3700 & 982.4 & 2718 & 1.779 & 1953 & 1.212 & $1.53 \mathrm{E}-04$ \\
\hline 3700 & 1173.5 & 2527 & 1.789 & 1601 & 1.141 & $6.91 \mathrm{E}-05$ \\
\hline 3950 & 1144.9 & 2805 & 1.764 & 1931 & 1.184 & $1.07 \mathrm{E}-04$ \\
\hline 4200 & 1146.8 & 3053 & 1.789 & 2148 & 1.545 & $4.09 \mathrm{E}-04$ \\
\hline 4475 & 1442.6 & 3032 & 1.736 & 1971 & 1.912 & $5.68 \mathrm{E}-04$ \\
\hline 4990 & 1122.9 & 3867 & 1.674 & 3111 & 1.058 & $1.68 \mathrm{E}-06$ \\
\hline
\end{tabular}

Table 10 Gas storage measurement results for the second set of shale sample data.

\begin{tabular}{|l|l|l|l|l|l|l|}
\hline $\mathbf{P}_{\mathbf{c}}$ & Psf & $\begin{array}{l}\text { Differential } \\
\text { Pressure, } \\
\mathbf{P}_{\mathbf{c}}-\mathbf{P}_{\mathbf{s f}}\end{array}$ & $\mathbf{n}$ & $\begin{array}{l}\text { Effective Stress, } \\
\mathbf{P}_{\mathbf{c}}-\mathbf{n}_{\mathbf{p}} * \mathbf{P}_{\mathbf{s f}}\end{array}$ & $\mathbf{V}_{\mathbf{p}}$ & $\mathbf{C}_{\mathbf{p}}$ \\
\hline $\mathbf{p s i}$ & psia & $\mathbf{p s i a}$ & - & $\mathbf{p s i a}$ & $\mathbf{c c}$ & $\mathbf{1 / p s i}$ \\
\hline 2250.00 & 1561.79 & 688.21 & 1.115 & 508.09 & 1.056 & $1.18 \mathrm{E}-05$ \\
\hline 2550.00 & 1685.28 & 864.72 & 1.352 & 271.11 & 0.984 & $4.71 \mathrm{E}-05$ \\
\hline 2850.00 & 1730.25 & 1119.75 & 1.368 & 483.77 & 0.965 & $6.46 \mathrm{E}-05$ \\
\hline 3150.00 & 1756.59 & 1393.41 & 1.293 & 878.94 & 1.056 & $2.75 \mathrm{E}-06$ \\
\hline 3450.00 & 1761.91 & 1688.09 & 1.338 & 1092.35 & 1.056 & $2.24 \mathrm{E}-05$ \\
\hline
\end{tabular}


Table 10. Continued

\begin{tabular}{|l|l|l|l|l|l|l|}
\hline $\mathbf{P}_{\mathbf{c}}$ & Psf & $\begin{array}{l}\text { Differential } \\
\text { Pressure, } \\
\mathbf{P}_{\mathbf{c}}-\mathbf{P}_{\text {sf }}\end{array}$ & $\mathbf{n}$ & $\begin{array}{l}\text { Effective } \\
\text { Stress, } \\
\mathbf{P}_{\mathbf{c}}-\mathbf{n}_{\mathbf{s}}\end{array}$ & $\mathbf{V}_{\mathbf{p}}$ & $\mathbf{C}_{\mathbf{p}}$ \\
\hline $\mathbf{p s i}$ & $\mathbf{p s i a}$ & $\mathbf{p s i a}$ & - & $\mathbf{p s i a}$ & $\mathbf{c c}$ & $\mathbf{1 / p s i}$ \\
\hline 3750.00 & 1755.46 & 1994.54 & 1.334 & 1408.53 & 1.043 & $6.35 \mathrm{E}-05$ \\
\hline 4050.00 & 1756.30 & 2293.70 & 1.363 & 1657.01 & 1.056 & $9.84 \mathrm{E}-06$ \\
\hline 4350.00 & 1750.85 & 2599.15 & 1.435 & 1837.12 & 1.043 & $3.08 \mathrm{E}-06$ \\
\hline 4650.00 & 1746.50 & 2903.50 & 1.409 & 2188.90 & 1.026 & $7.38 \mathrm{E}-05$ \\
\hline
\end{tabular}

Table 11 Gas storage measurement results for the carbonate sample.

\begin{tabular}{|c|c|c|c|c|c|c|}
\hline \multirow[t]{2}{*}{$\mathbf{P}_{\mathbf{c}}$} & \multirow[t]{2}{*}{$\mathbf{P}_{\mathbf{s f}}$} & $\begin{array}{c}\text { Differential } \\
\text { Pressure, }\end{array}$ & \multirow[t]{2}{*}{$\mathbf{n}$} & $\begin{array}{c}\text { Effective } \\
\text { Stress, } \\
\end{array}$ & \multirow[t]{2}{*}{$\mathbf{V}_{\mathbf{p}}$} & \multirow[t]{2}{*}{$\mathrm{C}_{\mathrm{p}}$} \\
\hline & & $\mathbf{P}_{\mathrm{c}}-\mathbf{P}_{\mathrm{sf}}$ & & $\mathbf{P}_{\mathrm{c}}-\mathbf{n} * \mathbf{P}_{\mathrm{sf}}$ & & \\
\hline psi & psia & psia & - & psia & cc & $1 / \mathrm{psi}$ \\
\hline 500 & 81.9 & 418 & 1.848 & 349 & 3.383 & $4.66 \mathrm{E}-04$ \\
\hline 1000 & 468.1 & 532 & 1.312 & 386 & 3.287 & $4.56 \mathrm{E}-06$ \\
\hline 1500 & 332.0 & 1168 & 1.795 & 904 & 3.353 & $7.04 \mathrm{E}-05$ \\
\hline 1500 & 516.1 & 984 & 1.785 & 579 & 3.342 & $3.75 \mathrm{E}-05$ \\
\hline 1750 & 392.1 & 1358 & 1.862 & 1020 & 3.315 & $2.81 \mathrm{E}-05$ \\
\hline 2000 & 317.9 & 1682 & 1.922 & 1389 & 3.369 & $8.94 \mathrm{E}-05$ \\
\hline 2500 & 157.8 & 2342 & 1.964 & 2190 & 3.316 & 7.67E-05 \\
\hline 2500 & 327.7 & 2172 & 1.900 & 1877 & 3.297 & $1.65 \mathrm{E}-05$ \\
\hline 3000 & 281.0 & 2719 & 1.912 & 2463 & 3.285 & $6.18 \mathrm{E}-06$ \\
\hline 3000 & 534.4 & 2466 & 1.035 & 2447 & 3.355 & $4.44 \mathrm{E}-05$ \\
\hline 3500 & 146.4 & 3354 & 1.981 & 3348 & 3.302 & $5.13 \mathrm{E}-05$ \\
\hline 3500 & 303.9 & 3196 & 1.888 & 2926 & 3.281 & $1.62 \mathrm{E}-06$ \\
\hline 4000 & 208.1 & 3792 & 2.047 & 3574 & 3.349 & 1.09E-04 \\
\hline 4000 & 464.6 & 3535 & 1.872 & 3130 & 3.301 & $1.46 \mathrm{E}-05$ \\
\hline 4500 & 178.2 & 4322 & 1.979 & 4147 & 3.300 & $3.78 \mathrm{E}-05$ \\
\hline
\end{tabular}

Similarly, the values for $\mathrm{V}_{\mathrm{p} 0}$ are plotted in Figure 9, Figure 10, Figure 11 for sandstone and shale samples. The sandstone sample presents small variations in pore volume due to stress change, while the shale sample shows only a slight variation due to such changes in stress. This indicates, that the pore volume is insensitive to stress changes throughout measurements for the case of 
sandstone but has little sensitivity for the case of shale. Carbonate core plug sample is also insensitive to the effective stress as seen in Figure 12
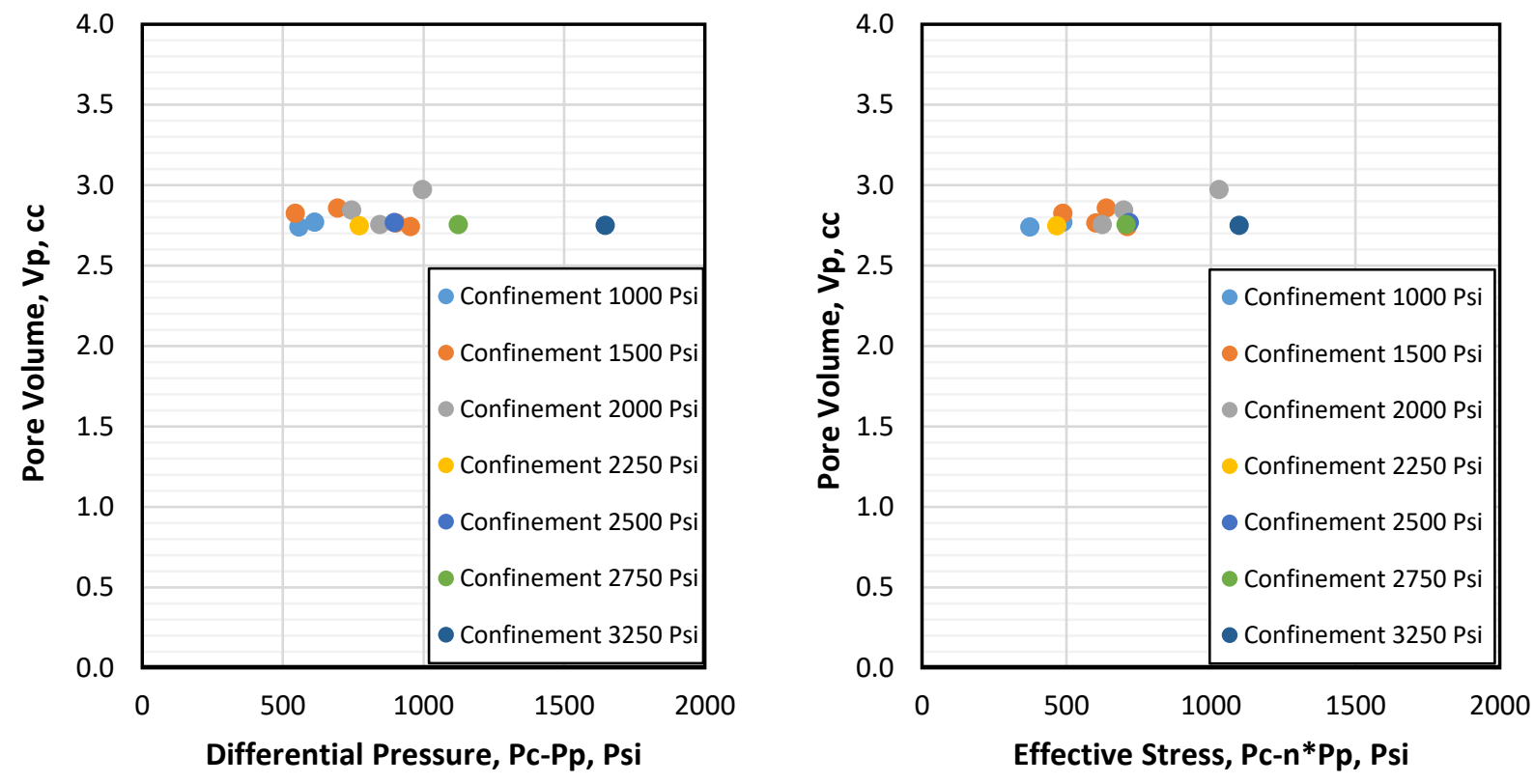

Figure 9 Estimated pore volume for sandstone samples as a function of differential pressure (LEFT) and effective stress (RIGHT). 

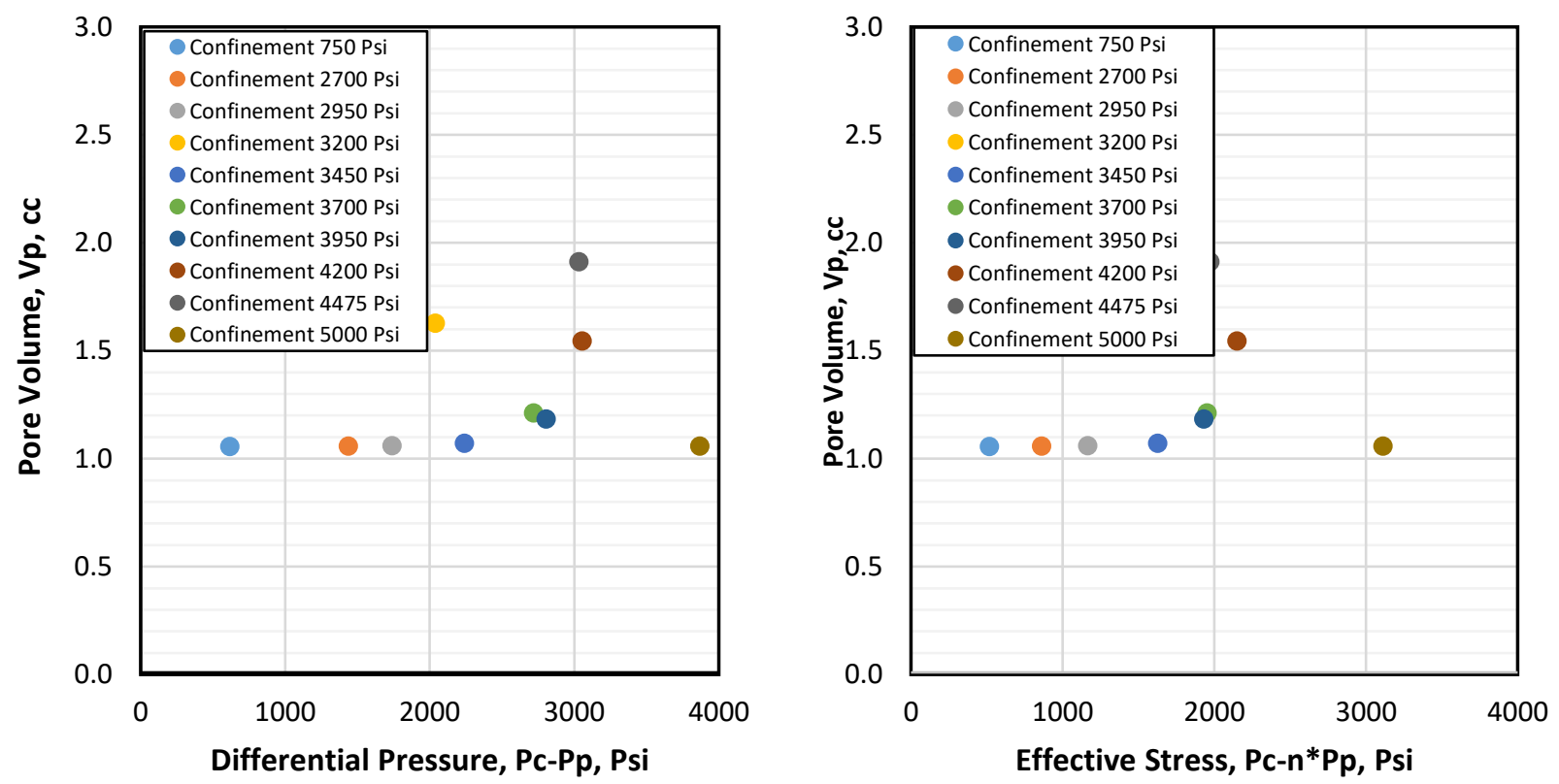

Figure 10 Estimated pore volume for shale sample ( $1^{\text {st }}$ data set), as a function of differential pressure (LEFT) and effective stress (RIGHT).
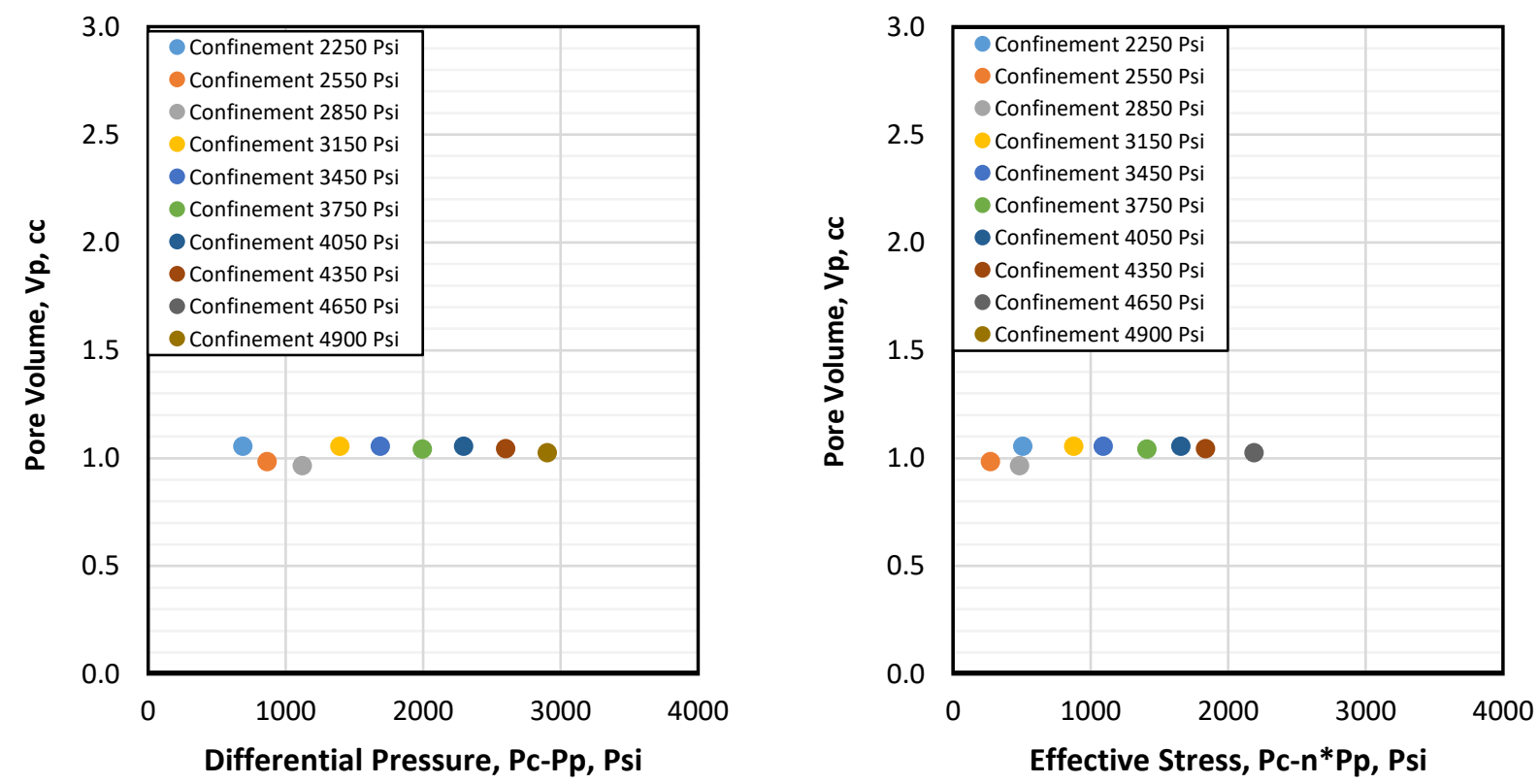

Figure 11 Estimated pore volume for shale sample ( $2^{\text {nd }}$ data set) as a function of differential pressure (LEFT) and effective stress (RIGHT). 

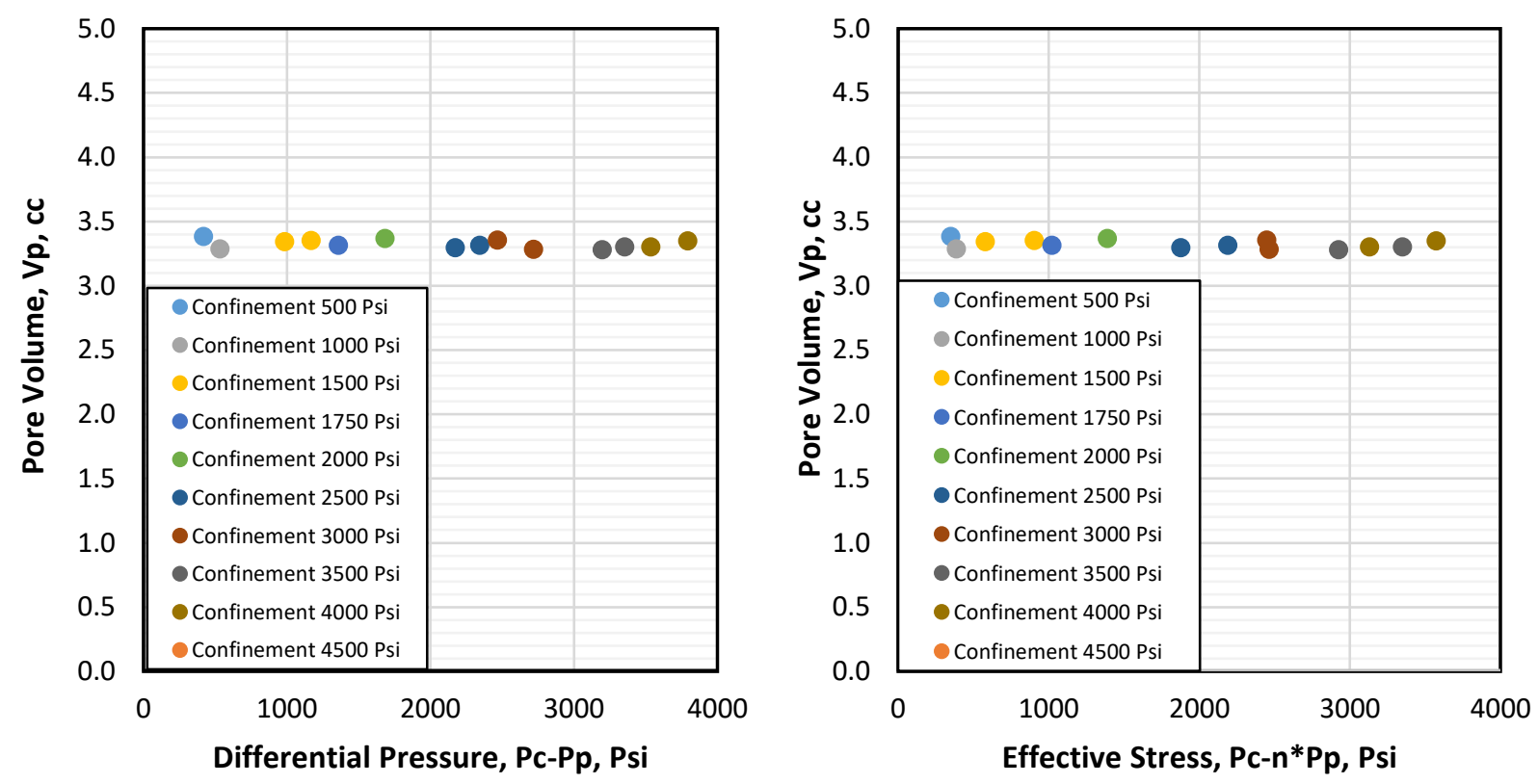

Figure 12 Estimated pore volume for carbonate sample as a function of differential pressure (LEFT) and effective stress (RIGHT).

Figure 13, Figure 14 and Figure 15 show the estimated effective stress coefficient as a function of the applied pressure difference and as a function of the effective stress. The effective stress uses the value of the coefficient at measured data point. Clearly, using the differential pressure as a measure cause the sandstone results to be somewhat clustered and without any trend; instead, when we display the data using the effective stress, the results are uniformly distributed. In the case of sandstone sample, we observe the coefficient with values below 1.5. The average value of the coefficient for sandstone is around 1.2. In the case of shale, the coefficient of effective stress is slightly larger with values between 1.1-1.79. A relatively high confining pressure of 5,000 psi was applied to the shale, when the coefficient of effective stress is close to 1.8 , so the effective stress did not change greatly. 

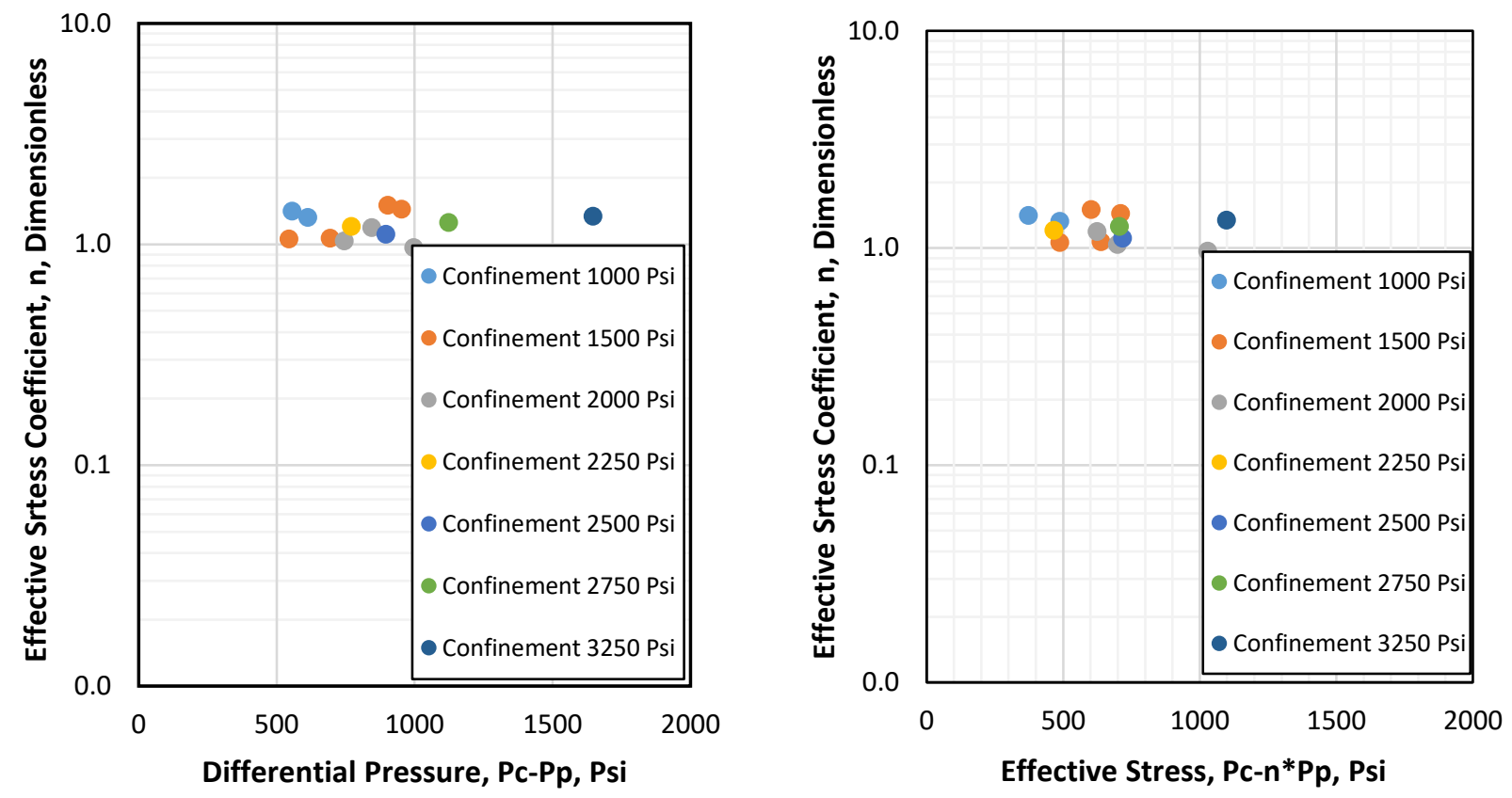

Figure 13 Estimated effective stress coefficient for sandstone sample as a function of differential pressure (LEFT) and as a function of effective stress (RIGHT).
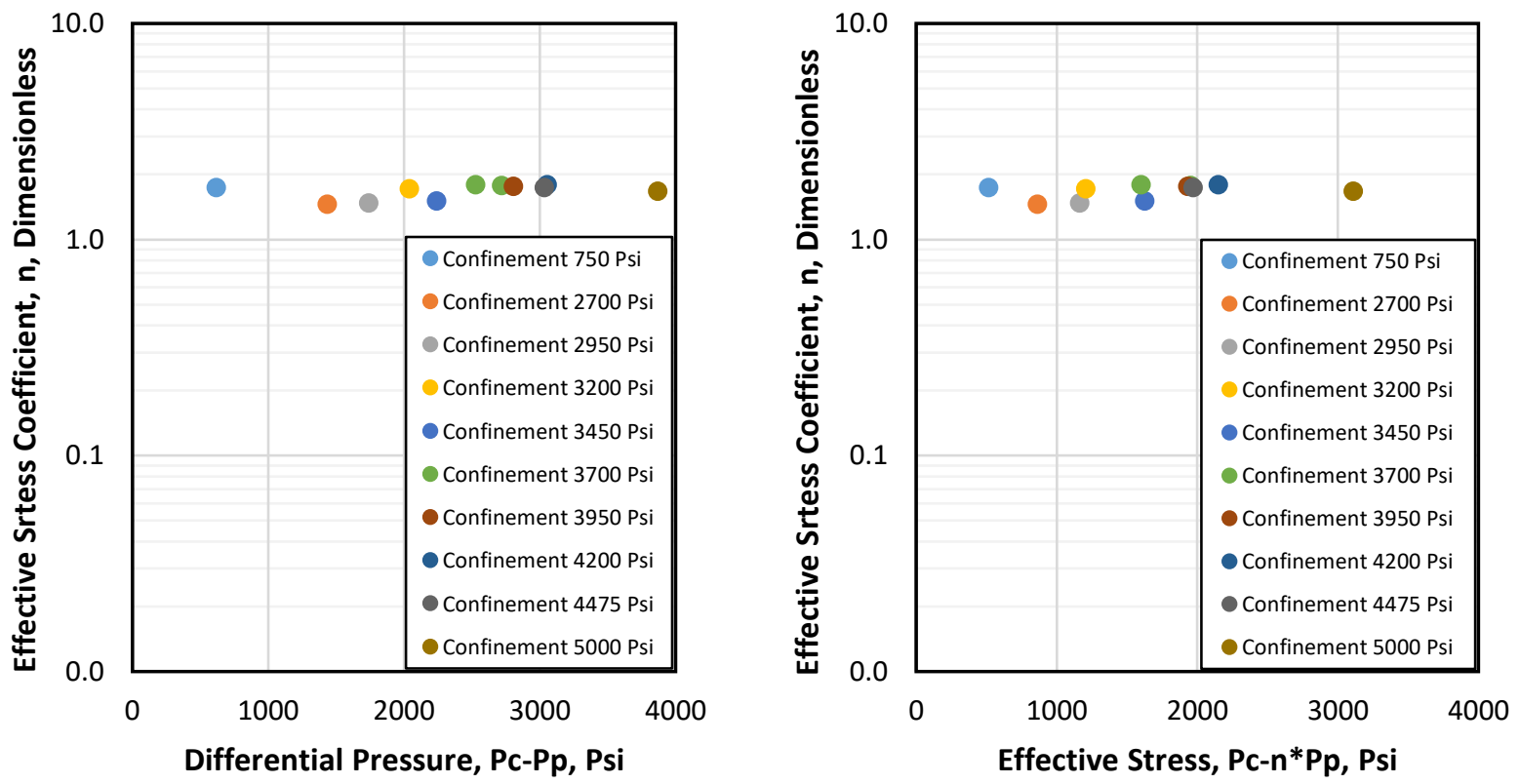

Figure 14 Estimated effective stress coefficient for shale sample ( $1^{\text {st }}$ data set), as a function of differential pressure (LEFT) and as a function of effective stress (RIGHT). 

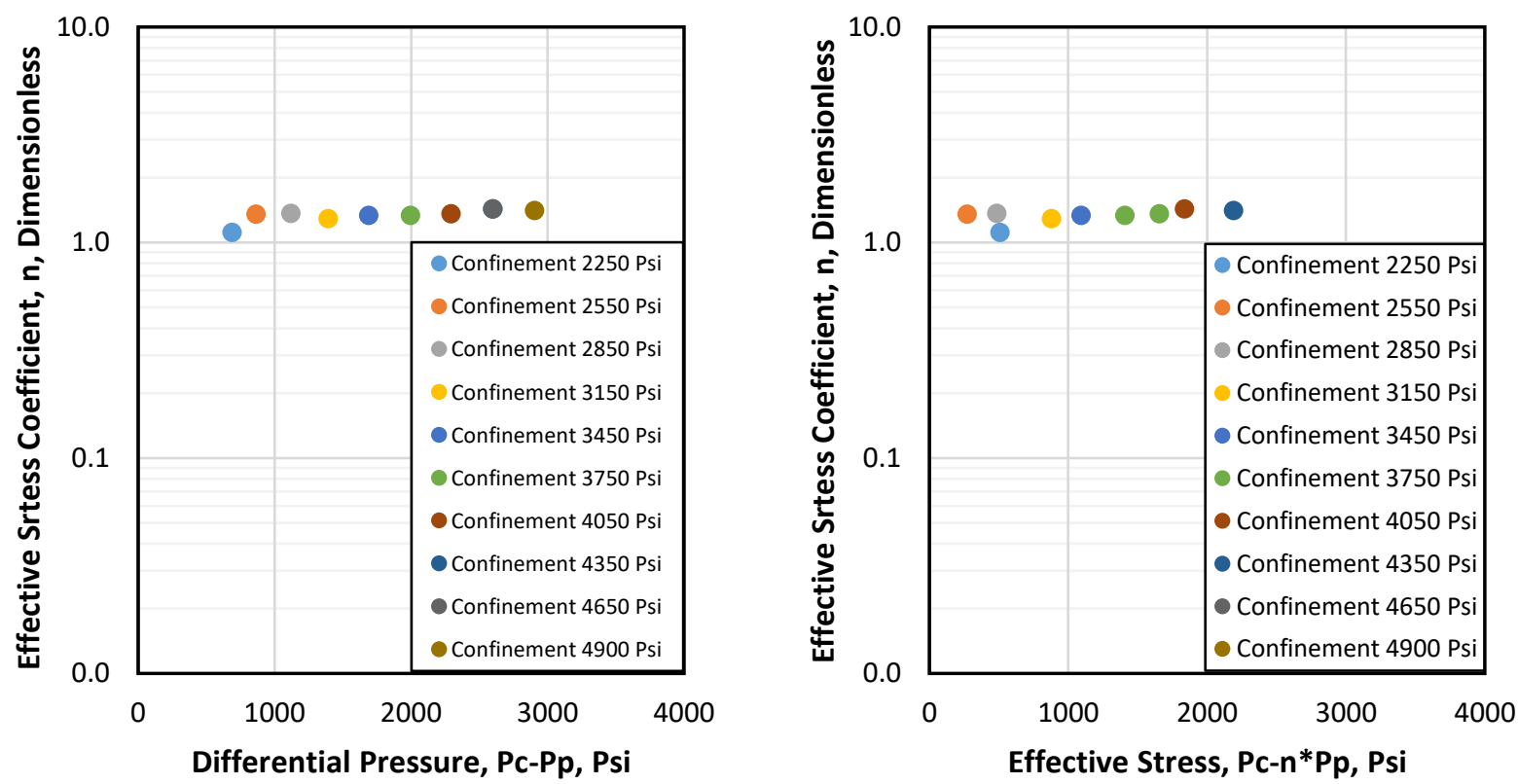

Figure 15 Estimated effective stress coefficient for shale ( $2^{\text {nd }}$ data set $)$ samples as a function of differential pressure (LEFT) and as a function of effective stress (RIGHT).

The average value for shale is 1.7 for the first data set and 1.3 in the case of second data set. The carbonate sample exhibit larger effective stress coefficient, with values around 1.8, as seen in Figure 16. It is apparent that permeability of the sample comes into play, as the lower the permeability of the matrix, the higher the effective stress coefficient will be (permeability measurements were performed using pulse decay method but are not reported here as it is out of the scope of this project).

Effective stress coefficient is a property that weighs the contribution of pore pressure to effective stress. This property has been studied recently by several authors, using distinct methodologies. Depending upon the physical quantity measured (i.e. bulk compressibility, deformation modulus, permeability, electrical conductivity, seismic wave velocity), effective stress coefficient can have different connotation (Qiao, Wong, Aguilera, \& Kantzas, 2012). Here, we cite examples of effective stress coefficient obtained for velocities and for transport processes. 
It is important to clarify that our methodology is producing values of effective stress coefficient for a storage process, therefore values obtained could be slightly different from the review cases we invoke here. In the literature, it has been reported that effective stress coefficient can have values slightly larger than one. For instance, at the lowest effective stress, some values close to 1.3 were reported for permeability measurements on a mudstone. Moreover, as effective stress increases, coefficient diminishes, to values less than 1 (Hasanov \& Prasad, 2018). Similarly, values of effective pressure coefficient $\mathrm{n}$ for sonic ( $\mathrm{P}$ and $\mathrm{S}$ ) wave propagation velocities, were reported close to 1 at low differential pressure (500 psi) and decreasing over $30 \%$ at intermediate to high differential pressure (2000-3000 psi) (Tinni, Sondergeld, Rai, \& Simo, 2011).
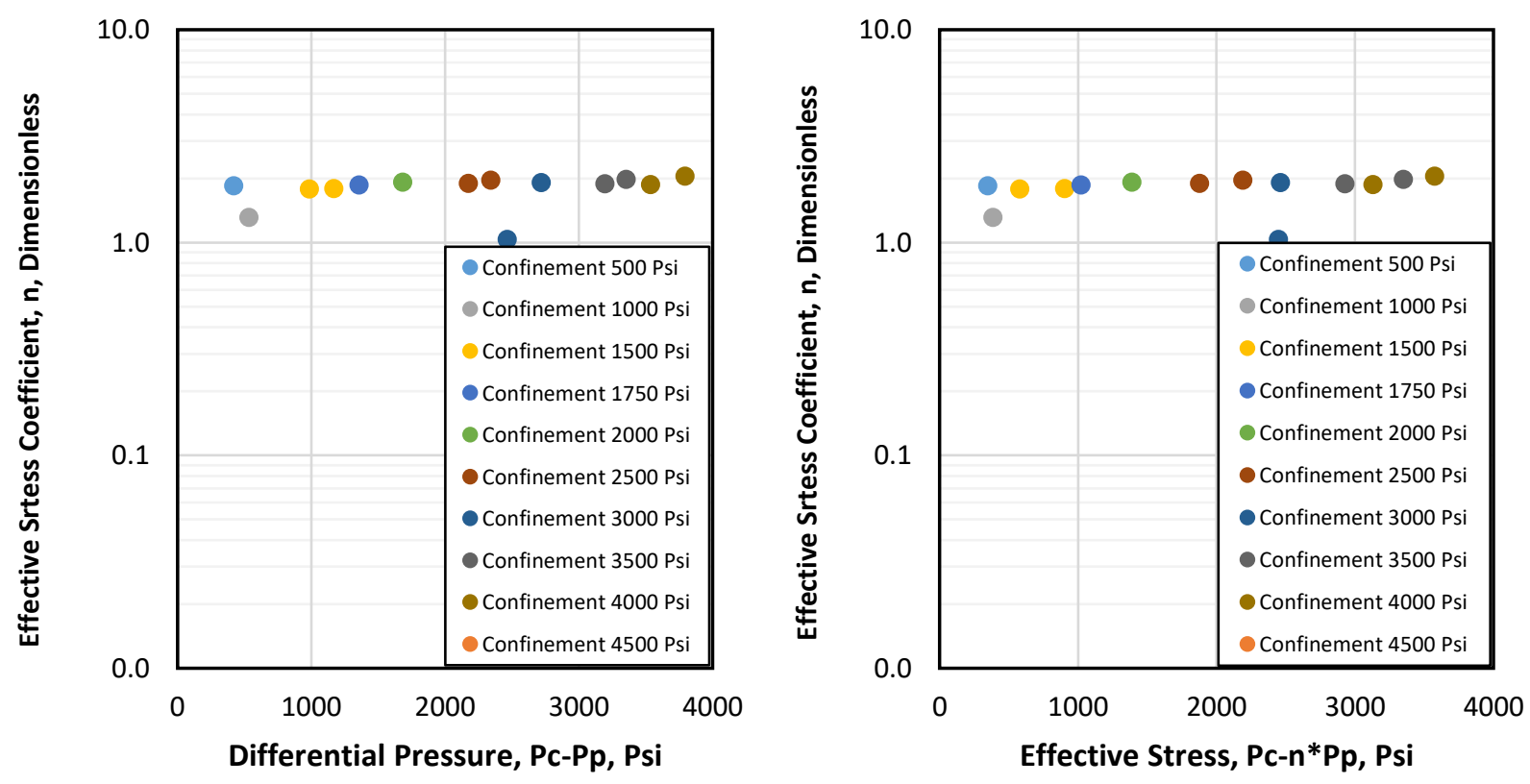

Figure 16 Estimated effective stress coefficient for a carbonate sample as a function of differential pressure (LEFT) and as a function of effective stress (RIGHT). 
In their work, the authors mention other values for effective pressure coefficient $\mathrm{n}$ produced by several researchers, ranging from 0.61 to values higher than 1 for sandstones from several basins, by producing $\mathrm{V}_{\mathrm{p}}$ and $\mathrm{V}_{\mathrm{s}}$ velocity measurements, as well as for permeability measurements. All in all, our values are in a similar range of those reported in literature but out results indicate effective stress coefficient is overall insensitive to effective stress applied.

We can observe from Figure 13 and Figure 14, how plotting the data considering confinement pressure as third variable, produces a trend. This trend indicates that confinement pressure has a dominant effect on the plug; for instance, from the Figure 14 (Shale case), having a constant coefficient $\mathrm{n}$ at low (1000psi) and high (3000 psi) confinement pressures is producing separate trends (different confinement pressures) meaning the plug is responding mechanically in a different way.

Overall, the higher the confinement pressure, the higher the effective stress coefficient. Shale plug data in Figure 15 and Figure 16 also shows separate trends for the coefficient when confinement pressure is considered as third variable, and the coefficient stays nearly constant when plotted as function of the effective stress.

Finally, Figure 17, Figure 18, show the estimated coefficient of the isothermal pore compressibility, $\mathrm{C}_{\mathrm{p}}$. The average pore compressibility is $2.0 \times 10^{-5} \mathrm{psi}^{-1}$ for sandstone and almost $2.0 \times 10^{-4} \mathrm{psi}^{-1}$ for the shale sample ( $1^{\text {st }}$ data set), which oscillates more with the applied pressure. 

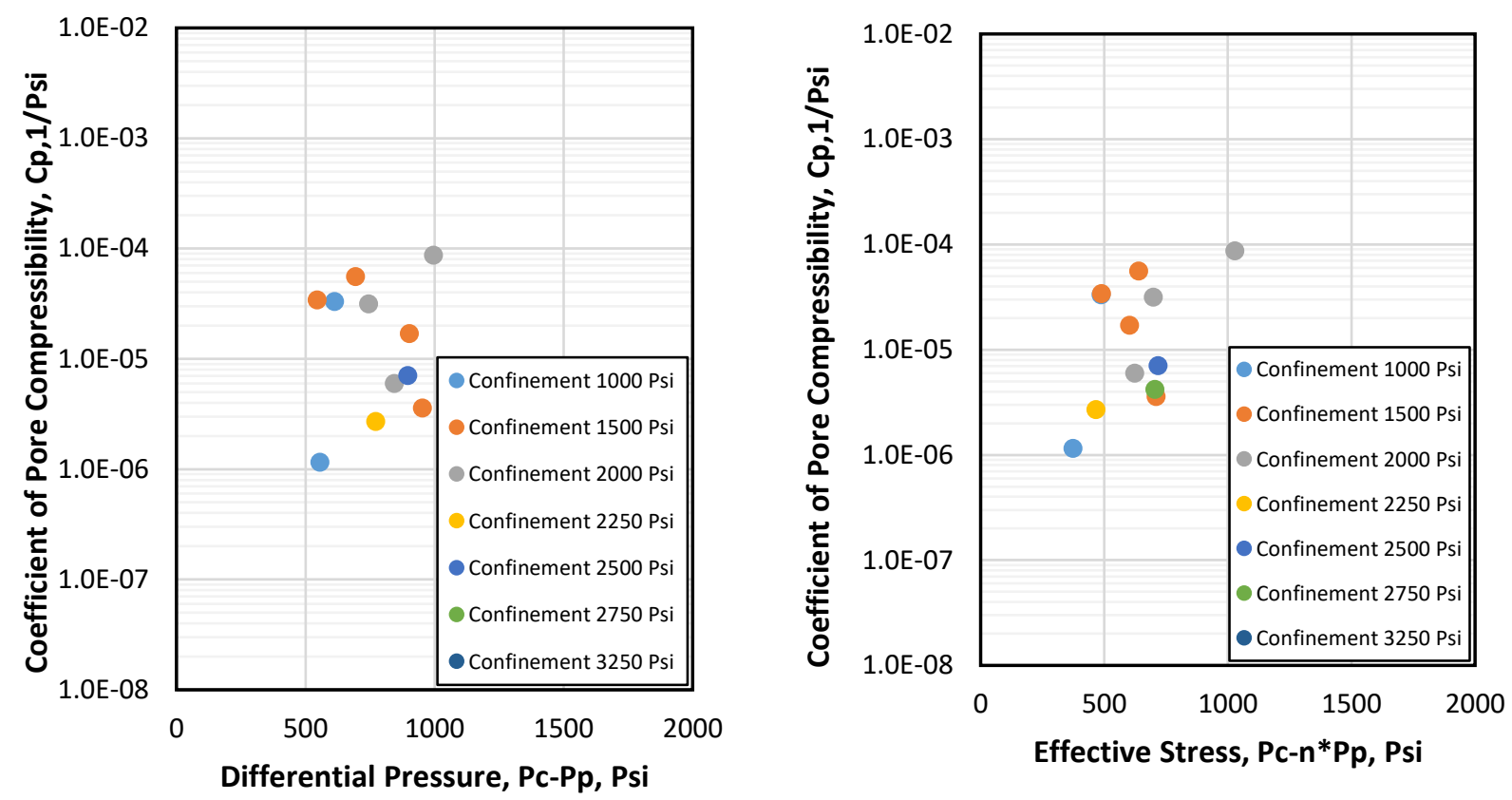

Figure 17 Estimated pore compressibility for the sandstone sample as a function of differential pressure (LEFT) and effective stress (RIGHT).
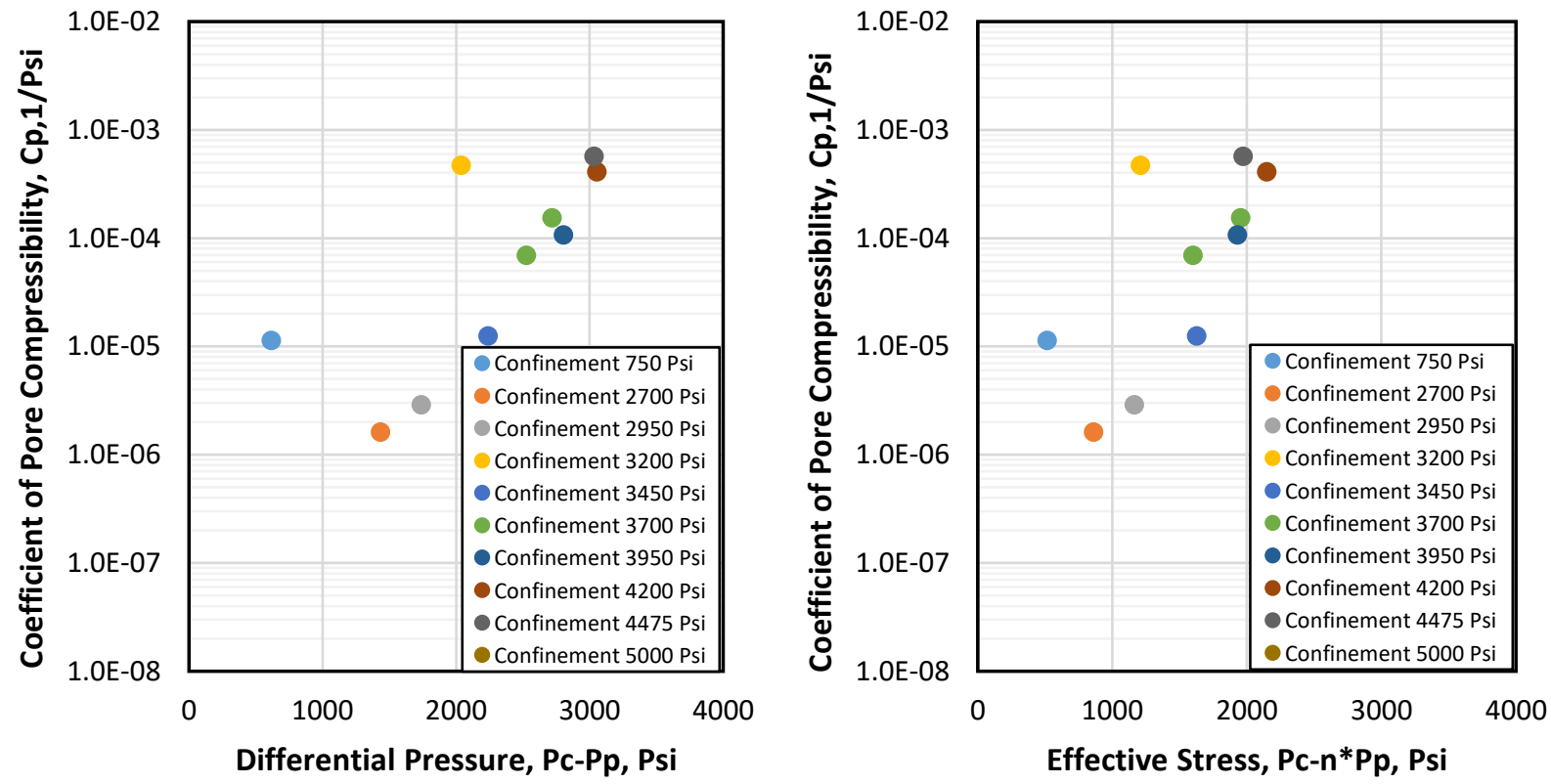

Figure 18 Estimated pore compressibility for the shale sample ( $1^{\text {st }}$ data set) as a function of differential pressure (LEFT) and effective stress (RIGHT). 
Shale plug ( $2^{\text {nd }}$ set) has an average $3.3 \times 10^{-5} \mathrm{psi}^{-1}$ while carbonate has an average pore compressibility of $7.3 \times 10^{-5} \mathrm{psi}^{-1}$ as seen in Figure 19 and Figure 20, being less compliant rocks than the first shale plug. The higher values for the coefficient are related to higher pore pressure applied as we progress in the uptake gas process and related to rock stiffness. As before, the higher the confinement pressure applied to the core plug, the higher the differential pressure and the effective stress. Overall, the compressibility values change two orders of magnitude in between $1.0 \times 10^{-4}-1.0 \times 10^{-6} \mathrm{psi}^{-1}$.
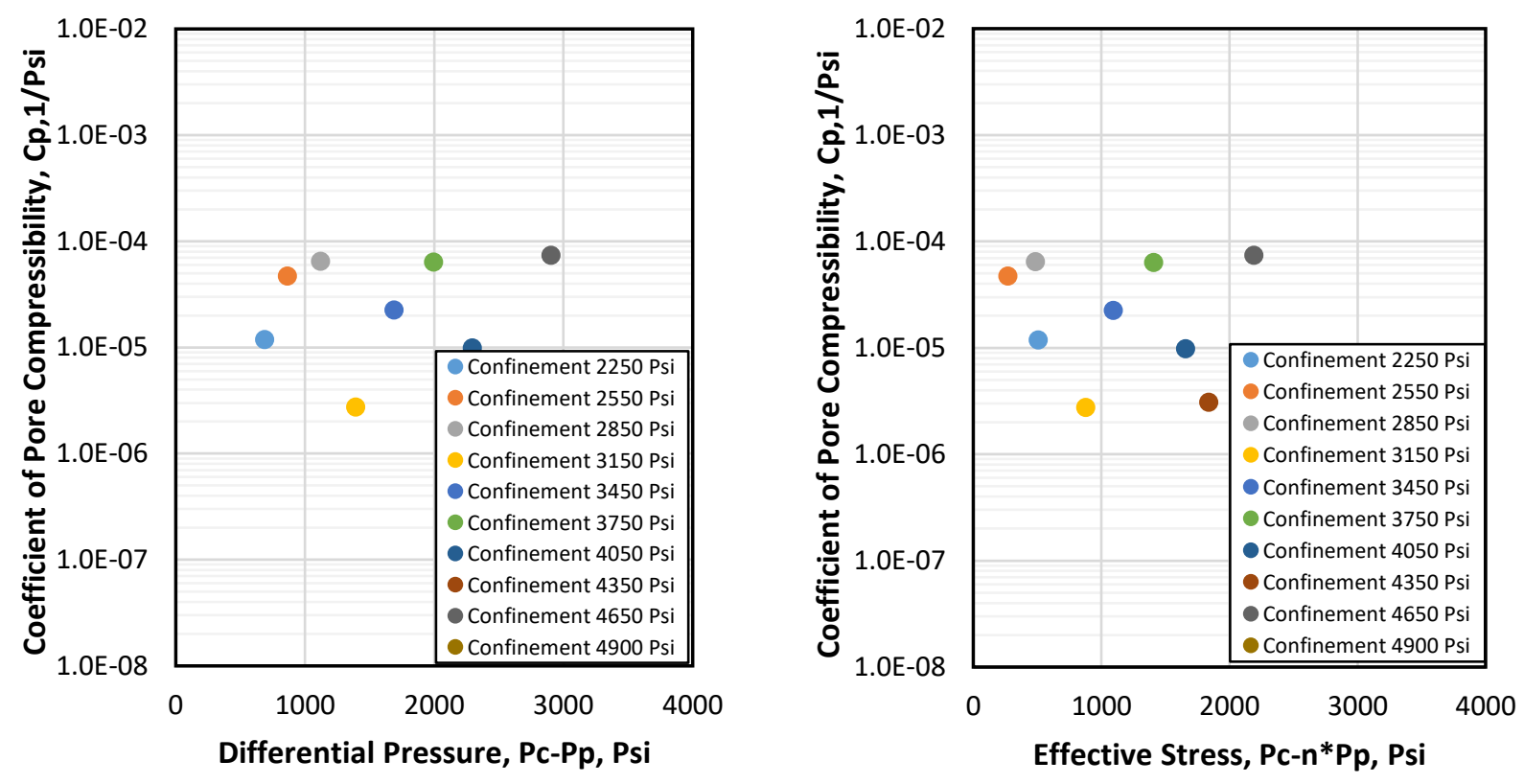

Figure 19 Estimated pore compressibility for the shale sample ( $2^{\text {nd }}$ data set) as a function of differential pressure (LEFT) and effective stress (RIGHT). 

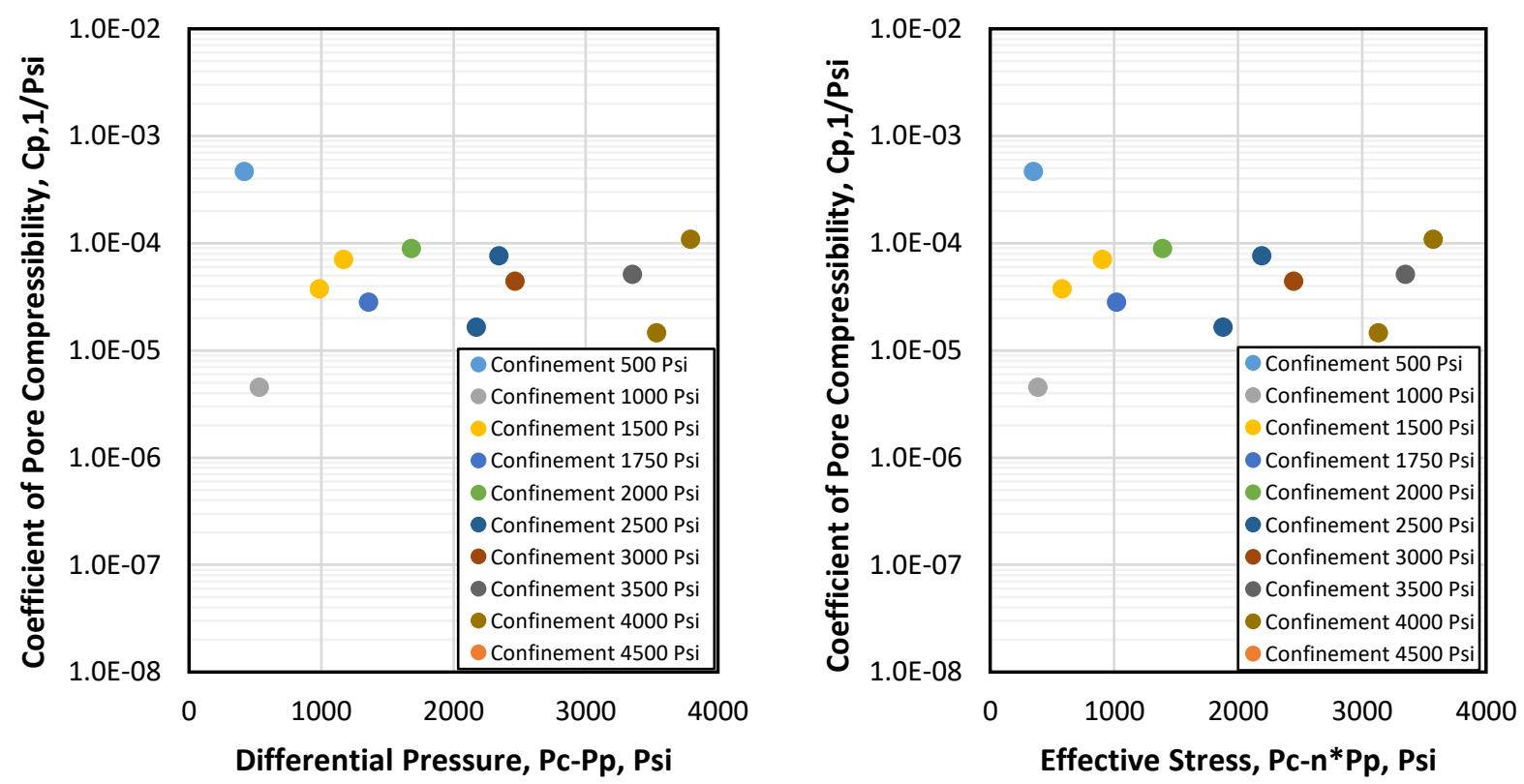

Figure 20 Estimated pore compressibility for the carbonate sample as a function of differential pressure (LEFT) and effective stress (RIGHT).

In the literature, several authors have measured pore compressibility in the range of $1.0 \times 10^{-}$ ${ }^{5}-1.0 \times 10^{-6} \mathrm{psi}^{-1}$ for the shale samples. Particularly, Kang (Kang, 2011) and Kang et al. (Kang, 2014). Reported pore compressibility in the order of $9 \times 10^{-5}$ to $2 \times 10^{-6} \mathrm{psi}^{-1}$ measured in shale samples using a gas permeameter. Similarly, Xiao and Ling also reported compressibility in the order of $1-5 \times 10^{-5} \mathrm{psi}^{-1}$ using both pulse decay permeability measurements and triaxial stress measurements on resource shale rock samples (Kegang Ling J. H., 2014). Davudov reported pore compressibility in the order of $1 \times 10^{-5} \mathrm{psi}^{-1}$ using MICP technique in shale samples (Davud Davudov, 2017). In his paper he points out the difference between accessible pore compressibility, which is in the order of magnitude reported in this paper $\left(1.0 \times 10^{-4}-1.0 \times 10^{-5} \mathrm{psi}^{-1}\right)$, and inaccessible pore compressibility in the order of $1 \times 10^{-7} \mathrm{psi}^{-1}$. He compared those compressibility values to the pore compressibility measured at constant bulk compressibility $\left(\mathrm{C}_{\mathrm{bc}}\right)$ and measured at constant pore compressibility $\left(\mathrm{C}_{\mathrm{pc}}\right)$; these, being in the order of $1 \times 10^{-5} \mathrm{psi}^{-1}-1 \times 10^{-6} \mathrm{psi}^{-1}$. They argue that it 
is necessary to reach pore pressures as high as $8000 \mathrm{psi}$ to reduce the pore compressibility in the order of $1 \times 10^{-6} \mathrm{psi}^{-1}$ (Davud Davudov and Rouzbeh Ghanbamezhad Moghanloo, 2018). It is feasible that for the higher values we have, we are permeating only the accessible part of the pores, which would explain why our pore compressibility is slightly higher than the conventional case (sandstone sample values). On the other hand, it is also possible that in the case of the shale sample, we are experiencing the effect of partially opened microcracks and fissures that are well known to exist even for particle sizes of less than $0.7 \mathrm{~mm}$ (Tinni, et al., 2012).

A plot for comparison with literature values is included below, Figure 21 and Figure 22 where effective stress coefficient is observed slightly above the range for a measurement done on 6-tight sand core plugs, using seismic wave velocities and electrical resistivity measurements. The data for comparison is obtained from experimental data published before (Tinni, Sondergeld, Rai, \& Simo, 2011). Similarly, for pore comparison on pore compressibility, data is compared to pore compressibility derived from MICP measurements done on shale core plugs, right before intrusion of mercury, in what the authors call compression of bulk volume stage. A knowledge of matrix compressibility allows them to derive pore compressibility from this test. The pore compressibility we derive (red triangles) is falling around the range of their measurements. Further measurements at higher effective stress (high confinement pressure and low pore pressure) would be needed to approximate the middle region of the plot. To obtain compressibility on the order of $1 \times 10^{-6} \mathrm{psi}^{-1}$, higher confinement pressures would be needed (our current design, stands up to 5000 psi confinement). Overall our data is falling within the range of other data published in literature. 


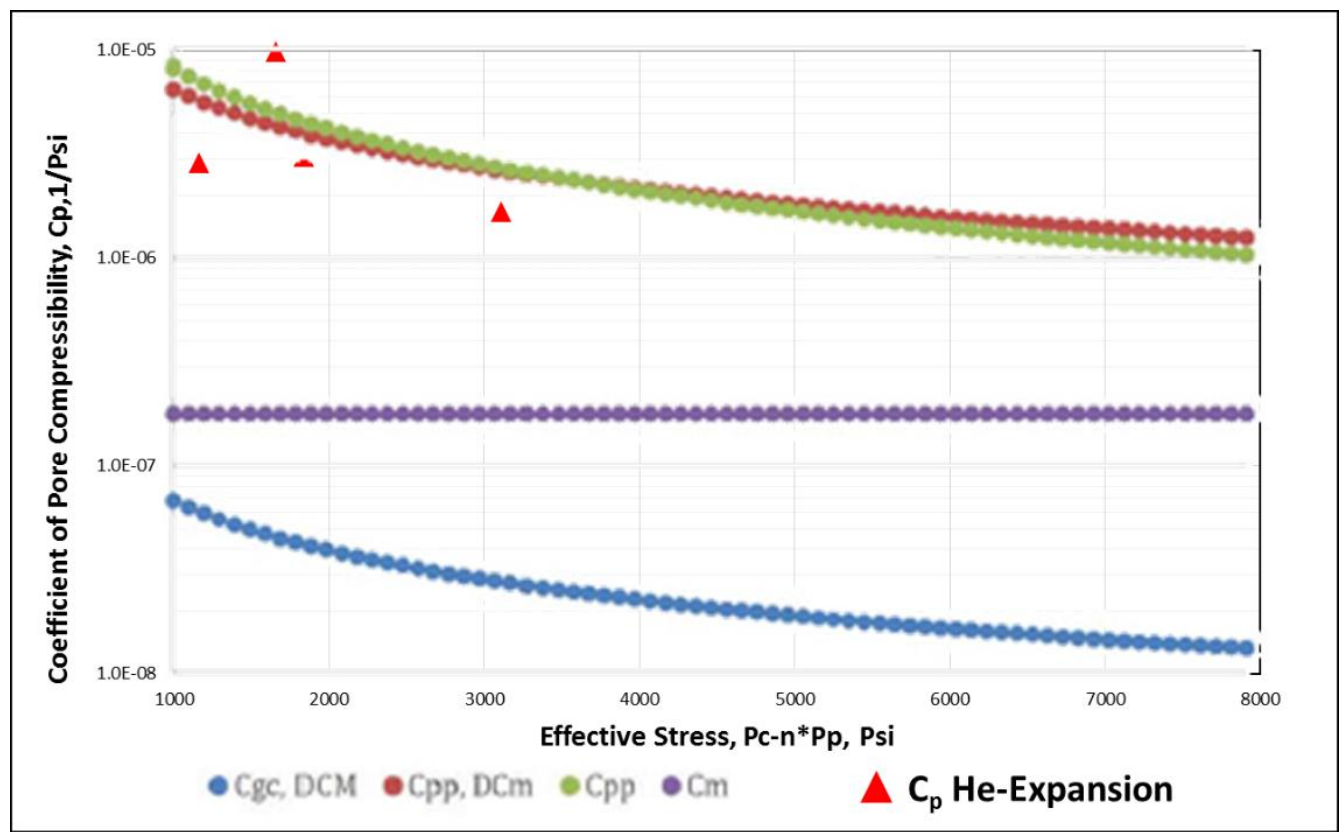

Figure 21 Comparison of shale pore compressibility measured in this study (red triangle) vs. published data in literature (Adapted from Davudov et al. 2018)

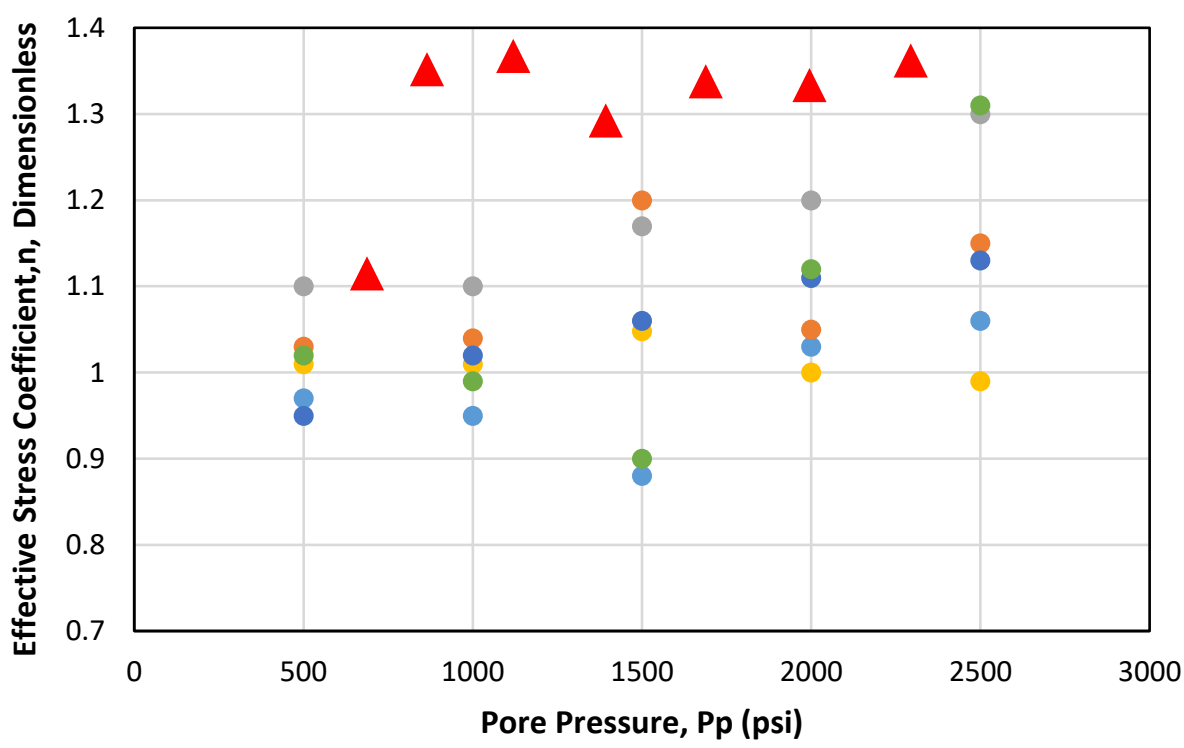

- sample 2 sample 4 sample 5 sample 6 sample 8 sample $9 \Delta$ He-Exp

Figure 22 Comparison of effective stress coefficient $\mathrm{n}$ for shale measured in this study (red triangle) vs. published data in literature (Adapted from Tinni et al. 2011) 
5.4 Sensitivity of the results to the equilibrium pressure (Pf)

In this section we reproduce the results reported previously, when equilibrium pressure $\left(\mathrm{P}_{\mathrm{f}}\right)$ is changed deliberately. The motivation for this quick analysis is the uncertainty in final pressure inherent to corrections done in raw pressure data, due to temperature fluctuations and gas leakage

Equilibrium pressure was varied $+/-5 \%$ and the properties were recalculated accordingly. In Figure 23, Figure 24 and Figure 25 we can observe that a slight Pf increase changes $\mathrm{V}_{\mathrm{p}}$ slightly, but apparently the impact is minimum on the effective stress coefficient. On the other hand, as $\mathrm{P}_{\mathrm{f}}$ changes, the pore compressibility coefficient, can change one order of magnitude. In summary, the uncertainties in measurements can impact the storage mainly due to large fluctuations in the estimated pore compressibility.

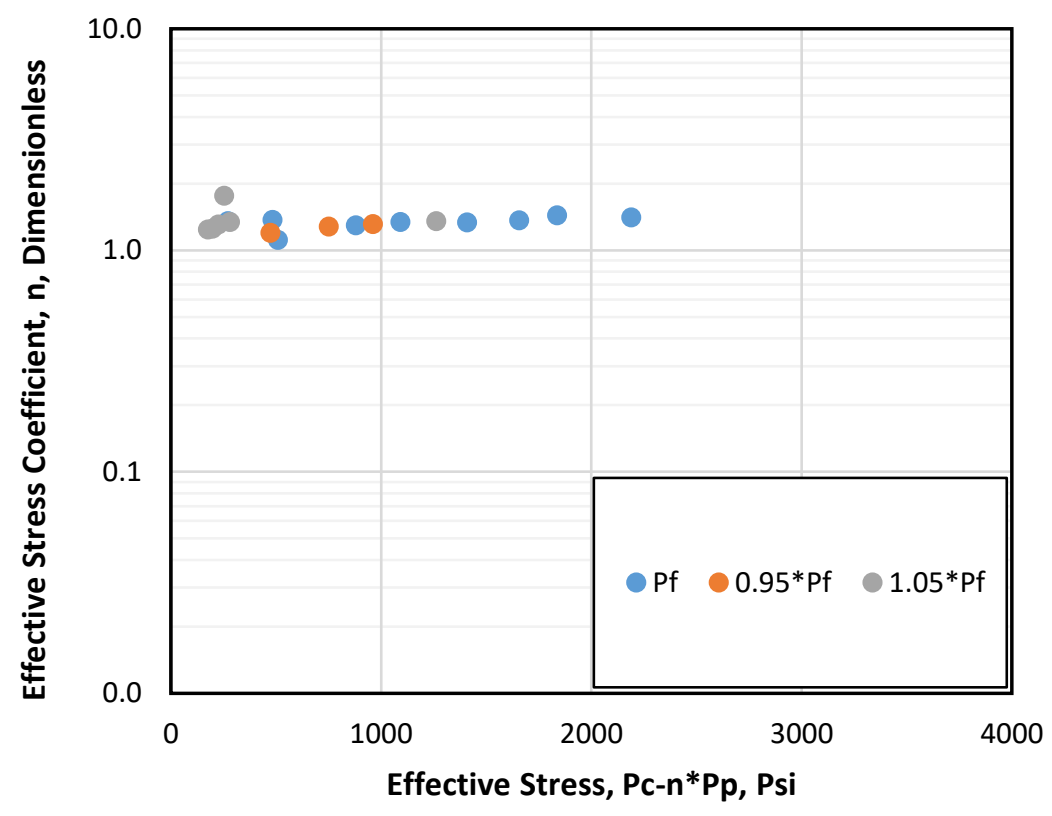

Figure 23 Equilibrium pressure impact on the effective stress coefficient (n). 


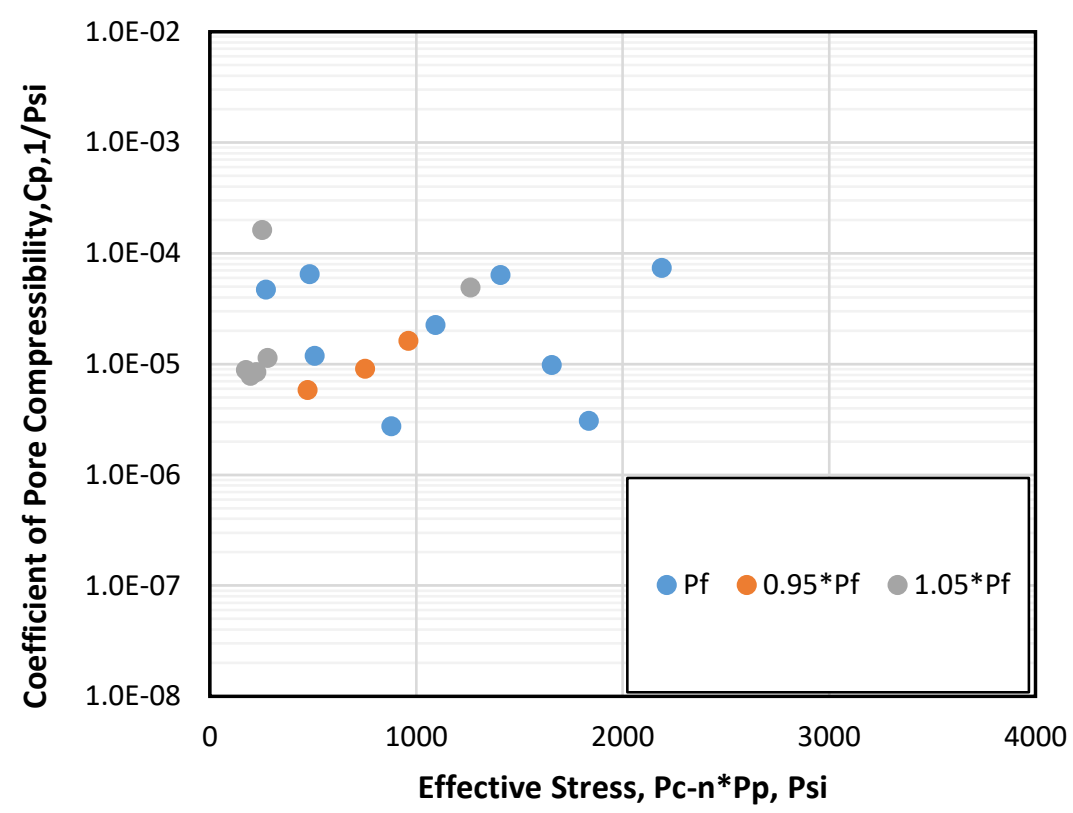

Figure 24 Equilibrium pressure impact on the Isothermal coefficient of pore compressibility $\left(\mathrm{C}_{\mathrm{p}}\right)$.

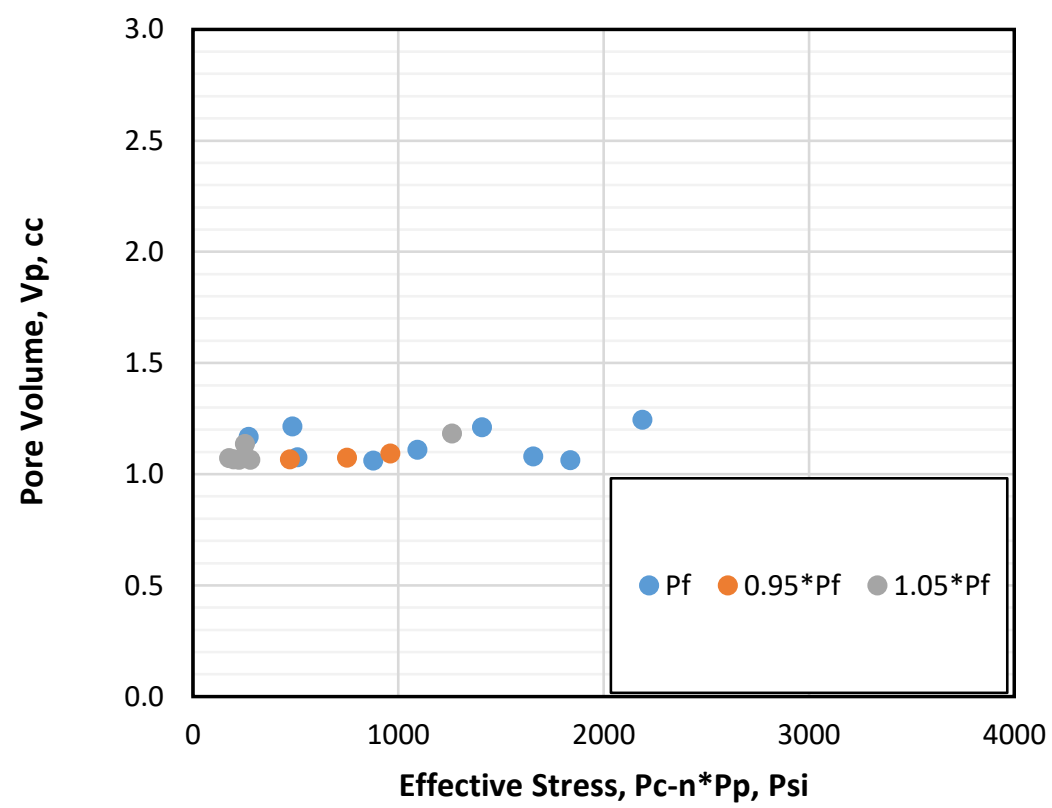

Figure 25 Equilibrium pressure impact on Pore volume (Vp). 


\section{SUMMARY AND CONCLUSIONS}

\subsection{Summary}

In conclusion, in this study I have developed a new laboratory analysis method in order to evaluate the gas storage capacity of the rock under effective stress. The approach is important because it considers the traditional approach of measuring gas storage coupled with the geomechanics of the rock sample. The pore volume measurements showed that the samples used in the laboratory have pore volumes that are slightly sensitive to the effective stress in the case of shale. The effective stress coefficient is around 1.2 but the values are high up to 1.8 for the shale case which could indicate significant lamination and anisotropy in the sample. Extremely tight carbonate (dolomite) rocks also exhibited effective stress coefficient values close to 1.8 , which let us infer a close relation between matrix permeability, and the coefficient. Further measurements using various samples are necessary for detailed analysis.

Poro-elastic quantities, such as bulk- and grain-volume moduli, are traditionally measured using tri-axial compression test. Direct measurement of the effective stress coefficient is timeconsuming. The new method uses a traditional core-holder setup available in every petroleumrelated laboratory. The measurements and analysis are relatively fast. It could be a new routine laboratory method for storage capacity measurements of tight, clay-rich formations.

\subsection{Conclusions}

- Effective stress coefficient, $\mathrm{n}$, could be determined easily for a sandstone core plug, a carbonate core plug and a shale core plug. The values obtained are in average 1.2 (min 0.9-max 1.5) for sandstone; an average value of $1.5(\min 1.1-\max 1.8)$ for the shale plug and an average value of 1.8 (min 1.03-max 2.04) for the carbonate sample. The values reported for effective stress coefficient are in close agreement 
to those reported in the literature for other types of processes (mainly transport and seismic velocities).

- Trends of effective stress coefficient are rather constant for the case of shale and carbonate and tend to cluster for the case of sandstone. In general, the higher the confinement pressure, the higher the effective stress experienced by the plugs. Also, the tighter the matrix of the sample (lower permeability), the higher the effective stress coefficient.

- Isothermal coefficient of pore compressibility, $\mathrm{C}_{\mathrm{p}}$, is determined for the sandstone, shale and carbonate core plugs. An average value for pore compressibility of $2.2 \times 10^{-5} \mathrm{psi}^{-1}\left(\min 1.2 \times 10^{-6}-\max 8.7 \times 10^{-5} \mathrm{ps}^{-1}\right)$ is observed for sandstone sample, while shale has an average value of $1 \times 10^{-4} \mathrm{psi}^{-1}\left(\min 1.6 \times 10^{-6}-\max 5.7 \times 10^{-4} \mathrm{psi}^{-1}\right)$. Carbonate samples have an average value of $7.03 \times 10^{-5} \mathrm{psi}^{-1}\left(\min 1.62 \times 10^{-5}-\max \right.$ $\left.4.66 \times 10^{-4} \mathrm{psi}^{-1}\right)$.

- Reference pore volume at zero stress, $\mathrm{V}_{\mathrm{p} 0}$, is in close agreement between the measurement using our core-holder system, and an independent measurement done using a Temco porosimeter for the sandstone core-plug. An average value of 2.74 $\mathrm{cc}$ was obtained from the porosimeter, while using our set-up, a value of $2.65 \mathrm{cc}$ is obtained. The measurement error is $3.3 \%$, which is quite reasonable. As for the estimated reference pore volume of the shale sample near zero stress, it has a reference pore volume close to $1.06 \mathrm{cc}$ using porosimeter.

- Pore volume trend is constant for all measurements performed with effective stress, which is expected as pore compressibility obtained is low $\left(1.0 \times 10^{-5}-1.0 \times 10^{-6}\right)$, henceforth, despite including effective stress coefficient in our computations, pore 
volume is insensitive to stress changes. Only for the case of high pore compressibility in the shale sample $\left(1.0 \times 10^{-4}\right)$, some slight change in pore volume is observed.

- Higher effective stress is needed, to reach a constant trend of pore compressibility values in the order of $1.0 \times 10^{-6} \mathrm{psi}^{-1}$.

- This invention allows fast, easy and accurate estimation of the fluid storage capacity of the rock samples (e.g., sandstone, carbonates, and mudstones) and other porous materials (e.g., concrete, wood, unglazed ceramic) under effective stress without the need to make separate mechanical tests.

\subsection{Recommendations}

The methodology is to be tested against prototypical samples for further validation of the results. The method should also be extended to shale samples of several North-American basins for statistical reproduction and analysis, as currently it has only been tested in shale samples of Mississippian Lime - Woodford Basin. Additional samples with variable TOC and thermal maturity would need to be measured under the same laboratory conditions to observe the effect on storage capacity, including effective stress in organic rich shales. Differing samples in their nature, could aid to understand better gas storage capacity of organic rich shales. Measurements could be measured at elevated temperatures to observe any effect on the mechanical response of the rocks in a more accurate reservoir conditions scenario.

The most critical part in the experimental phase is gas leakage. This problem can be mitigated by careful observation of the pressure response and correct identification of leaky threads and fittings of the device or part that produces the leakage. The Hassler type core holder has an internal rubber, which if not properly sealed (hydraulically) could cause leakage problems. 
Reference and dead volumes need to be vacuumed properly or flushed from air, prior to any measurement, something that is not considered routinely. Flushing can be done with helium.

Collecting more pressure data at higher effective stress (higher confinement pressure/low pore pressures) can render the lower portion of pore compressibility values that we were not able to obtain in this study. The data can be used to fit non-linear regressions to pore compressibility, to be used later in sorption calculations. 


\section{NOMENCLATURE}

Petro-physical parameters

\begin{tabular}{|c|c|c|}
\hline$a_{i}$ & $=$ & Ratio of confinement pressure to pore pressure at any stage, dimensionless \\
\hline$a_{\text {avgi }}$ & $=$ & Average ratio of confinement pressure to pore pressure at any stage, dimensionless \\
\hline $\mathrm{a}_{0}$ & $=$ & Ratio of confinement pressure to pore pressure at reference stage, dimensionless \\
\hline$c_{b}$ & $=$ & Isothermal coefficient of bulk compressibility, $\mathrm{psi}^{-1}$ \\
\hline$c_{\mathrm{p}}$ & $=$ & Isothermal coefficient of pore compressibility, $\mathrm{psi}^{-1}$ \\
\hline$c_{p, c}$ & $=$ & Isothermal coefficient of pore compressibility with variable confinement, $\mathrm{psi}^{-1}$ \\
\hline$c_{p, p}$ & $=$ & Isothermal coefficient of pore compressibility with variable pore pressure, $\mathrm{psi}^{-1}$ \\
\hline $\mathrm{K}$ & $=$ & Bulk matrix moduli, $\mathrm{Pa}$ \\
\hline $\mathrm{K}_{\mathrm{s}}$ & $=$ & Grain matrix moduli, $\mathrm{Pa}$ \\
\hline $\mathrm{n}$ & $=$ & Effective stress coefficient, dimensionless \\
\hline $\mathrm{n}_{\mathrm{d}}$ & $=$ & Amount of gas in dead volume, mole \\
\hline $\mathrm{n}_{\mathrm{i}}$ & $=$ & Initial amount of gas the system, mole \\
\hline $\mathrm{n}_{\mathrm{f}}$ & $=$ & Final amount of gas the system, mole \\
\hline $\mathrm{n}_{\mathrm{r}}$ & $=$ & Amount of gas in reference volume, mole \\
\hline $\mathrm{n}_{\mathrm{s}}$ & $=$ & Amount of gas in sample pore volume, mole \\
\hline $\mathrm{P}_{0}$ & $=$ & Reference pressure, psia \\
\hline $\mathrm{P}$ & $=$ & Pressure of interest, psia \\
\hline $\mathrm{P}_{\mathrm{c}}$ & $=$ & Confinement pressure, psia \\
\hline $\mathrm{P}_{\mathrm{c} 0}$ & $=$ & Confinement pressure at reference stage, psia \\
\hline $\mathrm{P}_{\text {cavg }}$ & $=$ & Average confinement pressure between two consecutive stages, psia \\
\hline $\mathrm{P}_{\mathrm{d}}$ & $=$ & Pressure in dead volume, psia \\
\hline
\end{tabular}




$$
\begin{aligned}
& \mathrm{P}_{\mathrm{f}}=\text { Equilibrium pressure in dead volume and sample volume, psia } \\
& \mathrm{P}_{\mathrm{p}} \quad=\text { Pore pressure, } \mathrm{psia} \\
& \mathrm{P}_{\mathrm{p} 0} \quad=\text { Pore pressure at reference stage, psia } \\
& \mathrm{P}_{\text {pavg }}=\text { Average pore pressure between two consecutive stages, psia } \\
& \mathrm{P}_{\mathrm{r}} \quad=\text { Pressure in reference volume, psia } \\
& \mathrm{P}_{\mathrm{S}} \quad=\text { Pore pressure in sample, psia } \\
& P_{i} \quad=\text { equilibrium pressure in } \mathrm{V}_{\mathrm{i}} \text {, psia } \\
& \mathrm{Q}=\text { Petro-physical quantity of interest, psia } \\
& \mathrm{R}=\text { Ideal gas constant, } \mathrm{psi}-\mathrm{ft}^{3} / \mathrm{lbmol}-\mathrm{R} \\
& \mathrm{T}=\text { Reservoir temperature, }{ }^{\circ} \mathrm{R} \\
& \mathrm{V}_{\mathrm{d}} \quad=\text { Dead volume, } \mathrm{cc} \\
& \mathrm{V}_{\mathrm{P} 0} \quad=\text { Sample pore volume at zero pore stress, } \mathrm{cc} \\
& \mathrm{V}_{\mathrm{P}} \quad=\text { Sample pore volume, } \mathrm{cc} \\
& \mathrm{V}_{\mathrm{Pi}} \quad=\text { Sample pore volume at any pressure stage, } \mathrm{cc} \\
& \mathrm{V}_{\mathrm{r}} \quad=\text { Reference volume, } \mathrm{cc} \\
& \mathrm{V}_{\mathrm{s}} \quad=\text { Sample pore volume, } \mathrm{cc} \\
& \mathrm{z}_{\mathrm{d}}=\text { Gas correction factor at } \mathrm{P}_{\mathrm{d}} \text {, dimensionless } \\
& \mathrm{z}_{\mathrm{f}}=\text { Gas correction factor at } \mathrm{P}_{\mathrm{f}} \text {, dimensionless } \\
& \mathrm{z}_{\mathrm{r}} \quad=\text { Gas correction factor at } \mathrm{P}_{\mathrm{r}} \text {, dimensionless } \\
& \mathrm{z}_{\mathrm{s}} \quad=\text { Gas correction factor at } \mathrm{P}_{\mathrm{s}} \text {, dimensionless }
\end{aligned}
$$

where subscripts $r$ means reference volume, $d$ stands for dead volume, s represents sample pore volume. Similarly, i subscript represents initial state of any gas uptake stage, and f subscript stands for final state. Subscript 1 is for first stage, while subscript 2 represents $2^{\text {nd }}$ stage, and so on. Subscript avg means average between consecutive stages. 


\section{GREEK SYMBOLS}

$\begin{array}{ll}\alpha & =\text { Biot Coefficient, dimensionless } \\ \emptyset & =\text { Total porosity, } \% \\ \sigma & =\text { Effective stress, psi } \\ \sigma_{\mathrm{e}} & =\text { Effective stress, psi } \\ \sigma_{\mathrm{avg}} & =\text { Average effective stress between consecutive stages, psi }\end{array}$ 


\section{REFERENCES}

Abass, J. F. (1999). Experimental Evaluation of Biot's poroelastic parameter-Three different methods. Rock Mechanics for Industry, 349-355.

Abou-Kassem, \& Dranchuk, P. (1975). Calculation of Z factors for Natural Gases using Equations of State. Journal of Canadian Petroleum Technology, 34-36.

Ambrose, R., Hartman, R., M., D.-C., \& Akkutlu, I. (2012). New Pore-Scale considerations in shale gas in place calculations. SPE Unconventional Gas Conference (pp. 219-229). Pittsburgh, Pennsylvania: SPE.

Arthur, M. A., \& Sageman, B. B. (1994). Marine Black Shales. Annual Review of Earth and Planetary Sciences, 501-515.

Biot, M. A. (1940). General Theory of Three-Dimensional Consolidation. Journal of Applied Physics, 155-164.

Biot, M. A., \& Willis, D. (1957). The Elastic Coefficients of the Theory of Consolidation. Journal of Applied Mechanics (Reprinted), 1-8.

Bui, K., \& Akkutlu, I. Y. (2017). Hydrocarbons Recovery from model-Kerogen Nanopores. (SPE, Ed.) SPE Journal, 22(03), 854-855.

Christensen, N., \& Wang, H. (1985). The influence of pore pressure and confining pressure on dynamic elastic properties of Berea Sandstone. Geophysics, , Vol 50(2) 207-213.

Davud Davudov and Rouzbeh Ghanbamezhad Moghanloo, U. o. (2018). Pore Volume Compressibility in Shale-Revisited. SPE.

Davud Davudov, R. G. (2017). Investigation of shale pore compressibility impact on production with reservoir simulation. SPE, 1-16.

EIA. (2011, May 9). U.S Energy Information Administration. Retrieved September 15, 2018, from U.S Energy Information Administration: https://www.eia.gov/analysis/studies/usshalegas/

Geertsma, J. (1956). The effect of Fluid Pressure Decline on Volumetric changes of porous rocks. Society of Petroleum Engineers, 331-340.

Hampton, J., \& Boitnott, G. (2018). The misnomet of "Effective Stress" and its relation to Biot Coefficients. ARMA.

Hasanov, A., \& Prasad, M. (2018). Effective Stress Law for Permeability of a mudstone sample. SEG International Exposition and 88th Annual Meeting (p. 6). SEG.

Hornby, B. E. (1996). An Experimental Investigation of Effective Stress Principles for Sedimentary Rocks. SEG Meetings, 1707-1710.

J.M Santos, I. A. (2012). Laboratory Measurements of Sorption Isotherm Under Confining Stress with pore volume effects. (pp. 924-931). Calgary: SPE Journal. 
Jun He, K. L. (2014). A New Method to determine Biot Coefficient of Bakken Samples. ARMA.

Kang, S. M. (2011). Carbon Dioxide Storage Capacity of Barnett Shale. Norman, Oklahoma.

Kegang Ling, J. H. (2014). A New Method to determine pore compressibility. ARMA.

Kegang Ling, J. H. (2016). Comparisons of Biot's Coefficients of Bakken Core Samples Measured by Three Methods. ARMA.

Kim, B., \& Akkutlu, I. (2018). Laboratory measurement of microproppant placement quality using split core plug permeability under stress. SPE Hydraulic fracturing technology conference. Wodlands, TX: SPE.

M., A., Khan, K., Abdulraheem, A., Rahim, Z., \& Al-Qahtani, M. (2002). Experimental Determination of Elastic Anisotropy and Biot's Constant in a Saudi Arabian Reservoir Sandstone. Abu Dhabi International Petroleum Exhibition and Conference (pp. 1-7). Abu Dhabi: SPE.

Nur, A., \& Byerlee, J. (1971). An Exact Effective Stress Law for Elastic Deformation of Rock with Fluids. Journal of Geophysical Research, 6414-6419.

Passey, Q., Bohacs, K., Esch, W., Klimentidis, R., \& Shina, S. (2010). From Oil-Prone Source Rock to Gas-Producing Shale Reservoirs-Geologic and Petrophysical Characterization of Unconventional Shale-Gas Reservoirs. CPS/SPE International Oil \& Gas Conference and Exhibition (pp. 1-29). Beijing, China: SPE.

Qiao, L. P., Wong, R. C., Aguilera, R., \& Kantzas, A. (2012). Determination of Biot's EffectiveStress Coefficient for Permeability of Nikanassin Sandstone. Journal of Canadian Petroleum Technology, 193-197.

Reed, F. W. (2009). Pore Networks and Fluid Flow in Gas Shales. SPE Annual Technical Conference and Exhibition (pp. 1-8). New Orleans: SPE.

Robert G. Loucks, R. M. (2009). Morphology, Genesis And Distribution of Nanometer Scale Pores in Siliceous Mudstones of the mississipian Barnet Shale. Journal of Sedimentary Research, 848-861.

Robert G. Loucks, R. M. (2012). Spectrum of Pore types and networks in mudrocks and a descriptive classification for matrix-related mudrocks pores. AAPG, 1071-1098.

S.M. Kang, E. F. (2011). Carbon Dioxide Storage Capacity of Organic-Rich Shales. SPE Journal $16(4), 842-854$.

Santos, J. M., \& Akkutlu, I. Y. (2013). Laboratory Measurement of Sorption Isotherm Under Confining Stress with Pore-Volume Effects. SPE Journal, 924-930.

Sarker, R., \& Batzle, M. (June 2008). Effective stress coefficient in shales and its applicability to Eaton's equation. pp. 798-804. 
Seungmo Kang, D. I., \& I. Yucel Akkutlu, T. A. (2014). Gas Storage Capacity of Iljik and Hasandong Shales in Gyongsang Basin, South Korea. Unconventional Resources technology conference.

Simmons, T. T. (1972). Effecto of pore pressure on the velocity of compressional waves in low porosity rocks. Journal of geophysical research, 3731-3743.

Skempton, A. W. (1960). Effective Stress in Soils, Concrete and Rocks. Pore Pressure and Suction in Soils, Butterworths, 4-16.

Sondergeld, C., Newsham, K., Cominsky, J., Rice, M., \& Rai, C. (2010). Petrophysical Considerations in Evaluating and Producing Shale Gas Resources. SPE Unconventional Gas Conference (pp. 1-34). Pittsburgh, Pennsylvania: SPE.

Statista. (2018, January 15). Statista. Retrieved September 15, 2018, from Statista: https://www.statista.com/statistics/183740/shale-gas-production-in-the-united-statessince-1999/

Terzaghi, K., Peck, R. B., \& Mesri, G. (1996). Soil Mechanics in Engineering Practice. John Wiley \& Sons, Inc.

Tinni, A., Fathi, E., Agarwal, R., Sondergeld, C., Akkutlu, Y. I., \& Rai, C. (2012). Shale Permeability Measurements on Plugs and Crushed Samples. SPE Canadian Unconventional Resources (p. 14). Calgary, Alberta, Canada: Society of Petroleum Engineers.

Tinni, A., Sondergeld, C. H., Rai, C., \& Simo, H. (2011). Effective Pressure and Microstructure Control on Resistivity Formation Factor and Seismic Waves Velocities. SPE, 1-12.

Warpinski, N., \& Teufel, L. (June 1992). Determination of the Effective Stress Law for Permeability and Deformation in Low Permeability Rocks. SPE Formation Evaluation, 123-131.

Xuejun Zhou, A. V. (2015). A combined Method to measure Biot's Coefficient for Rock. ARMA, $1-8$.

Yuzheng Lan, R. G. (2017). Pore Compressibility of Shale Formations. Society of Petroleum Engineers, 1778-1789.

Zhou, X. (2017). Biot's Effective Stress Coefficient of Mudstone Source Rocks. ARMA, 1-11.

Zimmerman, R. W., Somerton, W. H., \& King, M. S. (1986). Compressibility of Porous Rocks. Journal of geophysical Research, 765-777.

Zoback, X. M. (2017). Laboratory experiments simulating poroelastic stress changes associated with depletion and injection in low-porosity sedimentary rocks. Journal of Geophysical Research:Solid Earth, 1-26. 


\section{APPENDIX A \\ DEAD VOLUME DETERMINATION}

To measure dead volumes in the laboratory, both water injection using a hydraulic water pump and gas injection using a known volume (Cylinder filled up with gas) were used. For the gas case, the laboratory set up observed in Figure 4 was allowed to take volumes of gas from the reference cylinder until pressure of equilibrium was recorded from transducers, then Boyle's law was applied. Also, from the hydraulic water pump, the system was water-flooded, keeping track of the water volumes injected on each part of the device by aid of the pump's dial pad, until the dead volumes were entirely filled up with water. Gas measurements proved to be more accurate, so these volumes were included in the computations.

For the case of gas, using Boyle's law, if we have a cylinder filled up with gas, that can expand its gas on the dead volumes, in two consecutive steps (first filling upstream, then downstream volumes), we can write:

$\mathrm{P}_{\text {cylinder }}=835.5 \mathrm{psig}$

$\mathrm{P}_{\mathrm{f} 1}=688.35 \mathrm{psig}$

$\mathrm{P}_{\mathrm{f} 2}=639.44 \mathrm{psig}$

$\mathrm{V}_{\text {cylinder }}=82.03 \mathrm{cc}$;

$\mathrm{V}_{\text {caps }}=1.18 \mathrm{cc}$; (end caps of core-holder, measured with water)

$\mathrm{n}_{\mathrm{eq} 1}=\mathrm{n}_{\text {cylinder }}+\mathrm{n}_{\text {upstream }}$

$\mathrm{P}_{\text {eq1 }} \mathrm{V}_{\text {upstream }}=\mathrm{P}_{\text {cylinder }} \mathrm{V}_{\text {cylinder }}+\mathrm{P}_{\text {atm }} \mathrm{V}_{\text {upstream }}$;

$V_{\text {upstream }}=\frac{\mathrm{P}_{\text {cylinder }}-\mathrm{P}_{\mathrm{f} 1}}{\mathrm{P}_{\mathrm{f} 1}-\mathrm{P}_{\mathrm{atm}}} V_{\text {pipe }}=\frac{835.55-688.35}{688.35-14.7} \times 82.03=17.535 \mathrm{cc} ;$

Similarly, 
$\mathrm{V}_{\text {downstream }}=\frac{\mathrm{P}_{\mathrm{f} 1}-\mathrm{P}_{\mathrm{f} 2}}{\mathrm{P}_{\mathrm{f} 2}-\mathrm{P}_{\mathrm{atm}}}\left(\mathrm{V}_{\text {cylinder }}+\mathrm{V}_{\text {upstream }}\right)+\mathrm{V}_{\text {caps }}=\frac{835.55-688.35}{688.35-14.7} \times 82.03+1.18 \mathrm{cc}=8.796 \mathrm{cc}$;

The core holder caps volumes were previously measured using water, then added to downstream volume. The pressures were obtained directly from transducers readings as shown in the Figure 26.

Applying Boyle's law we determined the following values for dead volumes of the equipment, where upstream volume is all dead volumes from Valve \#1 up to valve \# 2 (basically reference volume), and all downstream volumes are right after valve\#2 including all surrounding dead volumes of transducers, and Valve\#3 volumes ( See Figure 4Error! Reference source not found.).

Some example of dead volumes using water injection is reported below in Table 12. The process was manual, where each part of the equipment had to be measured separately and labeled

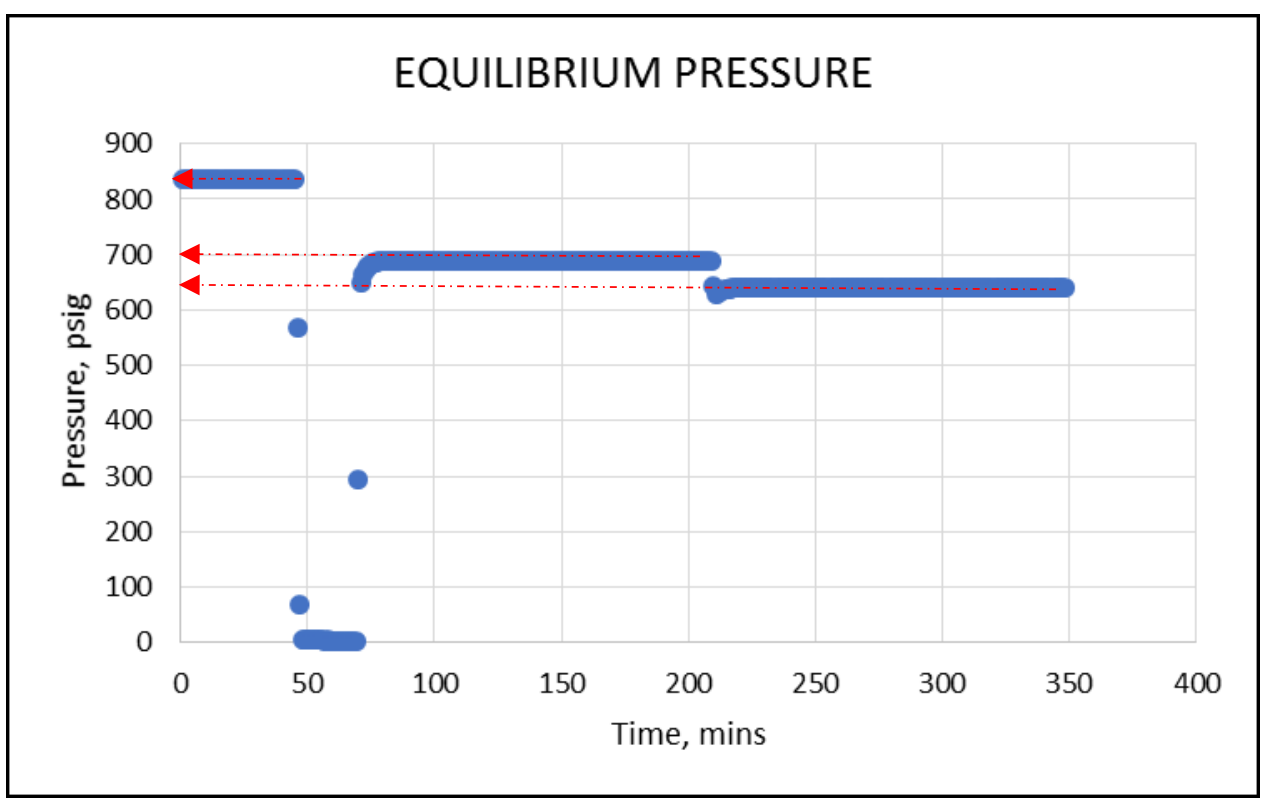

Figure 26 Pressure measurement for dead volumes determination using gas expansion. 
accordingly, as volume\#1 through \#5, for identification. Human error during the measurement is likely, because each individual measurement done on every part of the device was started/stopped after water was visually observed to come in/out (that leaves room for error), therefore, we considered gas measurements more accurate.

We used different sets of dead volumes, as our setup was modified over time: first we had an initial configuration where pressures for Shale plug \#2 were determined, used water and gas, applied Boyle's law; afterwards, we modified the setup and added another transducer (To monitor confining pressure transducer independently of water pump dial pad reading) and measured its corresponding dead volumes, using gas as well, to measure pressures on both shale plug \#1 and sandstone plug. As can be observed below in Table 13, the methods produced different results, and there is a fair agreement between gas runs.

Table 12 Dead volumes measurement using water.

\begin{tabular}{|r|l|r|}
\hline Volume & $\begin{array}{l}\text { Reading } \\
\text { from dial } \\
\text { Pad }\end{array}$ & $\begin{array}{r}\text { Water } \\
\text { reading } \\
\text { (cc) }\end{array}$ \\
\hline \multirow{2}{*}{$\mathbf{1}$} & Initial & 492.15 \\
\cline { 2 - 3 } & Final & 480.87 \\
\hline VOLUME. & Difference & $\mathbf{1 1 . 2 8}$ \\
\hline 1+alpha & Initial & 185.92 \\
\cline { 2 - 3 } & Final & 184.13 \\
\hline \multirow{2}{*}{$\mathbf{2}$} & Initial & 186.63 \\
\cline { 2 - 3 } & Final & 180.39 \\
\hline VOLUME. & Difference & $\mathbf{6 . 2 4}$ \\
\hline 2+alpha & Initial & 169.39 \\
\cline { 2 - 3 } & Final & 168.77 \\
\hline VOLUME. & Difference & $\mathbf{0 . 6 2}$ \\
\hline \multirow{3}{*}{} & Initial & 172.31 \\
\cline { 2 - 3 } & Final & 170 \\
\hline VOLUME. & Difference & $\mathbf{2 . 3 1}$ \\
\hline $\mathbf{4}$ & Initial & 471.4 \\
\hline MOVEABLE & Final & 470.75 \\
\hline CAPS & & \\
\hline & & \\
\hline
\end{tabular}


Table 12. Continued

\begin{tabular}{|c|c|c|}
\hline Volume & $\begin{array}{l}\text { Reading } \\
\text { from dial } \\
\text { Pad }\end{array}$ & $\begin{array}{r}\text { Water } \\
\text { reading } \\
(c c)\end{array}$ \\
\hline VOLUME. & Difference & 0.65 \\
\hline 5 & Initial & 469.51 \\
\hline FIXED CAPS & Final & 469.1 \\
\hline VOLUME. & Difference & 0.82 \\
\hline \multicolumn{2}{|c|}{ TOTAL UPSTREAM } & 13.07 \\
\hline \multicolumn{2}{|c|}{ TOTAL DOWNSTREAM } & 10.64 \\
\hline
\end{tabular}

Table 13 Dead volumes measurement using different fluids

\begin{tabular}{|c|l|l|l|}
\hline Item & $\begin{array}{l}\text { Water } \\
\text { Measurements for } \\
\text { initial core holder } \\
\text { setup }\end{array}$ & $\begin{array}{l}\text { Gas } \\
\text { Measurements for } \\
\text { initial core holder } \\
\text { setup }\end{array}$ & $\begin{array}{l}\text { Gas } \\
\text { Measurements } \\
\text { for modified core } \\
\text { holder set up }\end{array}$ \\
\hline Upstream Volume (cc) & 13.07 & 19.21 & 17.53 \\
\hline $\begin{array}{c}\text { Downstream Volume } \\
\text { (cc) }\end{array}$ & 10.64 & 6.64 & 26.79 \\
\hline Total Volume (cc) & 23.71 & 25.85 & 26.32 \\
\hline
\end{tabular}




\section{APPENDIX B}

\section{FLUID LEAKAGE AND FLUCTUATING TEMPERATURE CORRECTIONS AND EQUILIBRIUM PRESSURE DETERMINATION}

As for the equilibrium pressure determination at each pressure stage, the procedure detailed in the Chapter 3 was applied, raw pressures were obtained, which were corrected for leakage and temperature in most of the cases. The correction for pressure is obtained from the slope of the raw data, starting from the point of pure leakage determined visually from the graph and correction was then applied by subtraction of the product of [slope]x[pressures] from the raw pressures measured (or from the temperature corrected pressure, in case great temperature fluctuation was observed). Results looks like the one obtained in Figure 27.

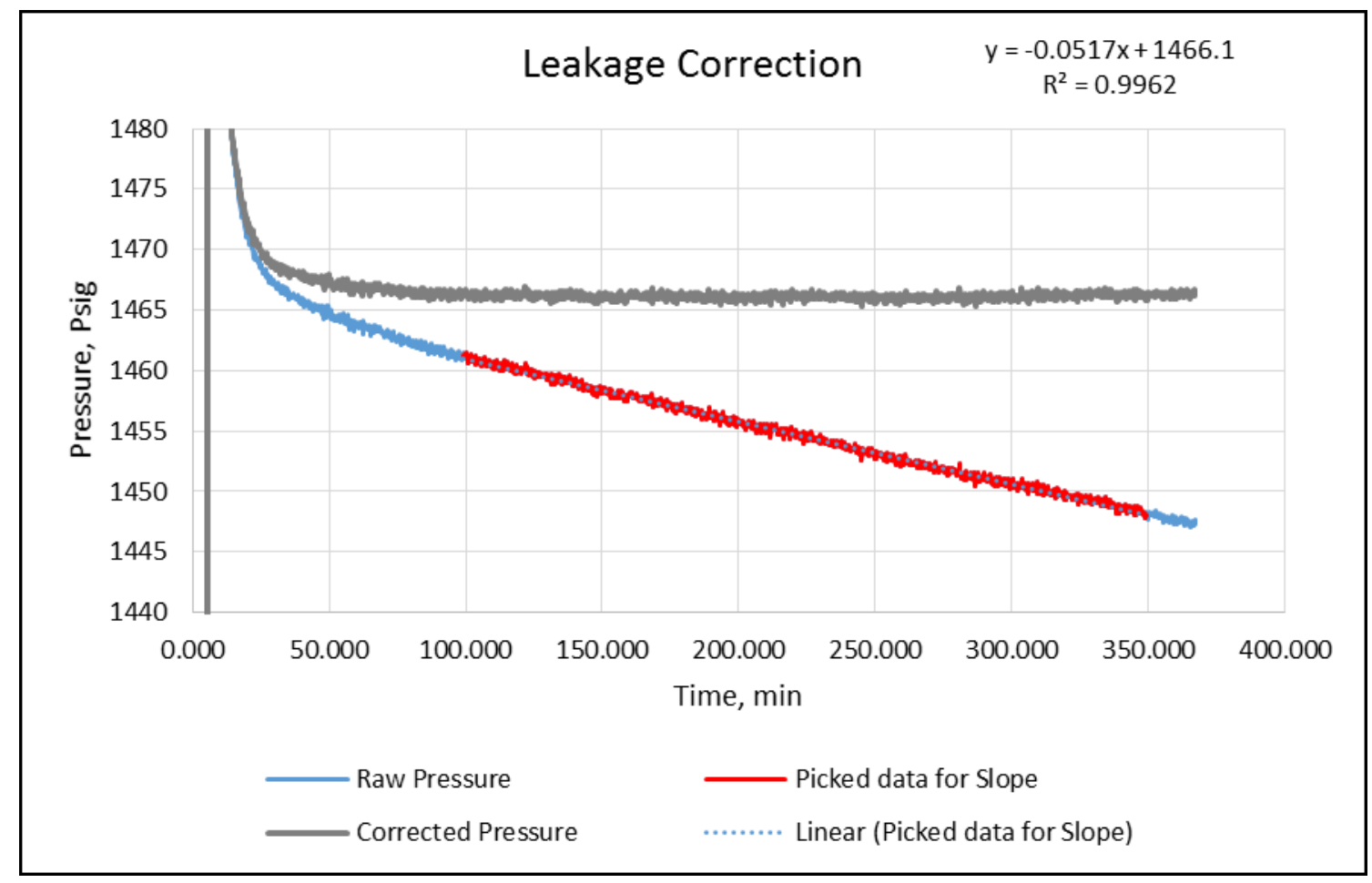

Figure 27 Example of graphical method for gas leakage correction. 
When deviations in temperature were observed, temperature corrections were performed prior to leakage corrections by using the Equation of state (EOS) written for two consecutive pressure stages, as follows,

$\mathrm{P}_{1} \mathrm{~V}=\mathrm{Z}_{1} \mathrm{nRT}_{1}$

$\mathrm{P}_{2} \mathrm{~V}=\mathrm{Z}_{2} \mathrm{nRT}_{2}$

As moles are assumed to be constant between pressure measurements, we equalize moles,

$\mathrm{n}=\frac{\mathrm{P}_{1} \mathrm{~V}}{\mathrm{Z}_{1} \mathrm{RT}_{1}} ;$

$\mathrm{n}=\frac{\mathrm{P}_{2} \mathrm{~V}}{\mathrm{Z}_{2} \mathrm{RT}_{2}} ;$

$\frac{\mathrm{P}_{1} \mathrm{~V}}{\mathrm{Z}_{1} \mathrm{RT}_{1}}=\frac{\mathrm{P}_{2} \mathrm{~V}}{\mathrm{Z}_{2} \mathrm{RT}_{2}} ;$

And solve for the desired pressure, as $\mathrm{P}_{2}=\mathrm{P}_{\mathrm{C}, \mathrm{T}}$ and $\mathrm{P}_{1}=\mathrm{Ps}$

$\frac{\mathrm{P}_{1}}{\mathrm{Z}_{1} \mathrm{~T}_{1}}=\frac{\mathrm{P}_{2}}{\mathrm{Z}_{2} \mathrm{~T}_{2}} ;$

$\mathrm{P}_{\mathrm{c}, \mathrm{T}}=\mathrm{P}_{\mathrm{s}} \times \frac{\mathrm{Z}_{2} \mathrm{~T}_{2}}{\mathrm{Z}_{1} \mathrm{~T}_{1}} ;$

Using this relation, we corrected each raw pressure where temperature fluctuated greatly (5-7-degree Fahrenheit). An example graph is produced below where in red we have temperature, in blue is raw pressure data and in grey color is temperature corrected pressure data. After this temperature correction, leakage correction can be performed accordingly. From experimental data collected, a correction by leakage will look like the following graph, Figure 28.

Where the slope of pure leakage was picked in the last part of the gray colored curve. In this case, a slope of $-0.01482 \mathrm{psi} / \mathrm{min}$ was estimated to correct for leakage. Final corrected pressure is shown in orange color, in Figure 29. 


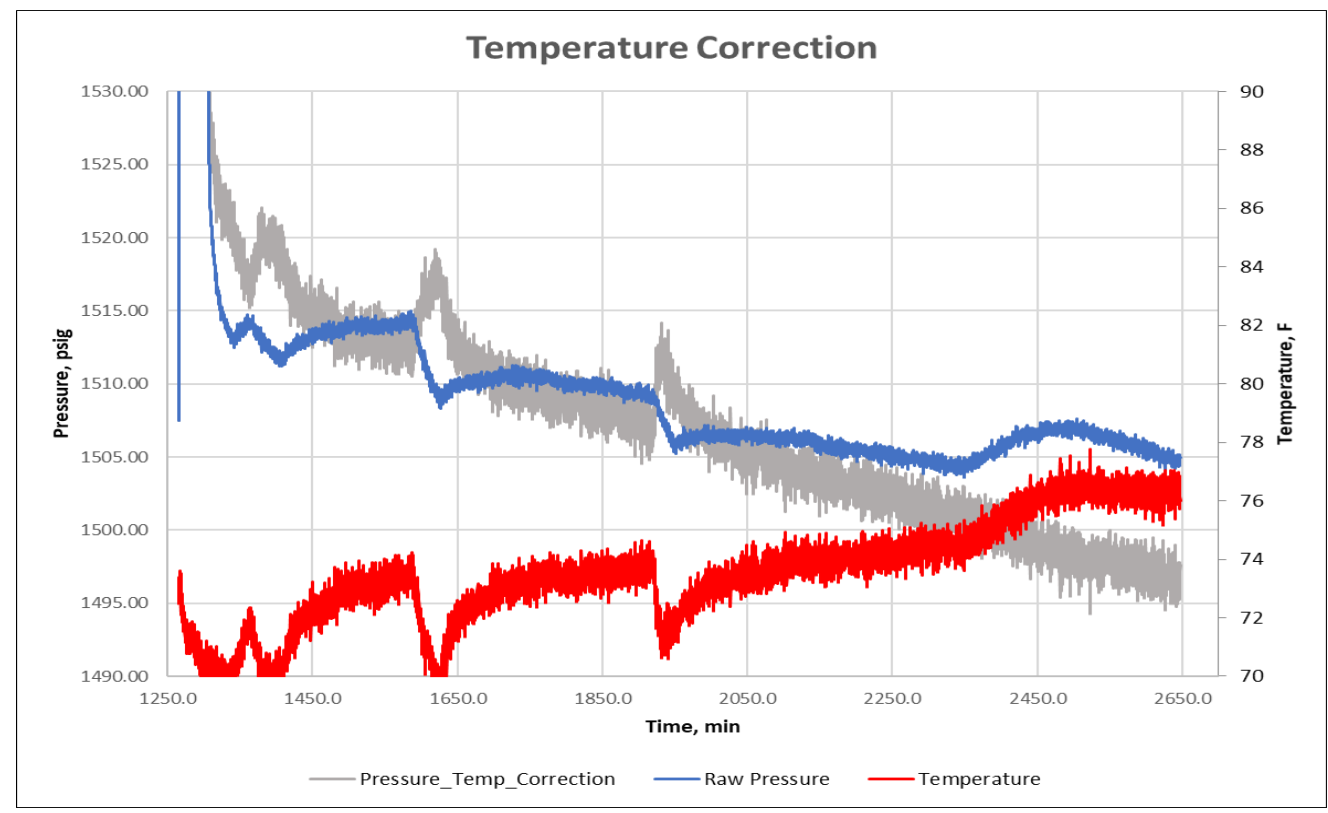

Figure 28 Step 1. Temperature correction method.

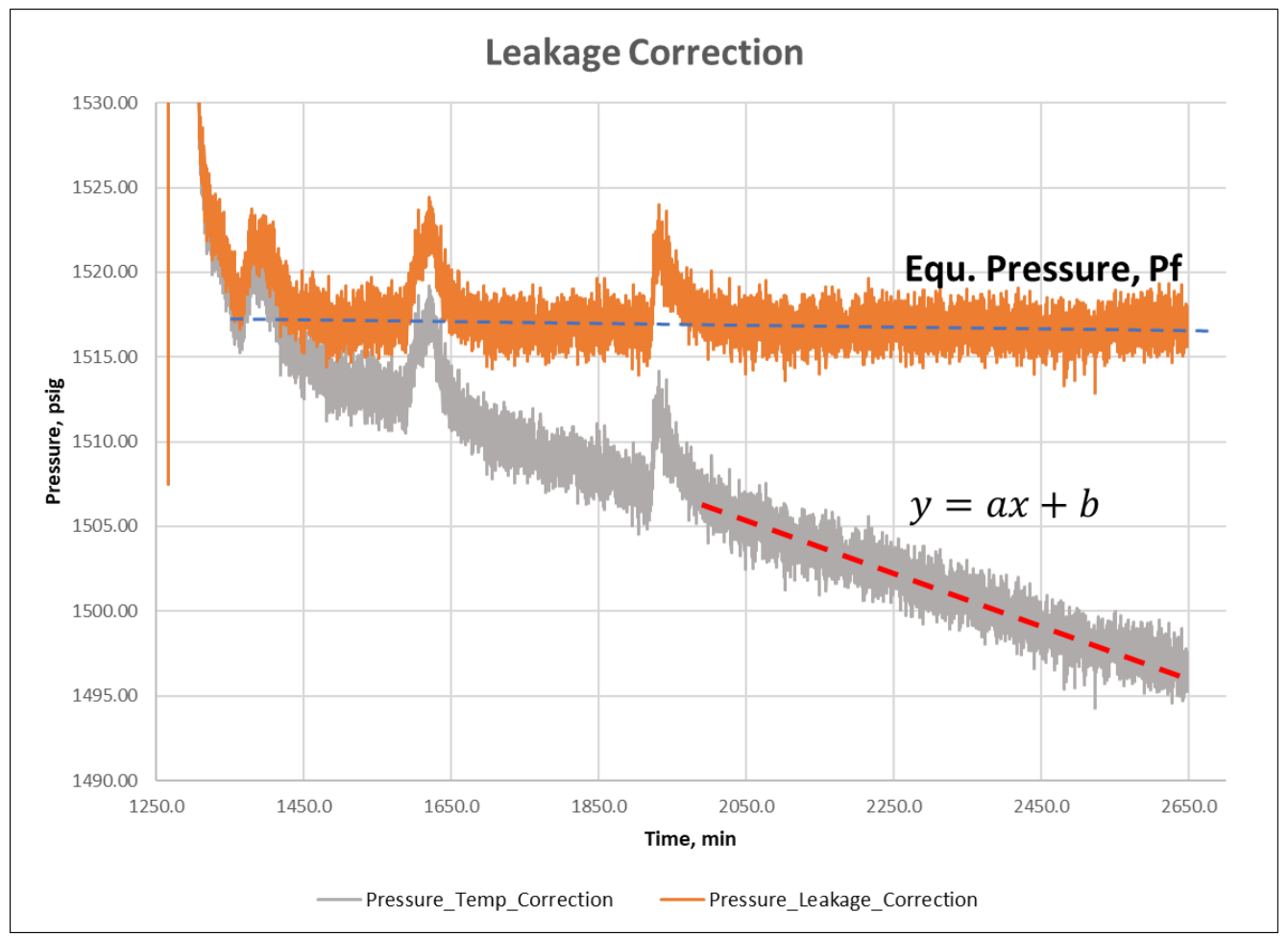

Figure 29 Step 2. Leakage correction applied after temperature correction. 